Aus der Klinik für Allgemein-, Viszeral- und Kinderchirurgie (Prof. Dr. med. M. Ghadimi)

der Medizinischen Fakultät der Universität Göttingen

\title{
Evaluation von Anti-HER-2-Substanzen für die Therapie des kolorektalen Karzinoms
}

\author{
INAUGURAL - DISSERTATION \\ zur Erlangung des Doktorgrades \\ der Medizinischen Fakultät der \\ Georg-August-Universität zu Göttingen \\ vorgelegt von \\ Anna-Lena Clara Metzger, geb. Jakubzik \\ aus \\ Geesthacht
}


Dekan:

Referent/in:

Ko-Referent/in:

Drittreferent/in:

Datum der mündlichen Prüfung: $\quad$ 03.11.2020
Prof. Dr. med. W. Brück

PD Dr. med. M. Grade

Prof. Dr. rer. nat. D. Kube

Prof. Dr. med. M. Oppermann 
Hiermit erkläre ich, die Dissertation mit dem Titel „Evaluation von AntiHER-2-Substanzen für die Therapie des kolorektalen Karzinoms" eigenständig angefertigt und keine anderen als die von mir angegebenen Quellen und Hilfsmittel verwendet zu haben.

Göttingen, den

(Unterschrift) 
Die Daten, auf denen die vorliegende Arbeit basiert, wurden publiziert:

Conradi LC, Spitzner M, Metzger AL, Kisly M, Middel P, Bohnenberger H, Gaedcke J, Ghadimi MB, Liersch T, Ruschoff J et al. (2019): Combined targeting of HER-2 and HER-3 represents a promising therapeutic strategy in colorectal cancer. BMC Cancer 19, 880 


\section{Inhaltsverzeichnis}

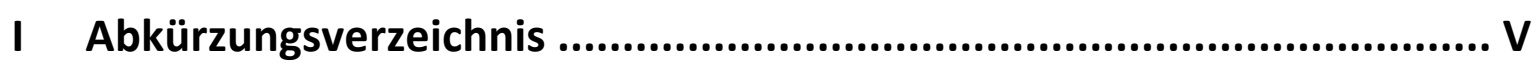

II Abbildungsverzeichnis .................................................................. VIII

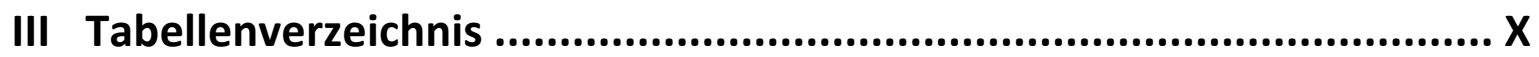

1 Einleitung und Fragestellung ...................................................... 1

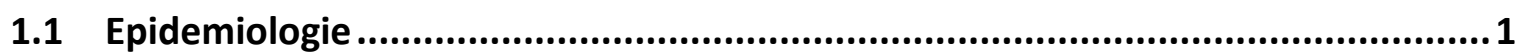

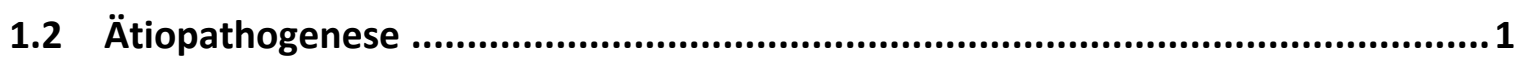

1.2.1 Chromosomales Progressionsmodell................................................................ 2

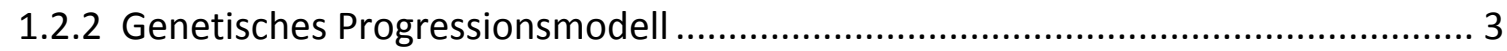

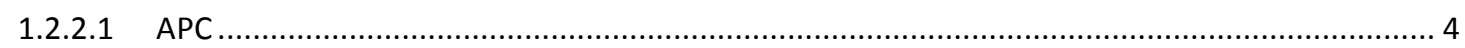

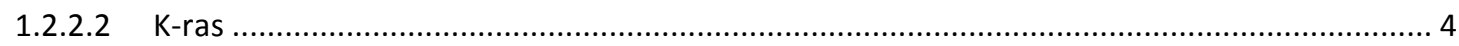

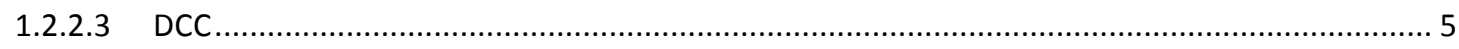

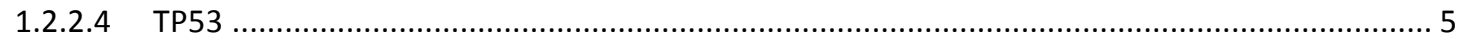

1.3 Klassifikation und klinische Einteilung.......................................................

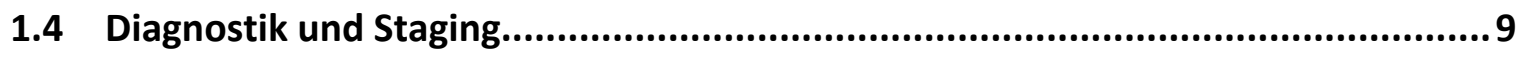

1.5 Stadienabhängige Therapie........................................................................... 11

1.5.1 Therapie des Kolonkarzinoms (UICC I-III) ...................................................... 11

1.5.2 Therapie des Rektumkarzinoms (UICC I-III) ................................................... 12

1.5.3 Therapie des kolorektalen Karzinoms im UICC-Stadium IV ............................... 13

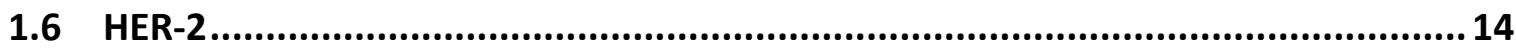

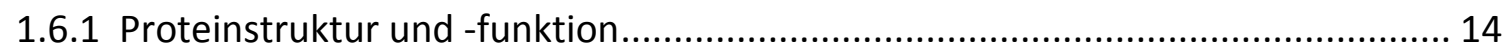

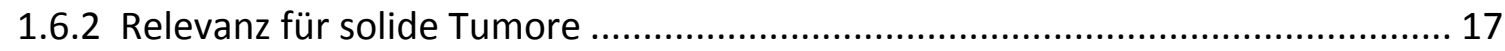

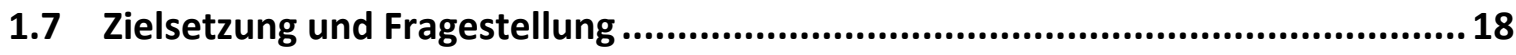




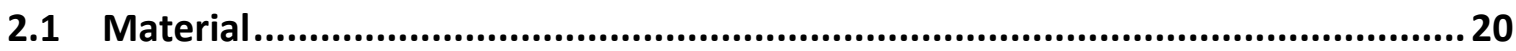

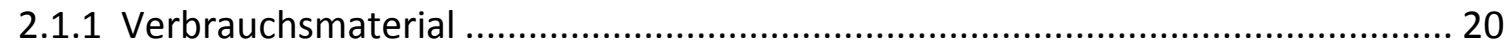

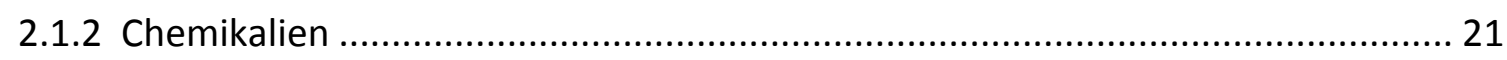

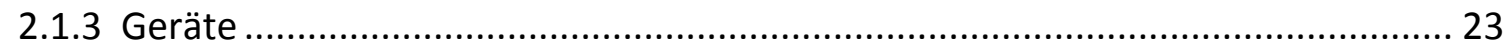

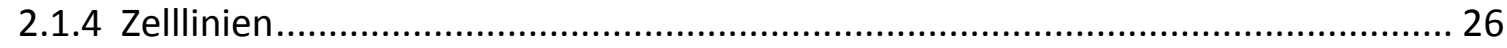

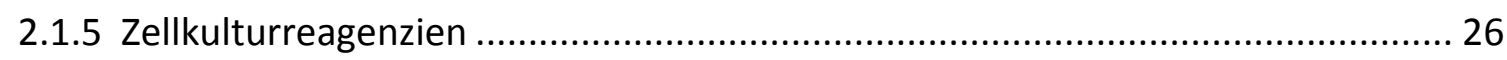

2.1.6 Inhibitoren, Antikörper und Chemotherapeutika ............................................ 27

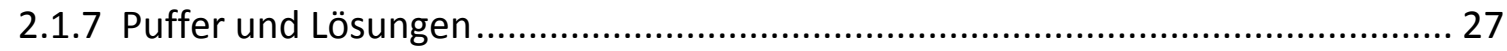

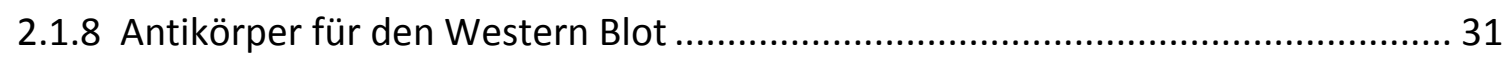

2.1.9 Substanzen und Protokolle für den Färbeautomaten BenchMark XT ................. 31

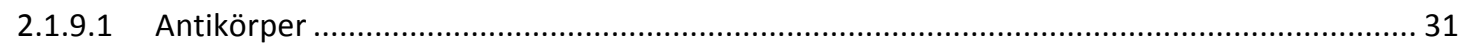

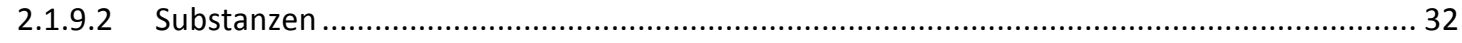

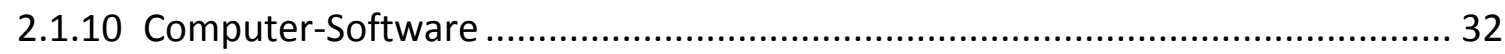

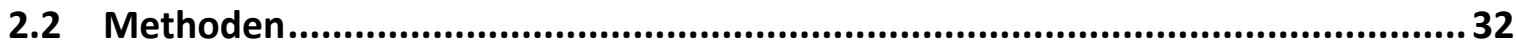

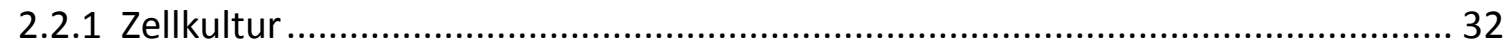

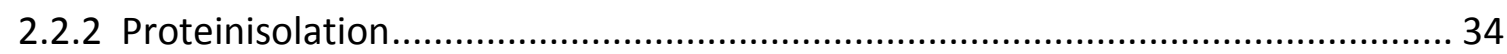

2.2.3 Photometrische Proteinkonzentrations-Messung ........................................... 35

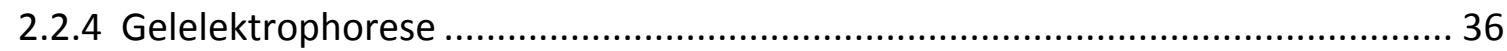

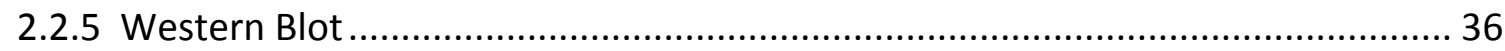

2.2.6 Anfertigung von Paraffinblöcken und -schnitten ............................................. 37

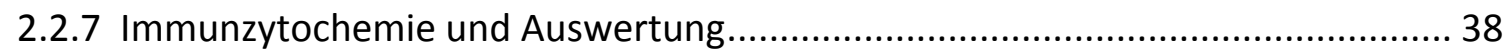

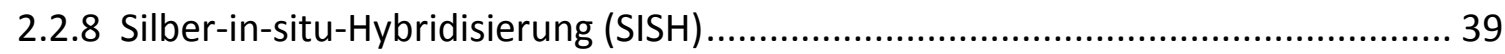

2.2.9 Messung der Zellviabilität nach Anti-HER-2-Therapie ..................................... 42

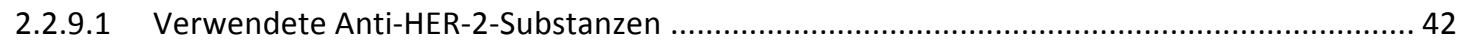

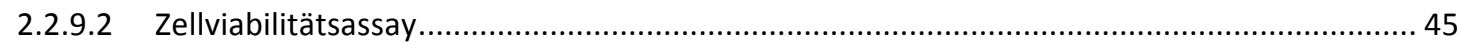

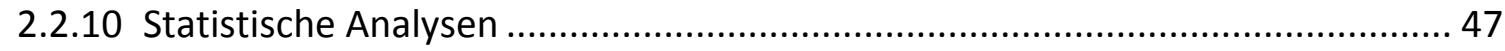

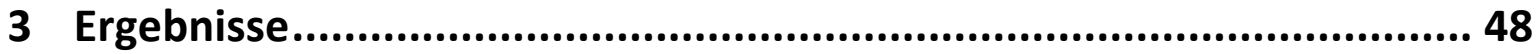

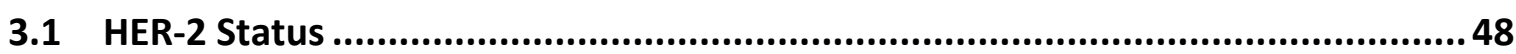

3.1.1 Immunzytochemische Färbungen von HER-2 an Paraffinschnitten ..................... 49 


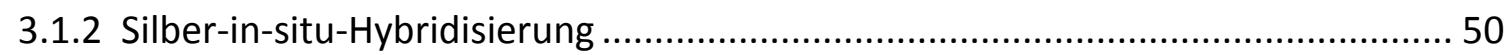

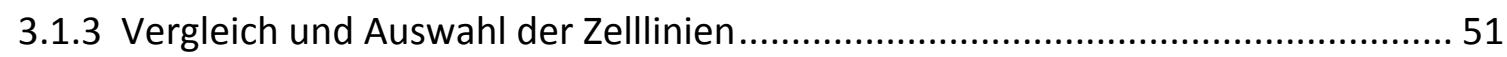

3.2 Behandlung mit Anti-HER-2-Substanzen................................................... 52

3.2.1 pAkt-Level und Zellviabilitätsmessung ........................................................ 52

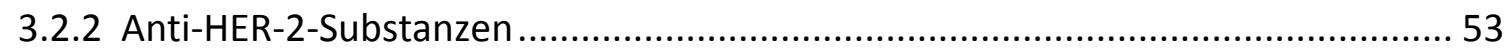

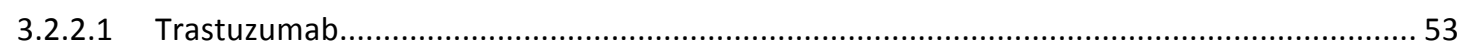

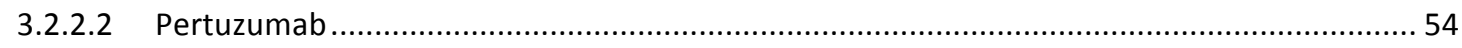

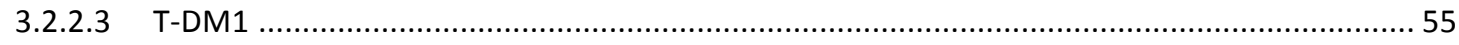

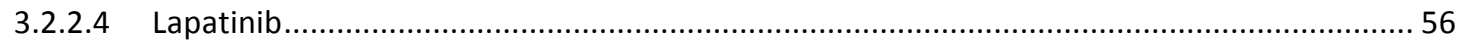

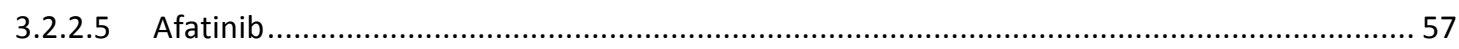

3.2.3 Kombination Trastuzumab und Pertuzumab .................................................. 58

3.2.3.1 Trastuzumab kombiniert mit Pertuzumab .................................................................... 59

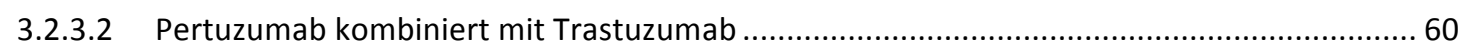

3.2.4 Kombination der Anti-HER-2-Substanzen mit 5-FU und Oxaliplatin .................... 63

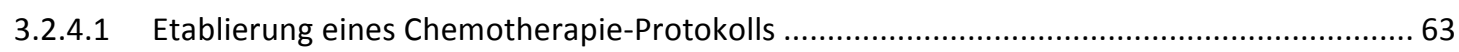

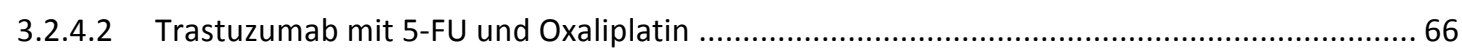

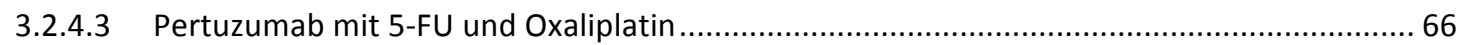

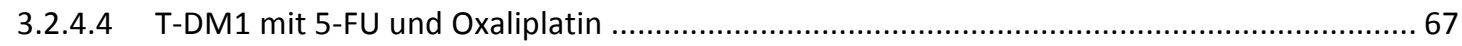

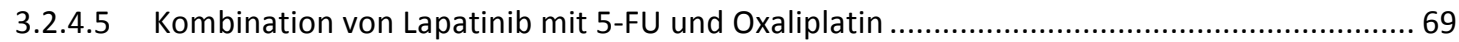

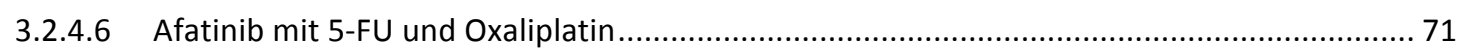

3.2.5 Zusammenfassung der Ergebnisse................................................... 73

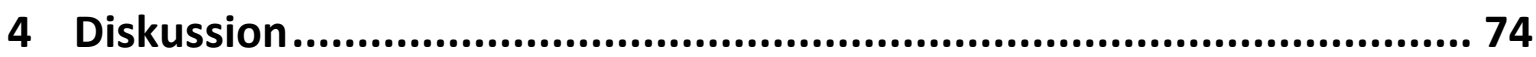

4.1 Klinische Problematik ............................................................................. 74

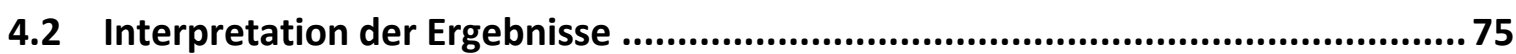

4.2.1 HER-2-Positivität der kolorektalen Karzinomzelllinien ..................................... 75

4.2.2 HER-2-Positivität im kolorektalen Karzinom ..................................................... 77

4.2.3 Klinischer Einsatz von Anti-HER-2-Substanzen .............................................. 78

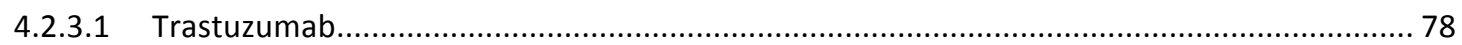

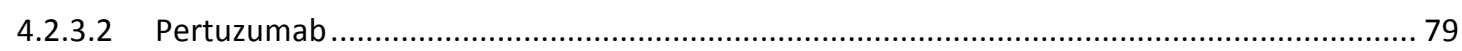

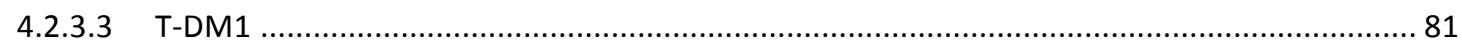

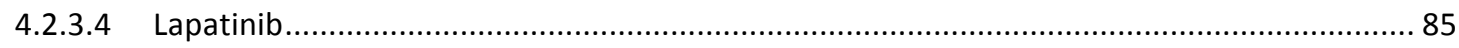

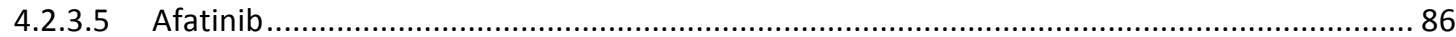


4.2.4 Vergleich der Monotherapie und der Kombination mit 5-FU und Oxaliplatin...... 89

4.3 Mögliche Rolle von HER-3 in der Resistenz gegenüber Anti-HER-2-Substanzen... 89

4.4 Einsatz von Anti-HER-2-Substanzen im kolorektalen Karzinom .........................91

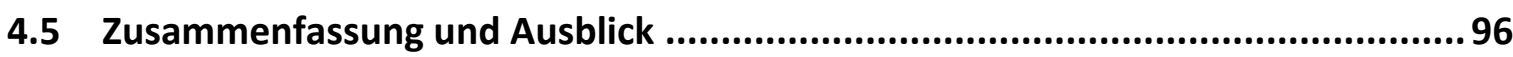

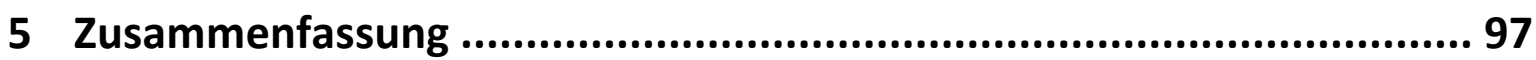

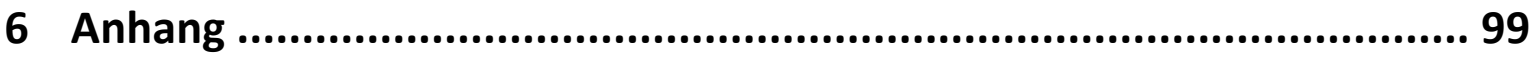

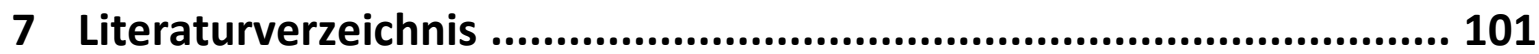




\section{Abkürzungsverzeichnis}

\begin{tabular}{|c|c|}
\hline $5-\mathrm{FU}$ & 5-Fluorouracil \\
\hline $\mathrm{AlO}$ & Arbeitsgemeinschaft Internistische Onkologie \\
\hline Akt/pAkt & Proteinkinase $\mathrm{B} /$ phosphorylierte Proteinkinase $\mathrm{B}$ \\
\hline APC & adenomatous polyposis coli \\
\hline APR & abdominoperineale Rektumexstirpation \\
\hline APS & Ammoniumpersulfat \\
\hline ARO & Arbeitsgemeinschaft Radiologische Onkologie \\
\hline (T)ARR & (tiefe) anteriore Rektumresektion \\
\hline ATCC & American Type Culture Collection \\
\hline BCA & Bicinchoninsäure \\
\hline BSA & bovines Serumalbumin \\
\hline CA 19-9 & Carbohydrate-Antigen 19-9 \\
\hline CAO & Chirurgische Arbeitsgemeinschaft für Onkologie \\
\hline CEA & Carcinoembryonales Antigen \\
\hline CIMP & CpG-Island-Methylator-Phänotyp \\
\hline CIN & chromosomale Instabilität \\
\hline CpG & Cytosin-phosphatidyl-Guanin \\
\hline CT & Computertomographie \\
\hline DAB & 3,3'-Diaminobenzidin \\
\hline DCC & deleted in colorectal carcinoma \\
\hline DIG & Digoxigenin \\
\hline DMSO & Dimethylsulfoxid \\
\hline DNA & Desoxyribonukleinsäure \\
\hline DNP & Dinitrophenyl \\
\hline DTT & 1,4-Dithio-DL-threit(ol) \\
\hline $\mathrm{EC}_{50}$ & halbmaximale effektive Konzentration \\
\hline $\mathrm{ECL}$ & enhanced chemoluminescece \\
\hline
\end{tabular}




\begin{tabular}{|c|c|}
\hline EDTA & Ethylendiamintetraessigsäure \\
\hline EGF/EGFR & epidermal growth factor / epidermal growth factor receptor \\
\hline FAP & familiäre adenomatöse Polyposis \\
\hline FBS & fetales bovines Serum \\
\hline FDA & Food and Drug Administration \\
\hline GDP/GTP & Guanin-Diphosphat/Guanin-Triphosphat \\
\hline GEKID & Gesellschaft der Epidemiologischen Krebsregister in Deutschland \\
\hline GLM & generalisierte Lineare Modelle \\
\hline $\mathrm{HCl}$ & Salzsäure \\
\hline HER-1-4 & human epidermal growth factor 1-4 \\
\hline HNPCC & hereditäres nicht-polypöses kolorektales Karzinom \\
\hline HRP & horseradish-Peroxidase \\
\hline ICC & Immunzytochemie \\
\hline IgG & Immunglobulin Typ G \\
\hline $\mathrm{IHC}$ & Immunhistochemie \\
\hline ISH/SISH/FISH & (Silber-/Fluoreszenz-) In-situ-Hybridisierung \\
\hline $\mathrm{KCl}$ & Kaliumchlorid \\
\hline kDA & Kilodalton \\
\hline KRK & kolorektales Karzinom \\
\hline $\mathrm{M}, \mathrm{mM}, \mu \mathrm{M}$ & Molar, Millimolar, Mikromolar \\
\hline MLH-1 & MutL homolog 1 \\
\hline MMR & mismatch repair \\
\hline MRT & Magnetresonanztomographie \\
\hline MSI/MSS & Mikrosatelliteninstabilität/Mikrosatellitenstabilität \\
\hline $\mathrm{NaCl}$ & Natriumchlorid \\
\hline $\mathrm{NaOH}$ & Natronlauge \\
\hline NRG & Neuregulin-1 \\
\hline NSCLC & nicht-kleinzelliges Lungenkarzinom \\
\hline
\end{tabular}




\begin{tabular}{ll} 
PBS & phosphate buffered saline \\
PI3K & Phosphoinositid-3-Kinase \\
PME & partielle mesorektale Exzision \\
PVDF & Polyvinylidenfluoridmembran \\
RCT & Radio-Chemotherapie \\
RKI & Robert-Koch-Institut \\
RNA & Ribonukleinsäure \\
RNAi & RNA-Interferenz \\
RIPA & radioimmunoprecipitation assay \\
rPm & revolutions per minute = Umdrehungen pro Minute \\
SDS-PAGE & Natriumdodecylsulfat-Polyacrylamid-Gelelektrophorese \\
T-DM1 & Trastuzumab-Maytansinoid, Trastuzumab-Emtansin \\
TBS(-T) & Tris-buffered saline (-Tween) \\
TME & totale mesorektale Exzision \\
TNM & Klassifikationssystem maligner Tumore \\
U & Einheiten \\
UICC & Union Internationale Contre le Cancer \\
ZEGF & vascular endothelial growth factor \\
RfK & Rür Krebsregisterdaten \\
\hline &
\end{tabular}




\section{Abbildungsverzeichnis}

Abbildung 1: Adenom-Karzinom-Sequenz - morphologische, chromosomale und genetische Veränderungen .....

Abbildung 2: Aufbau der Dickdarmwand und Einteilung der T-Kategorien beim kolorektalen Karzinom

Abbildung 3: Stadienadaptierte Therapie des Kolonkarzinoms.....

Abbildung 4: Stadienadaptierte Therapie des Rektumkarzinoms im unteren und mittleren Rektumdrittel

Abbildung 5: Die EGF-Rezeptorfamilie - Struktur und Funktion

Abbildung 6: Beurteilung der spezifischen Membranfärbung für HER-2 in der Immunzytochemie.

Abbildung 7: $\quad$ SISH-Reaktion

Abbildung 8: $\quad$ Red-ISH-Reaktion

Abbildung 9: $\quad$ Schema einer 96-Well-Platte.

Abbildung 10: Immunzytochemische Färbungen von HER-2 und Scoring am Beispiel der Zelllinien LS513 und SW837.

Abbildung 11: Western Blot und Zellviabilitätsmessung nach der Behandlung mit Trastuzumab

Abbildung 12: Western Blot und Zellviabilitätsmessung nach der Behandlung mit Pertuzumab

Abbildung 13: Western Blot und Zellviabilitätsmessung nach der Behandlung mit T-DM1

Abbildung 14: Western Blot und Zellviabilitätsmessung nach der Behandlung mit Lapatinib.

Abbildung 15: Western Blot und Zellviabilitätsmessung nach der Behandlung mit Afatinib

Abbildung 16: Western Blots und Zellviabilitätsmessungen nach Behandlung mit $1 \mu \mathrm{g} / \mathrm{ml}$ Trastuzumab und Pertuzumab

Abbildung 17: Western Blots und Zellviabilitätsmessungen nach Behandlung mit 20 bzw. $100 \mu \mathrm{g} / \mathrm{ml}$ Trastuzumab und Pertuzumab. 
Abbildung 18: Western Blots und Zellviabilitätsmessungen nach Behandlung mit $1 \mu \mathrm{g} / \mathrm{ml}$ Pertuzumab und Trastuzumab

Abbildung 19: Western Blots und Zellviabilitätsmessungen nach Behandlung mit 20, 50 bzw. $100 \mu \mathrm{g} / \mathrm{ml}$ Pertuzumab und Trastuzumab. 62

Abbildung 20: Zellviabilitätsmessungen nach Behandlung mit Oxaliplatin 63

Abbildung 21: Zellviabilitätsmessungen nach Behandlung mit 0,1 bzw 1,5 $\mu \mathrm{M}$ Oxaliplatin + 5-FU sowie 0,25 bzw. $3 \mu \mathrm{M}$ Oxaliplatin + 5-FU 64

Abbildung 22: Zellviabilitätsmessungen nach Behandlung mit 0,25 bzw. $3 \mu \mathrm{M}$ 5-FU + Oxaliplatin sowie 0,5 bzw. $6 \mu \mathrm{M}$ 5-FU + Oxaliplatin 65

Abbildung 23: Zellviabilitätsmessung nach der Behandlung mit Trastuzumab, 5-FU und Oxaliplatin 66

Abbildung 24: Zellviabilitätsmessung nach der Behandlung mit Pertuzumab, 5-FU und Oxaliplatin 67

Abbildung 25: Zellviabilitätsmessung nach der Behandlung mit T-DM1, 5-FU und Oxaliplatin 68

Abbildung 26: Vergleich der $\mathrm{EC}_{50}$ zwischen Mono- und Kombinationstherapie mit T-DM1, 5-FU und Oxaliplatin

Abbildung 27: Zellviabilitätsmessung nach der Behandlung mit Lapatinib, 5-FU und Oxaliplatin 70

Abbildung 28: Vergleich der EC $_{50}$ zwischen Mono- und Kombinationstherapie mit Lapatinib, 5-FU und Oxaliplatin

Abbildung 29: Zellviabilitätsmessung nach der Behandlung mit Afatinib, 5-FU und Oxaliplatin

Abbildung 30: Vergleich der $\mathrm{EC}_{50}$ zwischen Mono- und Kombinationstherapie mit Afatinib, 5-FU und Oxaliplatin 


\section{Tabellenverzeichnis}

Tabelle 1: $\quad$ UICC-Klassifikation des kolorektalen Karzinoms ..................................... 7

Tabelle 2: $\quad$ Übersicht der verwendeten kolorektalen Karzinomzelllinien ................. 26

Tabelle 3: Konzentrationsreihen der Anti-HER-2-Substanzen für die Proteiniso-

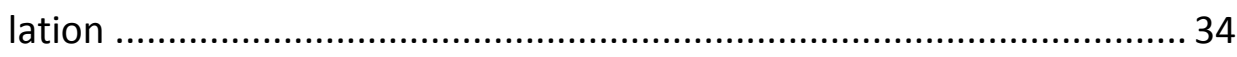

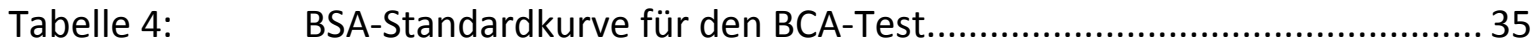

Tabelle 5: Dosierungen der Chemotherapeutika und Anti-HER-2-Substanzen für den Viabilitätsassay mit den Zelllinien LS513 und LS1034 ................... 45

Tabelle 6: Dosierungen der Chemotherapeutika und Anti-HER-2-Substanzen für den Viabilitätsassay mit der Zelllinie SW837 ...................................... 45

Tabelle 7: Molekulargenetische Charakteristika der kolorektalen Karzinomzell-

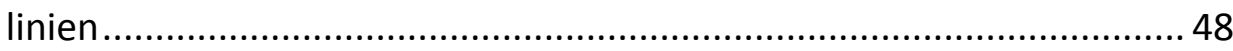

Tabelle 8: $\quad$ Ergebnisse der Immunzytochemie und SISH für die kolorektalen Karzinomzelllinien.

Tabelle 9: $\quad$ Vergleich der HER-2-Scoring-Kriterien beim Mamma-, Magen- und kolorektalen Karzinom ............................................................... 76

Tabelle 10: $\quad E_{50}$-Werte der Mono-/ Kombinationstherapie der Zelllinie LS513 ....... 99

Tabelle 11: $\quad \quad E_{50}$-Werte der Mono-/ Kombinationstherapie der Zelllinie LS1034 ..... 99

Tabelle 12: $\quad E_{50}-$ Werte der Mono-/ Kombinationstherapie der Zelllinie SW837 ... 100 


\section{Einleitung und Fragestellung}

\subsection{Epidemiologie}

Das kolorektale Karzinom (KRK) stellt mit einer weltweiten Inzidenz von über 1,8 Millionen Neuerkrankungen pro Jahr eine der häufigsten Tumorentitäten dar (Bray et al. 2018; Navarro et al. 2017; Siegel RL et al. 2017). Betroffen sind insbesondere Länder der westlichen Welt. Nach dem Mammakarzinom ist das KRK das zweithäufigste Malignom der Frau sowie nach dem Bronchial- und Prostatakarzinom das dritthäufigste Malignom des Mannes (Bray et al. 2018). In Deutschland treten jährlich etwa 60000 Neuerkrankungen auf (ZfKD und GEKID 2017). Obwohl die Sterblichkeitsrate dank präventiver Maßnahmen sowie Verbesserungen in der interdisziplinären Therapie innerhalb der letzten Jahre deutlich gesunken ist (Bosetti et al. 2011), stellt das KRK weiterhin die zweithäufigste krebsbedingte Todesursache hierzulande dar (ZfKD und GEKID 2017). Das mittlere Erkrankungsalter liegt für Frauen bei 75 Jahren, für Männer bei 71 Jahren. In lediglich etwa 10\% der Fälle ist mit der Entstehung eines KRK vor dem 55. Lebensjahr zu rechnen. Ein frühes Erkrankungsalter ist hierbei Hinweis auf eine erbliche Komponente. Das Risiko, im Laufe des Lebens an einem KRK zu erkranken, liegt bei etwa 6\% (ZfKD und GEKID 2017). In einer stetig älter werdenden Bevölkerung stellt diese Erkrankung heute und in der Zukunft ein großes sozioökonomisches Problem und eine wachsende Herausforderung dar.

\section{2 Ätiopathogenese}

Die Entstehung eines KRK ist bedingt durch genetische und epigenetische Faktoren. Etwa 80-85\% aller KRK entstehen sporadisch, bei ca. 15-20\% besteht eine hereditäre Komponente. Die häufigsten Erkrankungen mit genetischer Disposition sind dabei das Lynch-Syndrom und die familiäre adenomatöse Polyposis (FAP) (Gala und Chung 2011; Kerber et al. 2005). Ein erhöhtes Risiko besteht ebenfalls bei chronisch-entzündlichen Darmerkrankungen, insbesondere der Colitis ulcerosa (Fuchs et al. 2018). Lebensgewohnheiten wie das Rauchen, übermäßiger Alkoholkonsum, mangelnde körperliche Bewegung und eine fleischreiche, ballaststoffarme Ernährung gelten als exogene Risikofaktoren (Chan und Giovannucci 2010; Huxley et al. 2009). 
Entscheidend für die Entstehung eines KRK sind jedoch molekulargenetische Veränderungen. Es wurde eine „Adenom-Karzinom-Sequenz" beschrieben, nach der sporadische KRK aus „Darmpolypen“ entstehen (Day und Morson 1978; Morson 1974). Dieser Prozess umfasst ein Intervall von ca. 10 bis 15 Jahren (Vogelstein et al. 1988). Dabei entsteht ein Adenom durch Proliferation und den Verlust spezifischer Differenzierung des normalen Darmepithels (s. Abb. 1). Es werden Adenome mit niedrigund hochgradiger intraepithelialer Neoplasie unterschieden. Die Wuchsform stellt sich in den meisten Fällen als exophythisch in das Darmlumen („tubulär“) dar, seltener flach aufsitzend („villös“) oder als Mischform („tubulovillös“). Ein villöses Adenom birgt die größere Gefahr einer frühen Invasivität, da die Strecke bis zur Infiltration der Submukosa vergleichsweise kurz ist (Fuchs et al. 2018).

Den morphologischen Entwicklungsschritten wurden im Verlauf molekulargenetische Korrelate zugeordnet (Fearon und Vogelstein 1990; Vogelstein et al. 1988). Es handelt sich zum einen um chromosomale Aberrationen, zum anderen um (epi-)genetische Veränderungen. Durch Akkumulation dieser Veränderungen kommt es zur Progression der Karzinogenese. Im Folgenden sollen die chromosomalen und (epi-)genetischen Ursachen getrennt voneinander genauer erörtert und abschließend in Abbildung 1 gemeinsam mit der Morphologie der „Adenom-Karzinom-Sequenz" dargestellt werden.

\subsubsection{Chromosomales Progressionsmodell}

Chromosomale Aberrationen können sich als numerische oder strukturelle Veränderungen darstellen. Abweichend vom regulären diploiden Chromosomensatz führen numerische Aberrationen zu einer sogenannten Aneuploidie. Dies bedeutet, dass sich das gesamte Genom durch Fehlen oder Zugewinn einzelner Chromosomen oder deren Segmente verändert (Grade et al. 2015; Ried 2004). Die Mehrzahl aller KRK weist solche numerischen Aberrationen auf (Grade et al. 2006; The Cancer Genome Atlas Network 2012). Strukturelle Aberrationen umfassen Veränderungen der Chromosomen durch Amplifikation, Deletion, Insertion, Inversion oder Translokation von DNA-Abschnitten. Diesen Pathomechanismus bezeichnet man auch als chromosomale Instabilität (CIN), welche zur Karzinogenese führt (Lengauer et al. 1998). Es konnte gezeigt werden, dass bestimmte 
chromosomale Aberrationen mit den morphologischen Stadien in der Entstehung eines KRK korrelieren. Während frühe Adenome noch keine spezifischen Chromosomenaberrationen aufweisen, zeigen Adenome mit schweren Dysplasien Zugewinne der Chromosomen 7 und 20q. Invasive Karzinome weisen Verluste der Chromosomen 4, 8p und 18q sowie Zugewinne der Chromosomen 8q und 13 auf (Grade et al. 2006; The Cancer Genome Atlas Network 2012). Somit kann auch auf dieser Ebene ein Progressionsmodell konstruiert werden (s. Abb. 1).

Im Gegensatz dazu weisen weniger als 10\% der KRK einen diploiden Chromosomensatz auf. Eine mögliche Ursache sind Genmutationen des sogenannten Mismatch Repair (MMR-) Systems (Peltomaki 2003; Strand et al. 1993). Diese Karzinome gelten als Mikrosatelliten-instabil (Mikrosatelliteninstabilität, MSI). Mikrosatelliten sind repetitive DNASequenzen, bestehend aus bis zu sechs Basenpaaren, welche sich über das gesamte Genom verteilen und sich zwischen 10 und 60 Mal wiederholen können. Im Rahmen der DNA-Replikation können insbesondere hier Fehler entstehen, die normalerweise vom MMR-System behoben werden (Weber und Wong 1993). Sind jedoch Proteine dieses Systems verändert oder inaktiviert, beispielsweise durch Genmutation, Genverlust oder Methylierung der entsprechenden codierenden Genregionen, können fehlerhafte Basenpaarungen entstehen, welche zu Mutationen und Tumorgenese führen. Methylierungen finden insbesondere an Promotorregionen statt, welche reich (>60\%) an den Basen Cytosin und Guanin sind (CpG-Island-Methylator-Phänotyp, CIMP). Eine sporadische MSI entsteht am häufigsten durch diesen Mechanismus und konsekutive Inaktivierung des MLH1-Gens (Cunningham et al. 1998; Markowitz und Bertagnolli 2009). Neben der sporadischen Form kann eine MSI jedoch auch durch Keimbahnmutationen von MMR-Genen determiniert sein. Dieser Pathomechanismus liegt beim Lynch-Syndrom vor, auch als hereditäres nicht-polypöses kolorektales Karzinom (HNPCC) bekannt (Fearon 2011).

\subsubsection{Genetisches Progressionsmodell}

Über die letzten Jahrzehnte wurden verschiedene Gene und Signalwege identifiziert, welche maßgeblich an der Entstehung und Progression des KRK beteiligt sind. Dabei können 
sowohl somatische Mutationen als auch Keimbahnmutationen ursächlich sein. Im Folgenden sollen die häufigsten Genveränderungen vorgestellt werden.

\subsubsection{APC}

Das adenomatous polyposis coli (APC)-Tumorsuppressorgen kodiert für ein zytoplasmatisches Protein, welches freies $\beta$-Catenin bindet und dessen Abbau initiiert. Das $\beta$-Catenin ist ein Protein des Wnt-Signalweges, das unter anderem die Expression Zellzyklus-regulierender Gene aktiviert, beispielsweise c-MYC und Cyclin D1 (Clevers 2006). Bestehen Mutationen oder ein Verlust des APC-Gens, kann $\beta$-Catenin nicht mehr abgebaut werden und akkumuliert im Zellkern (Fearon 2011). Dies bedingt eine unkontrollierte Proliferation und kann zur Karzinogenese führen. Der familiären adenomatösen Polyposis (FAP), einer autosomal dominant vererbten Erkrankung, liegen Keimbahnmutationen von APC zugrunde (Bisgaard et al. 1994). Die Patienten weisen, in Abhängigkeit von Typ und Lokalisation der Mutation, bereits ab dem 2. Lebensjahrzehnt mehrere hundert adenomatöse Polypen im Bereich des gesamten Kolons auf (Groden et al. 1991). Unbehandelt entarten diese Adenome in nahezu 100\%, weshalb eine frühzeitige chirurgische Resektion empfohlen wird (Emons et al. 2015). Jedoch weisen auch bis zu $80 \%$ aller sporadischen KRK eine Inaktivierung von APC auf (Fearon 2011).

\subsubsection{K-ras}

Die Rat sarcoma (Ras)-Protoonkogene kodieren für membranständige Proteine wie K-ras, welche die Guaninnukleotide Guanin-Diphosphat (GDP) und Guanin-Triphosphat (GTP) binden können (G-Proteine). Im inaktiven Zustand ist GDP gebunden. Durch Ligandenbindung wird jedoch GDP durch GTP ersetzt und der Signalweg aktiviert. Diese Signalkaskade wird durch Wachstumsfaktor-Rezeptoren wie EGFR initiiert und bewirkt über den MAP-Kinase-Weg eine verstärkte Zellproliferation und -differenzierung (Fearon 2011; Gaedcke et al. 2010). Physiologisch wird schließlich GTP zu GDP hydrolysiert und es kommt zur Unterbrechung der Signalkaskade. Durch Punktmutationen wird diese GTPaseFähigkeit reduziert, so dass auch ohne externe Wachstumsfaktoren die Zellproliferation ständig stimuliert wird (Emons et al. 2015). 


\subsubsection{DCC}

Das DCC-Gen (deleted in colorectal carcinoma) ist ein Tumorsuppressorgen auf dem Chromosom 18q21, welches Apoptose induzieren kann (Saito et al. 1999). Es kodiert für den Netrin-1-Rezeptor, welcher mit dem Ligand Netrin-1 einen Komplex bildet und Apoptosesignale terminiert. Löst sich die Liganden-Rezeptor-Bindung, wird die Apoptose eingeleitet (Mehlen et al. 1998). Eine Deletion des Gens oder auch erhöhte Expression des Liganden führen somit zu Zellhyperplasien und schließlich zu neoplastischen Läsionen. Die Deletion oder Mutation des DCC-Gens scheint erst in späten Stadien der intestinalen Tumorgenese aufzutreten (Mazelin et al. 2004).

\subsubsection{TP53}

Eine zentrale Rolle in der Zellzyklusregulation spielt das Tumorsuppressorgen TP53, welches auf dem Chromosom 17p13 lokalisiert ist. Es kodiert für ein Protein (p53), das den Zellzyklusarrest in der G1-Phase einleitet, sofern DNA-Schäden auftreten und detektiert werden (Polyak et al. 1997). Es kommt zur Aktivierung diverser Reparaturmechanismen, um diese Schäden zu beheben. Ist dies nicht möglich, wird eine p53-assoziierte Apoptose eingeleitet (el-Deiry et al. 1994). Kommt es zu genetischen Veränderungen im sogenannten „Wächter des Genoms“, resultiert ein vermehrtes Überleben von Zellen mit DNASchäden und somit genetische Instabilität, welche zu weiteren Mutationen führen kann. Die Inaktivierung von p53 durch z. B. Deletion oder Mutation ist in der Karzinogenese verschiedener Tumorentitäten eine der häufigsten genetischen Veränderungen (Muller und Vousden 2014). Der Großteil aller kolorektalen Karzinome weist eine Mutation von p53 auf, jedoch nur ein geringer Anteil der kolorektalen Adenome. Daraus ist zu schlussfolgern, dass die Inaktivierung von p53 den Übergang vom Adenom zum invasiven Karzinom markiert (Baker et al. 1990; Lane 1992). 


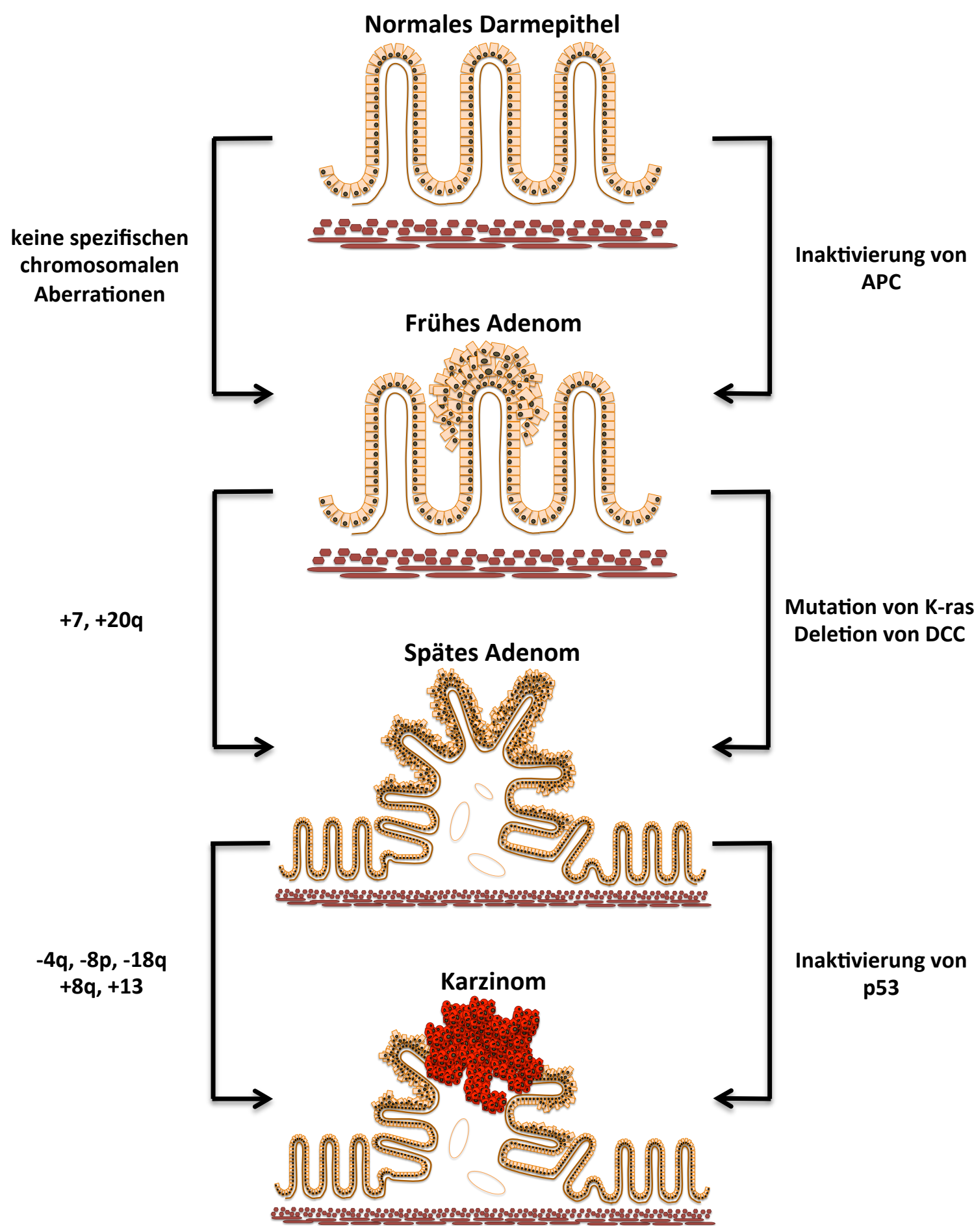

Abbildung 1: Adenom-Karzinom-Sequenz - morphologische, chromosomale und genetische Veränderungen

Dargestellt ist die Karzinogenese des sporadischen KRK. Schrittweise führen Veränderungen im Tumorsuppressorgen APC, im Onkogen K-ras und in den Tumorsupressorgenen DCC und TP53 zur Entwicklung eines Adenoms und schließlich invasiven Karzinoms. Assoziiert damit sind spezifische chromosomale Instabilitäten.

Diese Abbildung wurde von der Autorin der vorliegenden Arbeit selbst erstellt, modifiziert nach Grade et al. 2006 (S. 73 Fig.1) sowie Siegenthaler und Blum 2006 (S. 848, Abb. 31.9). 


\subsection{Klassifikation und klinische Einteilung}

Etwa $60 \%$ der KRK befinden sich im Rektum, 20\% im Sigma und je 10\% im rechten und linken Hemikolon (Fuchs et al. 2018). Klassifiziert wird das KRK nach dem Tumor-NodeMetastasis (TNM)-System. Dieses beinhaltet die Eindringtiefe des Tumors in die Wandschichten der Darmschleimhaut („,T“ - Tumor) (s. Abb. 2), den Befall von regionären Lymphknoten mit Tumorzellen (, $\mathrm{N}^{\prime \prime}$ - Nodus) und das Vorliegen von Fernmetastasen (,M“ - Metastasen). Vor allem diese Parameter bedingen die Prognose der Tumorerkrankung. Es müssen zur korrekten Stadieneinteilung mindestens 12 Lymphknoten im Resektat untersucht werden (Schmiegel et al. 2017).

Entsprechend bestimmten Kombinationen erfolgt eine Stadieneinteilung gemäß der Union internationale contre le cancer (UICC) (Wittekind 2017). Die Kombinationen und Zuordnung zu einem Stadium sind in Tabelle 1 zusammengefasst. Das UICC-Stadium ermöglicht die Zuordnung eines KRK zu einem bestimmten Therapieschema, ist aber hinsichtlich der Prognose nicht zwingend als einheitlich zu betrachten (Wittekind 2017).

\begin{tabular}{|c|ccc|}
\hline UICC-Stadium & T-Kategorie & N-Kategorie & M-Kategorie \\
\hline O & Tis* & N0 & M0 \\
\hline IIA & $\mathrm{T} 1, \mathrm{~T} 2$ & $\mathrm{~N} 0$ & $\mathrm{M} 0$ \\
IIB & $\mathrm{T} 3$ & $\mathrm{~N} 0$ & $\mathrm{M} 0$ \\
IIC & $\mathrm{T} 4 \mathrm{a}$ & $\mathrm{N} 0$ & $\mathrm{M} 0$ \\
\hline IIIA & $\mathrm{T} 4 \mathrm{~b}$ & $\mathrm{~N} 0$ & $\mathrm{M} 0$ \\
& $\mathrm{~T} 1, \mathrm{~T} 2$ & $\mathrm{~N} 1 \mathrm{a}$ & $\mathrm{M} 0$ \\
& $\mathrm{~T} 1$ & $\mathrm{~N} 2 \mathrm{a}$ & $\mathrm{M} 0$ \\
IIIB & $\mathrm{T} 3, \mathrm{~T} 4 \mathrm{a}$ & $\mathrm{N} 1$ & $\mathrm{M} 0$ \\
& $\mathrm{~T} 2, \mathrm{~T} 3$ & $\mathrm{~N} 2 \mathrm{a}$ & $\mathrm{M} 0$ \\
& $\mathrm{~T} 1, \mathrm{~T} 2$ & $\mathrm{~N} 2 \mathrm{~b}$ & $\mathrm{M} 0$ \\
& $\mathrm{~T} 4 \mathrm{a}$ & $\mathrm{N} 2 \mathrm{a}$ & $\mathrm{M} 0$ \\
IIIC & $\mathrm{T3}$ & $\mathrm{N} 2 \mathrm{~b}$ & $\mathrm{M} 0$ \\
& $\mathrm{~T} 4 \mathrm{~b}$ & $\mathrm{~N} 1, \mathrm{~N} 2$ & $\mathrm{M} 0$ \\
\hline IVA & jedes T & jedes N & $\mathrm{M} 1 \mathrm{a}$ \\
IVB & jedes T & jedes N & $\mathrm{M} 1 \mathrm{~b}$ \\
\hline *Tis = Carcinoma in situ & & & \\
\hline
\end{tabular}

Tabelle 1: UICC-Klassifikation des kolorektalen Karzinoms

Die Abbildung wurde modifiziert nach Wittekind 2017. 
- UICC 0: Bei einem Carcinoma in situ wachsen Tumorzellen unter Respektierung der Basalmembran (intraepithelial) bzw. der Lamina muscularis mucosae (intramukös) (s. Abb.2).

- UICC I: Ein lokal begrenztes KRK umfasst Eindringtiefen von der Submukosa (T1) bis in die Lamina muscularis propria (T2) (s. Abb. 2), zeichnet sich jedoch durch fehlenden Lymphknotenbefall und fehlende Fernmetastasen aus.

- UICC II: Von einem lokal fortgeschrittenen KRK spricht man bei Tumorinfiltrationen in die Subserosa (T3), in das viszerale Peritoneum (T4a) oder umliegende Organe (T4b) (s. Abb. 2) ohne Hinweis auf Lymphknoten- und Fernmetastasen.

- UICC III: Bei jedem T-Stadium, welches Lymphknotenmetastasen ohne Fernmetastasen aufweist, gilt ein UICC Stadium III. Dabei können solitäre (N1a), 2-3 (N1b), 4-6 (N2a) oder $\geq 7$ (N2b) regionäre Lymphknoten betroffen sein.

- UICC IV: Im fernmetastasierten Stadium kommt es zum Befall eines (M1a) oder mehrerer (M1b) Organe wie Leber und Lunge oder nichtregionärer Lymphknoten. Hierbei kann jedes T- und N-Stadium vorliegen. 


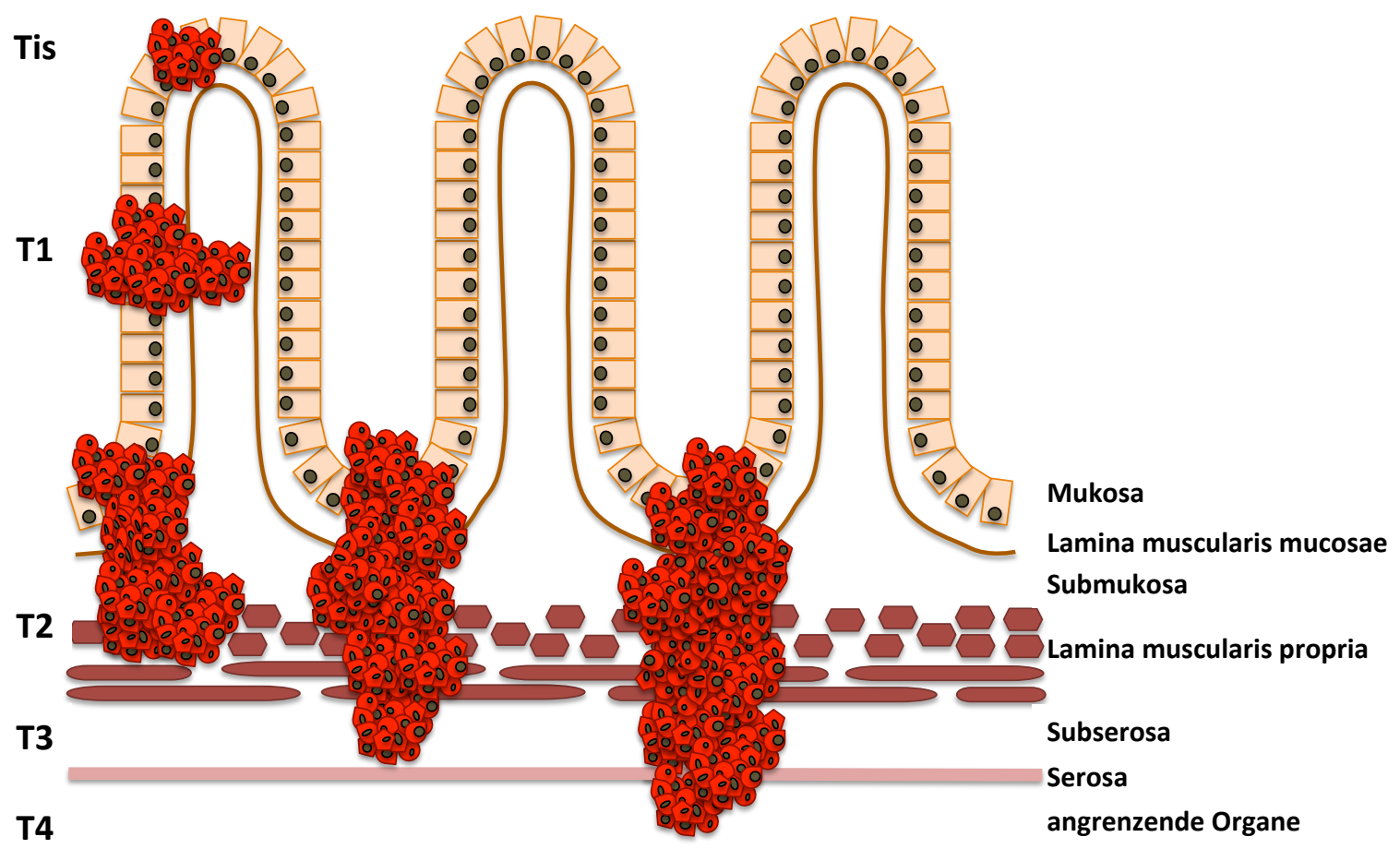

Abbildung 2: Aufbau der Dickdarmwand und Einteilung der T-Kategorien beim kolorektalen Karzinom

In der Abbildung dargestellt sind die Tumorinfitrationstiefen in Lagebeziehung zu anatomischen Strukturen:

- Tis - kein Durchbrechen der Lamina muscularis mucosae

- T1 - Durchbrechen der Lamina muscularis mucosae bis max. Submukosa

- T2 - Ausbreitung bis max. Lamina muscularis propria

- T3 - Ausbreitung bis max. Subserosa

- T4 - Durchbrechen der Serosa oder infiltration von Nachbarorganen

Die Abbildung wurde von der Autorin der vorliegenden Arbeit selbst erstellt, modifiziert nach Wittekind 2017 sowie Siegenthaler und Blum 2006 (S. 848, Abb. 31.9).

\subsection{Diagnostik und Staging}

Nach histologischer Diagnosesicherung erfolgt die prätherapeutische Ausbreitungsdiagnostik. Diese ist unerlässlich für die weitere Therapieplanung. Sowohl für das Kolon- als auch für das Rektumkarzinom gelten folgende Vorgehensweisen:

Zur Ermittlung des Risikos für familiären Darmkrebs sollte eine ausführliche Familienanamnese erhoben werden. Hierzu können z. B. spezielle Fragebögen der Deutschen Krebsgesellschaft verwendet werden. Sind erstgradige Verwandte insbesondere vor dem 50. Lebensjahr von einem KRK betroffen oder liegt eine Polyposis in der Familie vor, sind dies deutliche Hinweise auf eine hereditäre Komponente. Vorsorgeuntersuchungen bei Angehörigen sollten daraufhin engmaschig wahrgenommen und ggf. eine genetische Beratung in Anspruch genommen werden. Während der körperlichen Untersuchung wird 
eine digitale rektale Untersuchung zur orientierenden Einschätzung der Schließmuskelfunktion und Tumoren des Rektums durchgeführt.

Es erfolgt, sofern möglich, eine vollständige Koloskopie mit Biopsien weiterer unklarer Befunde, um Zweittumore auszuschließen, welche in etwa $4 \%$ der Fälle vorliegen (Barillari et al. 1990). Abhängig von den Ergebnissen der weiteren bildgebenden Diagnostik (siehe unten) sowie der individuellen klinischen Symptomatik sind weitere Fachdisziplinen konsiliarisch hinzuzuziehen. Neben einer routinemäßigen Blutuntersuchung sollten auch das carcinoembryonale Antigen (CEA) sowie das CarbohydrateAntigen 19-9 (CA 19-9) als Tumormarker bestimmt werden. Diese haben weniger eine diagnostische Aussagekraft, als dass sie einen Verlaufsparameter in der postoperativen Tumornachsorge darstellen (Duffy et al. 2014).

Zur Abklärung von Fernmetastasen der häufigsten Lokalisation (Leber, Lunge) sollten eine Abdomensonographie und eine Röntgen-Thorax-Untersuchung durchgeführt werden. Bei unklarem Befund oder dem Hinweis auf Fernmetastasen oder Organinfiltrationen sollten eine Computertomographie (CT) des Thorax und/oder des Abdomens und ggf. noch weitere Bildgebung oder andere organspezifische Untersuchungen ergänzt werden (Schmiegel et al. 2017).

Beim Rektumkarzinom kann bei der digitalen rektalen Untersuchung, je nach Tumorausbreitung, die Infiltration des Schließmuskels beurteilt werden. Eine starre Rektoskopie zur genauen Höhenlokalisation des Tumors ab der Linea anocutanea und eine Endosonographie sind durchzuführen, um die Eindringtiefe des Malignoms abzuschätzen und ggf. vergrößerte Lymphknoten darzustellen (Liersch et al. 2005). Zudem hat die Höhenlokalisation Einfluss auf die Therapie (s. 1.5.2). Ergänzend sollte auch eine MRT-Untersuchung des kleinen Beckens durchgeführt werden, um eine Infiltration im Bereich der mesorektalen Hüllfaszie sowie die Lagebeziehung zum Sphinkter zu beurteilen (Gaedcke et al. 2011). 


\subsection{Stadienabhängige Therapie}

Die Therapie des Kolonkarzinoms unterscheidet sich grundlegend von der des Rektumkarzinoms. Daher sollen die Prinzipien im Folgenden getrennt voneinander betrachtet werden.

\subsubsection{Therapie des Kolonkarzinoms (UICC I-III)}

Im Fall eines Kolonkarzinoms erfolgt, sofern kein Hinweis auf Fernmetastasen besteht, primär die onkologisch-chirurgische Resektion des Tumors. Die Resektionsgrenzen werden zum einen so gewählt, dass ein ausreichender Sicherheitsabstand zum Tumor gewährleistet ist. Zum anderen sollte das gesamte Lymphabstromgebiet dieses Bereiches mit den zugehörigen Lymphknoten reseziert werden (Schmiegel et al. 2017).

Die Lymphknoten befinden sich parakolisch sowie im Mesokolon und verlaufen radiär entlang der versorgenden Arterien. Sogar im Bereich der stammnahen Abgänge der Arterien können Lymphknotenmetastasen auftreten. Die Gefäße werden daher zentral abgesetzt. Daraus ergibt sich auch das Resektionsausmaß des entsprechenden Darmabschnitts. Das Präparat wird en bloc reseziert. Es konnte gezeigt werden, dass diese Operationen sowohl offenen-chirurgisch als auch laparoskopisch mit vergleichbaren postoperativen und onkologischen Ergebnissen durchführbar sind (Luglio und Nelson 2010). Nach histopathologischer Aufarbeitung gemäß den oben genannten Kriterien und Bestätigung von tumorfreien Resektionsrändern erfolgt ggf. eine adjuvante Chemotherapie, je nach vorliegendem Tumorstadium (s. Abb. 3) (Schmiegel et al. 2017).

Bei Vorliegen eines Kolonkarzinoms im Stadium UICCI nach vollständiger Resektion ist eine engmaschige Nachsorge aufgrund der geringen Rezidivrate nicht notwendig. Es sollten nach einem Jahr postoperativ eine komplette Koloskopie und bei unauffälligem Befund Koloskopien in Abständen von fünf Jahren erfolgen (Schmiegel et al. 2017). Im UICC-Stadium II wird eine adjuvante Chemotherapie nur bei Vorliegen von Risikofaktoren wie T4-Tumor, schlechter Differenzierungsgrad, weniger als 12 untersuchte Lymphknoten im Resektat sowie intraoperative Tumorperforation empfohlen. Ohne Risikofaktoren verbessert die adjuvante Chemotherapie das Überleben in diesem Stadium gemäß der pros- 
pektiven randomisierten multizentrischen QUASAR-Studie nur geringfügig (Quasar Collaborative Group et al. 2007). Grundsätzlich ist bei Vorliegen eines UICC-Stadium III eine adjuvante Chemotherapie indiziert (s. Abb. 3). Dadurch kann eine signifikante Verbesserung der Prognose erzielt werden (Gill et al. 2004; Loree und Cheung 2016). Die gängigen Chemotherapieregime beinhalten die Wirkstoffe 5-FU und Oxaliplatin (Schmiegel et al. 2017).

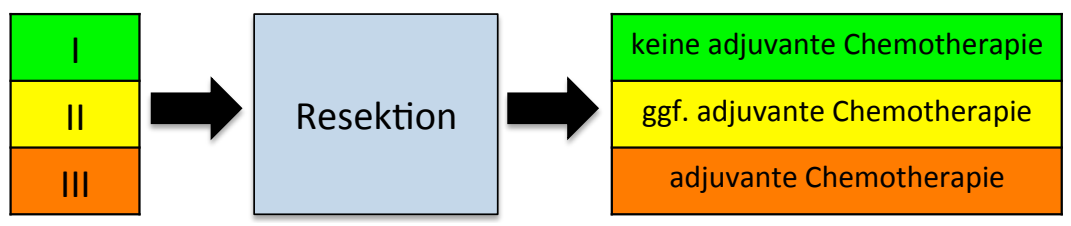

Abbildung 3: Stadienadaptierte Therapie des Kolonkarzinoms

\subsubsection{Therapie des Rektumkarzinoms (UICC I-III)}

Die Therapie des Rektumkarzinoms unterscheidet sich deutlich von der des Kolonkarzinoms (s. Abb. 4). Im UICC-Stadium I ist eine chirurgische Resektion ohne weitere Systemtherapie ausreichend, wobei ein T1-Karzinom mit dem Differenzierungsgrad G1 oder G2 („low-risk“) ohne Lymphgefäß- oder Veneneinbruch (LO, V0) oder bildgebenden Hinweis auf Lymphknotenmetastasen durch ein lokal resezierendes Verfahren wie eine transanale Vollwandexzision ausreichend behandelt werden kann (Gaedcke et al. 2011). In den UICC-Stadien II und III hat sich gemäß den Ergebnissen der CAO/ARO/AIO-94Studie eine neoadjuvante Radiochemotherapie (RCT) durchgesetzt (s. Abb. 4). Es konnte gezeigt werden, dass nach präoperativer RCT gefolgt von onkologischer Resektion sowie adjuvanter Chemotherapie die Lokalrezidivrate maßgeblich gesenkt wurde im Vergleich zur Operation mit anschließender RCT und adjuvanter Chemotherapie (Sauer et al. 2012; Sauer et al. 2004). Dies gilt für Karzinome des unteren $(<6 \mathrm{~cm})$ und des mittleren (6$12 \mathrm{~cm})$ Rektumdrittels. Rektumkarzinome im oberen Rektumdrittel $(12-16 \mathrm{~cm})$ werden entsprechend dem Schema für Kolonkarzinome therapiert.

Für eine onkologische Resektion mit ausreichendem Sicherheitsabstand stehen folgende chirurgische Methoden zur Verfügung, die abhängig von der Tumorlokalisation gewählt werden: die anteriore Rektumresektion (ARR), die tiefe anteriore Rektumresektion (TARR) 
und die abdominoperineale Rektumexstirpation (APR). Zusätzlich erfolgt die Entfernung der mesorektalen Hüllfaszie und damit der drainierenden Lymphknoten als totale mesorektale Exzision (TME) bei Tumoren des unteren und mittleren Rektumdrittels oder als partielle mesorektale Exzision (PME) bei Malignomen des oberen Rektumdrittels sowie des rektosigmoidalen Übergangs (Schmiegel et al. 2017).

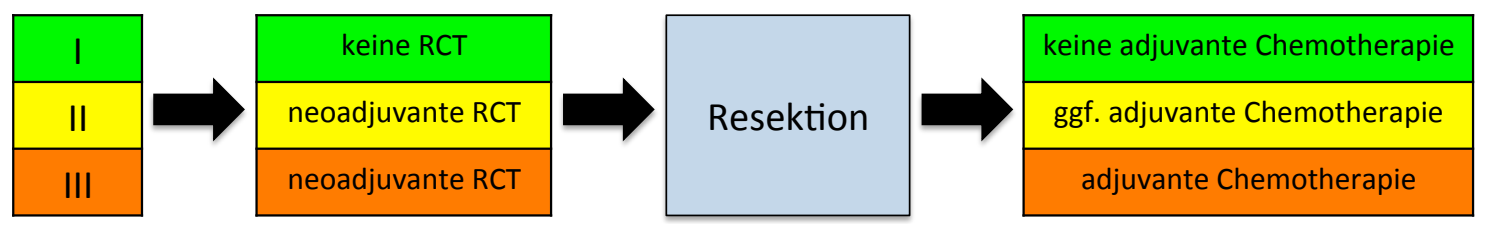

Abbildung 4: Stadienadaptierte Therapie des Rektumkarzinoms im unteren und mittleren Rektumdrittel

Wie beim Kolonkarzinom konnte mittlerweile gezeigt werden, dass das laparoskopische und das offen-chirurgische Vorgehen hinsichtlich der onkologischen und funktionellen Ergebnisse bei entsprechender Expertise des Operateurs vergleichbar sind (Bonjer et al. 2015; van der Pas et al. 2013). In diesem Kontext verglich die prospektiv randomisierte ROLARR-Studie die Roboter-assistierte mit der laparoskopischen Resektion des Rektumkarzinoms (Jayne et al. 2017). Die Ergebnisse dieser Studie zeigen, dass auch diese Verfahren vergleichbar sind, auch wenn die Langzeitergebnisse noch ausstehen.

Die neoadjuvante RCT sowie die adjuvante Chemotherapie werden leitliniengemäß mit einer 5-FU-Monotherapie durchgeführt. In der CAO/ARO/AIO-04-Studie wurde im Prüfarm zusätzlich Oxaliplatin eingesetzt. Hierdurch konnte zwar eine signifikante Verbesserung des krankheitsfreien Überlebens, nicht jedoch des Gesamtüberlebens bei vergleichbarer Toxizität gezeigt werden (Rödel et al. 2012; Rödel et al. 2015).

\subsubsection{Therapie des kolorektalen Karzinoms im UICC-Stadium IV}

Etwa $50 \%$ aller Patienten mit einem KRK entwickeln im Verlauf der Erkrankung Metastasen - am häufigsten in der Leber und in der Lunge (Graeter und Friedel 2016; Siegel R et al. 2012). Bereits bei Erstdiagnose finden sich bei ca. einem Viertel aller Patienten synchrone Lebermetastasen. Für ein KRK im Stadium IV nach UICC gibt es keine einheitliche 
Therapieleitlinie (Van Cutsem et al. 2016). Im Gegensatz zu anderen Tumorentitäten besteht jedoch selbst im metastasierten Zustand noch häufig die Möglichkeit eines kurativen Ansatzes durch Resektion oder lokale Ablation von Primarius und Metastasen in Leber und Lunge. Zum einen kann die Resektabilität primär bestehen. Zum anderen können (R)CT-Konzepte genutzt werden, um grenzwertig resektable oder nicht resektable Metastasen in ein resektables Stadium zu überführen (Adam et al. 2012; Folprecht et al. 2014). Grundvoraussetzung dafür ist, dass nach Resektion ausreichend hepatisches bzw. pulmonales Restgewebe verbleibt, um postoperativ eine pulmonale bzw. Leberinsuffizienz zu vermeiden. Das 5-Jahres-Überleben nach erfolgreicher Metastasenresektion liegt laut aktueller Datenlage bei etwa 50\% (Gonzalez und Gervaz 2015; Kanas et al. 2012). Besteht keine Aussicht auf ein kuratives Therapieziel, können lokal resezierende oder ablative Maßnahmen und/oder eine intensivierte Chemotherapie zur Reduktion von Organsymptomen, raschem Tumorprogress oder erhöhter Tumorlast erwogen werden.

Die derzeitigen Therapieschemata beinhalten in der Regel spezifische zielgerichtete Substanzen ("targeted drugs"), die in einer Kombination mit den gängigen Chemotherapeutika 5-FU, Oxaliplatin und Irinotecan verabreicht werden (Ahn DH et al. 2017). Dabei handelt es sich um den Angiogenesehemmer Bevacizumab, einen Antikörper gegen den vascular endothelial growth factor (VEGF), sowie Cetuximab und Panitumumab, Antikörper gegen den epidermal growth factor receptor (EGFR) (Schmiegel et al. 2017). Es kommt jedoch häufig zu primären oder sekundären Resistenzen gegen diese Substanzen, weshalb weiterhin die dringliche Notwendigkeit besteht, neue Therapiestrategien zu entwickeln (Bergers und Hanahan 2008; Takegawa et al. 2016). In diesem Kontext stellt vor allem HER-2 eine interessante Zielstruktur für die Therapie des KRK dar und soll daher im Folgenden näher betrachtet werden.

\subsection{HER-2}

\subsubsection{Proteinstruktur und -funktion}

Der human epidermal growth factor receptor 2 (HER-2, ErbB-2, HER-2/neu) ist ein Protein mit einer Größe von 185 kDa (Schechter et al. 1984) und wird codiert durch ein Gen auf 
dem Chromosom 17q21 (Half et al. 2004). Es ist Mitglied einer Familie von vier Transmembran-Tyrosinkinaserezeptoren (HER-1/ErbB1/EGFR, HER-2/ErbB2, HER-3/ErbB3, HER4/ErbB4). Diesen gemeinsam sind jeweils extrazelluläre Domänen und ein lipophiles Transmembransegment. Spezifische extrazelluläre Bindungsstellen für Liganden werden von EGFR, HER-3 und HER-4 exprimiert, nicht jedoch von HER-2 (Ferguson et al. 2003). Ungebunden liegen diese Rezeptoren in einem inaktiven Zustand vor. Durch Ligandenbindung kommt es zur Konformationsänderung, welche eine Homo- oder Heterodimerisation der Rezeptoren untereinander möglich macht (s. Abb. 5). HER-2 liegt bereits in einer „offenen“ bindungsfähigen Konformation vor (Cho et al. 2003; Garrett et al. 2003) und stellt daher den bevorzugten Dimerisationspartner der übrigen Rezeptorproteine dar (GrausPorta et al. 1997).

Erst durch Dimerisation ist eine Transphosphorylierung von intrazellulär gelegenen Tyrosinresten und somit die Aktivierung von nachgeschalteten Signalwegen möglich. EGFR, HER-2 und HER-4 weisen eine aktive intrazelluläre Tyrosinkinase-Domäne auf, während die eigene Tyrosinkinaseaktivität von HER-3 sehr schwach bis gar nicht ausgeprägt ist (Guy et al. 1994; Yarden und Sliwkowski 2001). Die Phosphorylierung von Tyrosinresten der EGF-Rezeptorproteine geschieht dabei an asymmetrisch verbundenen, katalytischen intrazellulären Domänen, wobei ein Monomer allosterisch die katalytische Aktivität des Bindungspartners aktiviert (Zhang et al. 2007). An den phosphorylierten Tyrosinresten können Proteine binden und durch Phosphorylierung Signalkaskaden ansteuern. Letztendlich können Homodimere aus EGFR, HER-2 und HER-4 entstehen, wobei HER-2Homodimere jedoch nur ligandenunabhängig bei starker Überexpression gebildet werden. HER-3-Homodimere können nicht entstehen. Für Heterodimere ist jegliche Kombination der vier Membranrezeptoren denkbar (Roskoski 2014). HER-3 ist in der Lage, durch Dimerisation mit anderen Mitgliedern der Rezeptortyrosinkinasefamilie und folglich Transphosphorylierung PI3K zu aktivieren (Pinkas-Kramarski et al. 1996; Soltoff et al. 1994). Insbesondere das Heterodimer HER-2/HER-3 ist hinsichtlich der ligandengesteuerten Phosphorylierung und Aktivierung der nachgestellten Signalkaskade die stärkste Verbindung und stellt das potenteste Onkoprotein dar (Baselga und Swain 2009). 


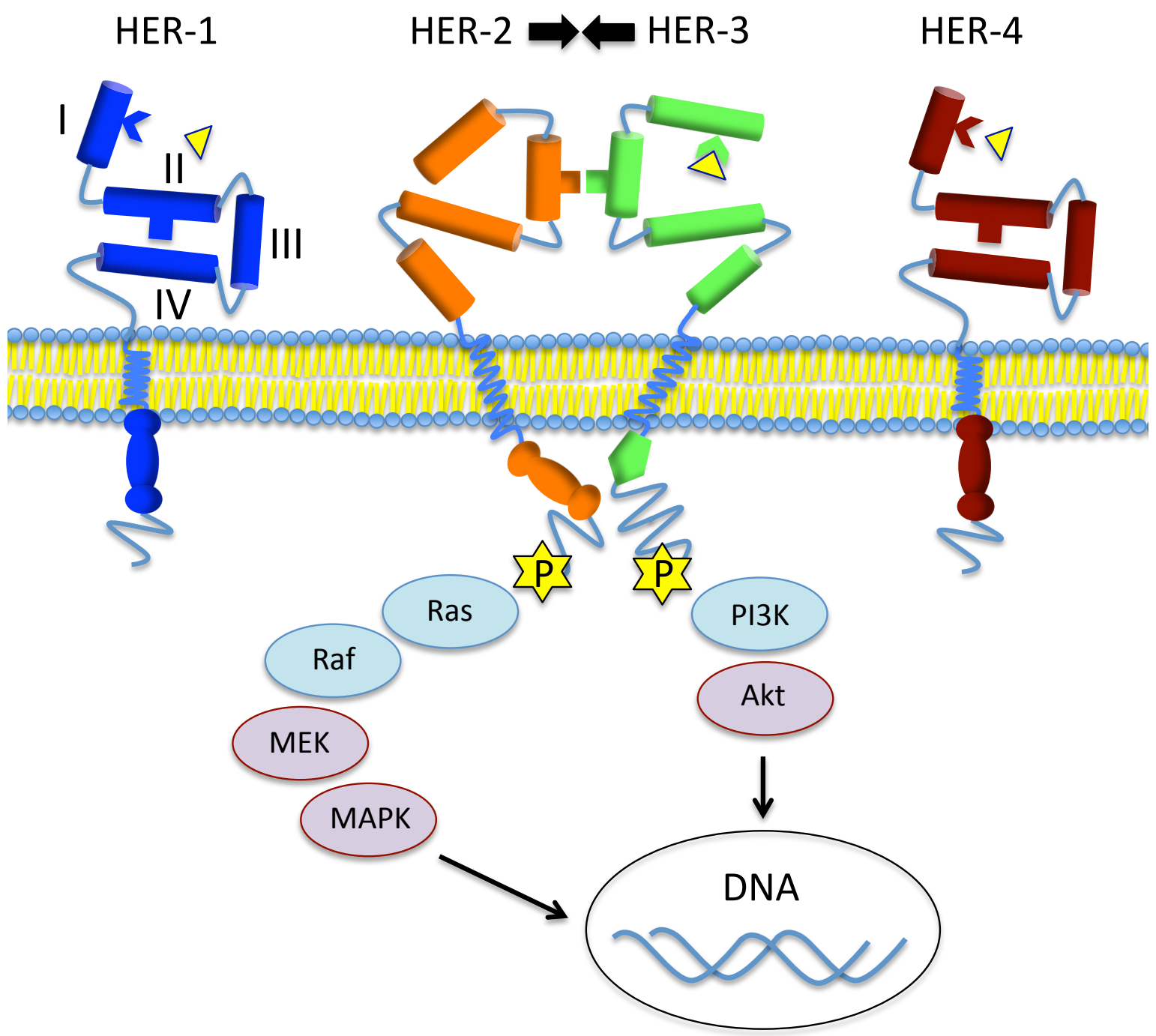

\section{Abbildung 5: Die EGF-Rezeptorfamilie - Struktur und Funktion}

Dargestellt sind die vier Rezeptortyrosinkinasen der EGFR-Familie mit ihren jeweiligen extrazellulären Domänen, Transmembran-Domänen und intrazellulären Tyrosinkinase-Domänen. Liganden (gelbes Dreieck) binden im Fall von EGFR, HER-3 und HER-4 an die Domäne I, woraufhin es zur Konformationsänderung kommt. HER-2 liegt bereits ohne Ligandenbindung im voraktivierten Zustand vor. In diesem Zustand kommt es zur Homo- oder Herterodimerisation zweier Rezeptoren über die extrazelluläre Domäne II (dargestellt am Beispiel von HER-2 und HER-3). Intrazellulär werden dadurch die Tyrosinkinasedomänen transphosphoryliert und nachgeschaltete Signalkaskaden werden durch Phosphorylierung (gelber Stern mit „P") aktiviert. Exemplarisch zeigen sich hier die Signalwege über PI3K/Akt sowie über Ras/MAPK.

Diese Abbildung wurde von der Autorin der vorliegenden Arbeit selbst erstellt, modifiziert nach Baselga und Swain 2009 (S. 465-466, Box 1 und Fig. 1).

Die Aktivierung der nachgeschalteten Signalkaskaden führt zu Proliferation, Differenzierung und Migration der Zelle und zur Inhibierung der Apoptose (Hudis 2007). Es werden Signalwege über Proteine wie PI3K/Akt und Ras/MAPK stimuliert (s. Abb. 5) (Yarden und Sliwkowski 2001). Die intrazellulären Signalkaskaden können ebenfalls teilweise über den 
fibroblast growth factor receptor oder den insulin-like growth factor receptor I aktiviert werden (Lu et al. 2001).

\subsubsection{Relevanz für solide Tumore}

Die karzinogene Rolle von HER-2 ist durch diverse Mechanismen gekennzeichnet: Genamplifikation, Rezeptor-Überexpression, aktivitätssteigernde Mutation, Überexpression von Liganden der Dimerisationspartner oder Verlust negativer Kontrollmechanismen. Letztendlich kommt es hierdurch zur deregulierten Aktivierung der nachgeschalteten Signalkaskade. Dies kann zu enthemmter Zellproliferation, Angiogenese, Apoptosehemmung und Tumordissemination führen (Menard et al. 2004; Moasser 2007). Eine Relevanz von HER-2 ist für zahlreiche Tumorentitäten beschrieben worden.

Ein Musterbeispiel für einen HER-2-positiven Tumor ist das Mammakarzinom. Etwa 25-35\% dieser Karzinome weisen eine Überexpression bzw. Genamplifikation von HER-2 auf, was mit einer signifikant schlechteren Prognose einhergeht (Slamon et al. 1987). Bereits 1998 wurde Trastuzumab in Kombination mit der üblichen Chemotherapie für die Erstlinientherapie des HER-2-positiven metastasierten Mammakarzinoms zugelassen (Pegram et al. 1998). Dieser monoklonale Antikörper, welcher spezifisch an die extrazelluläre Domäne von HER-2 bindet, verbessert signifikant das progressionsfreie sowie das Gesamtüberleben (Slamon et al. 2001). Auch in der Monotherapie zeigt der Antikörper eine gute Ansprechrate in ca. $25 \%$ der HER-2 überexprimierenden metastasierten Mammakarzinome (Vogel et al. 2002). Aufgrund der sehr positiven Ergebnisse der HERAStudie (NCT00004067), in der es zu einer signifikanten Verbesserung des krankheitsfreien und des Gesamtüberlebens führte, wurde Trastuzumab auch für die adjuvante Therapie des HER-2-positiven Mammakarzinoms zugelassen (Romond et al. 2005). Im Verlauf wurden weitere gegen HER-2 gerichtete Substanzen wie Lapatinib (Geyer et al. 2006), T-DM1 (Verma et al. 2012), Pertuzumab (Baselga et al. 2012; Swain et al. 2015b) und Afatinib (Harbeck et al. 2016) untersucht, entweder in Kombination mit oder alternativ zu Trastuzumab (s. 4.2.3). 
Neben dem Mammakarzinom konnte eine Überexpression und/oder Amplifikation von HER-2 auch in anderen Tumorentitäten nachvollzogen werden, u.a. beim Lungenkarzinom (Hirashima et al. 2001), bei Karzinomen des oberen Gastrointestinaltraktes (Reichelt et al. 2007) sowie auch beim KRK (Valtorta et al. 2015). So wurde eine Überexpression von HER-2 in etwa $20 \%$ der Magen- bzw. Kardiakarzinome beschrieben (Gravalos und Jimeno 2008). Zudem scheint ein positiver HER-2-Status mit einer negativen Prognose und einem aggressiveren Krankheitsverlauf assoziiert zu sein (Jorgensen und Hersom 2012). In der internationalen ToGA-Studie (NCT01041404) wurde die Standardtherapie des irresektablen und/oder metastasierten HER-2-positiven Magen- und Kardiakarzinoms verglichen mit der Hinzunahme von Trastuzumab. Hier führte die Kombination mit Trastuzumab zu einer signifikanten Verlängerung des Gesamtüberlebens. Auch das progressionsfreie Überleben und die Radiosensitivität zeigten sich im Trastuzumab-Arm verbessert (Bang et al. 2010).

Zudem wurden von unserer Arbeitsgruppe Daten zur HER-2-Expression beim KRK publiziert. Dabei zeigte sich ein positiver HER-2-Status, definiert in Analogie zum HER-2-Scoring beim Magenkarzinom mit einem Anteil von 26,7\% der lokal fortgeschrittenen Rektumkarzinome (Conradi et al. 2013). In kolorektalen Lebermetastasen war HER-2 bei $8 \%$ der Patienten überexprimiert (Styczen et al. 2015). Innerhalb der HERACLES-Studie wurden kürzlich bereits Patienten mit HER-2 positivem metastasierten KRK und Resistenz gegen eine Anti-EGFR-Therapie bei KRAS Exon 2 Wildtyp erfolgreich mit einer Kombination aus Trastuzumab und Lapatinib behandelt (Siena et al. 2018) (s. 4.4).

\subsection{Zielsetzung und Fragestellung}

Zusammenfassend stellt das KRK die zweithäufigste Krebs-assoziierte Todesursache dar und hat trotz Implementierung verbesserter bzw. multimodaler Therapiestrategien eine unbefriedigende Überlebensrate vor allem in der metastasierten Situation. Da sich gegen die gängigen therapeutisch eingesetzten Substanzen häufig Resistenzen entwickeln, ist es notwendig, neue Zielstrukturen zu evaluieren und als Angriffspunkt spezifischer Therapien zu etablieren. Während beim Mammakarzinom bzw. beim Magen-/Kardiakarzinom HER-2-Inhibitoren bereits Einzug in den klinischen Alltag gehalten haben, ist die therapeu- 
tische Bedeutung im KRK weiterhin unklar. Daher sollten in dieser Arbeit Anti-HER-2Substanzen (Trastuzumab, Pertuzumab, T-DM1, Lapatinib und Afatinib) an kolorektalen Karzinomzellinien getestet werden, um zu evaluieren, ob eine gegen HER-2 gerichtete Therapie auch im KRK sinnvoll erscheint. Dabei sollen folgende Fragen beantwortet werden:

1. Lässt sich in kolorektalen Karzinomzelllinien eine Überexpression bzw. Genamplifikation von HER-2 nachweisen?

2. Beeinflussen gegen HER-2 gerichtete Substanzen die nachgeschaltete Signalkaskade sowie die Zellviabilität?

3. Ist eine duale HER-2-Hemmung wirksamer als eine Monotherapie?

4. Lässt sich die Effektivität der gegen HER-2 gerichteten Substanzen durch Hinzunahme eines Chemotherapieregimes steigern? 


\section{Material und Methoden}

\subsection{Material}

\subsubsection{Verbrauchsmaterial}

\begin{tabular}{|c|c|}
\hline Adhäsive Objektträger Starfrost & $\begin{array}{l}\text { Engelbrecht Medizin \& Labortechnik GmbH, } \\
\text { Edermünde, Deutschland }\end{array}$ \\
\hline Auslaufpipetten, serologische & STARLAB GmbH, Hamburg, Deutschland \\
\hline Deckgläser & $\begin{array}{l}\text { Gerhard Menzel GmbH, Braunschweig, } \\
\text { Deutschland }\end{array}$ \\
\hline Einfrierröhrchen & TPP, Trasadingen, Schweiz \\
\hline Einmalreagenzreservoirs, steril & $\begin{array}{l}\text { Carl Roth GmbH \& Co. KG, Karlsruhe, } \\
\text { Deutschland }\end{array}$ \\
\hline $\begin{array}{l}\text { Filterpapier, Chromatography Paper } \\
\text { 3MM Chr. }\end{array}$ & $\begin{array}{l}\text { Whatman }{ }^{\mathrm{TM}} \text { GE Healthcare Life Sciences, Litt- } \\
\text { le Chalfont, United Kingdom }\end{array}$ \\
\hline Filterpapier, Shandon Filter Cards & $\begin{array}{l}\text { Thermo Fisher Scientific Inc., Waltham, MA, } \\
\text { USA }\end{array}$ \\
\hline Flüssigkeitsreservoirs, Rotilabo ${ }^{\oplus} \mathrm{PVC}$ & $\begin{array}{l}\text { Carl Roth GmbH \& Co. KG, Karlsruhe, } \\
\text { Deutschland }\end{array}$ \\
\hline Mikrotomklingen, FEATHER ${ }^{\circ}$ & pfm, Köln, Deutschland \\
\hline Pasteurpipetten, Glas & $\begin{array}{l}\text { Brand GmbH \& Co. KG, Wertheim, } \\
\text { Deutschland }\end{array}$ \\
\hline $\begin{array}{l}\text { Pipettenspitze }(10 \mathrm{ml}) \text {, für Multipette } \\
\text { Stream }\end{array}$ & Eppendorf AG, Hamburg, Deutschland \\
\hline $\begin{array}{l}\text { Pipettenspitzen, Tip One }(10,200, \\
1000,1250 \mu l)\end{array}$ & STARLAB GmbH, Hamburg, Deutschland \\
\hline Platten, 12-Well Cellstar ${ }^{\circledR}$, steril & STARLAB GmbH, Hamburg, Deutschland \\
\hline Platten, 6-Well Cyto One, steril & STARLAB GmbH, Hamburg, Deutschland \\
\hline Platten, 96-Well Cyto One , steril & STARLAB GmbH, Hamburg, Deutschland \\
\hline $\begin{array}{l}\text { Platten, 96-Well, HTS Transwell }{ }^{\bullet} \text { steril, } \\
\text { schwarz }\end{array}$ & Corning Inc., Corning, NY, USA \\
\hline
\end{tabular}




\begin{tabular}{|l|l|}
\hline Reaktionsgefäße (1,5 ml) & $\begin{array}{l}\text { Carl Roth GmbH \& Co. KG, Karlsruhe, } \\
\text { Deutschland }\end{array}$ \\
\hline Reaktionsgefäße (2 und $5 \mathrm{ml})$ & Eppendorf AG, Hamburg, Deutschland \\
\hline Röhrchen, Falcon Tube (15 und 50 ml) & Sarstedt AG \& Co., Nümbrecht, Deutschland \\
\hline $\begin{array}{l}\text { Transfermembran, Immobilon }{ }^{\ominus}-\mathrm{P} \\
0,45 \mu \mathrm{m}\end{array}$ & Merck Millipore, Billerica, MA, USA \\
\hline Transferpipetten (3,5 ml) & \\
\hline Zellkulturflaschen Cyto One $(25,75$ & STARLAB GmbH, Hamburg Deutschland \\
und $225 \mathrm{~cm}{ }^{2}$ ) & \\
\hline Zellschaber, $300 \mathrm{~mm}$ & TPP, Trasadingen, Schweiz \\
\hline Zellspachtel, $195 \mathrm{~mm}$ & TPP, Trasadingen, Schweiz \\
\hline
\end{tabular}

\subsubsection{Chemikalien}

\begin{tabular}{|c|c|}
\hline 1,4-Dithio-DL-threit(ol) (DTT) & AppliChem GmbH, Darmstadt, Deutschland \\
\hline 2-Propanol & Merck KGaA, Darmstadt, Deutschland \\
\hline Ammoniumpersulfat (APS) & AppliChem GmbH, Darmstadt, Deutschland \\
\hline Pierce $^{\mathrm{TM}}$ BCA Protein Assay Kit & Thermo Fisher Scientific, Waltham, MA, USA \\
\hline Bovines Serumalbumin (BSA) & AppliChem GmbH, Darmstadt, Deutschland \\
\hline Brilliant Blau R250 Tabletten & Merck KGaA, Darmstadt, Deutschland \\
\hline Bromphenolblau & AppliChem GmbH, Darmstadt, Deutschland \\
\hline CellTiter-Blue ${ }^{\circledR}$ Cell Viability Assay & Promega, Mannheim, Deutschland \\
\hline Eindeckmittel, Vitro-Clud ${ }^{\circledR}$ & $\begin{array}{l}\text { R. Langenbrinck, Labor- und Medizintechnik, } \\
\text { Emmendingen, Deutschland }\end{array}$ \\
\hline Essigsäure $100 \% \mathrm{Ph}$. Eur., reinst & $\begin{array}{l}\text { Carl Roth GmbH \& Co. KG, Karlsruhe, } \\
\text { Deutschland }\end{array}$ \\
\hline Ethanol 99\% & Chemie Vertrieb, Hannover, Deutschland \\
\hline Ethanol, ROTIPURAN $\geq 99,8 \%$ & $\begin{array}{l}\text { Carl Roth GmbH \& Co. KG, Karlsruhe, } \\
\text { Deutschland }\end{array}$ \\
\hline
\end{tabular}




\begin{tabular}{|c|c|}
\hline $\begin{array}{l}\text { Ethylendiamintetraessigsäure (EDTA), } \\
0,5 \mathrm{M}, \mathrm{pH}=8,0\end{array}$ & $\begin{array}{l}\text { Quality Biological Inc., Gaithersburg, MD, } \\
\text { USA }\end{array}$ \\
\hline Formalin, $37 \%$ & Merck KGaA, Darmstadt, Deutschland \\
\hline Glycin & Sigma-Aldrich, St. Louis, MO, USA \\
\hline Hämalaun, Mayers & Merck KGaA, Darmstadt, Deutschland \\
\hline Kaliumchlorid $(\mathrm{KCl})$ & Merck KGaA, Darmstadt, Deutschland \\
\hline $\begin{array}{l}\text { Luminata }^{\mathrm{TM}} \text { Forte Western HRP Substra- } \\
\text { te }\end{array}$ & Merck Millipore, Billerica, MA, USA \\
\hline $\begin{array}{l}\text { Marker, Magic Mark }{ }^{\mathrm{TM}} \text { XP Western } \\
\text { Standard }\end{array}$ & Invitrogen, Darmstadt, Deutschland \\
\hline $\begin{array}{l}\text { Marker, Spectra }{ }^{\mathrm{TM}} \text { Multicolour Broad } \\
\text { Range Protein Ladder }\end{array}$ & Fermentas GmbH, St. Leon-Rot, Deutschland \\
\hline Methanol, ROTIPURAN $, \geq 99,9 \%$ & $\begin{array}{l}\text { Carl Roth GmbH \& Co. KG, Karlsruhe, } \\
\text { Deutschland }\end{array}$ \\
\hline $\begin{array}{l}\text { Milchpulver Blotting grade, pulv., fett- } \\
\text { arm }\end{array}$ & $\begin{array}{l}\text { Carl Roth GmbH \& Co. KG, Karlsruhe, } \\
\text { Deutschland }\end{array}$ \\
\hline Natrium Deoxycholat $\geq 97 \%$ (titration) & Sigma-Aldrich, St. Louis, MO, USA \\
\hline Natriumchlorid $(\mathrm{NaCl}), \geq 99,5 \%$ & $\begin{array}{l}\text { Carl Roth GmbH \& Co. KG, Karlsruhe, } \\
\text { Deutschland }\end{array}$ \\
\hline $\begin{array}{l}\text { Natriumdodecylsulfat (SDS)-Lösung } \\
10 \% \text { für die Molekularbiologie }\end{array}$ & AppliChem GmbH, Darmstadt, Deutschland \\
\hline Natriumhydroxid (NaOH) Plätzchen & Merck KGaA, Darmstadt, Deutschland \\
\hline Nonidet $\mathrm{P} 40$ (NP40) & AppliChem GmbH, Darmstadt, Deutschland \\
\hline $\begin{array}{l}\text { Phosphatase-Inhibitor Cocktail Tablet- } \\
\text { ten, PhosSTOP }\end{array}$ & $\begin{array}{l}\text { Roche Diagnostics GmbH, Mannheim, } \\
\text { Deutschland }\end{array}$ \\
\hline $\begin{array}{l}\text { Protease-Inhibitor Cocktail, Protease } \\
\text { Block }^{\mathrm{TM}}\end{array}$ & Fermentas GmbH, St. Leon-Rot, Deutschland \\
\hline Rotiphorese Gel 30 Lösung & $\begin{array}{l}\text { Carl Roth GmbH \& Co. KG, Karlsruhe, } \\
\text { Deutschland }\end{array}$ \\
\hline Salzsäure $(\mathrm{HCl}), 5 \mathrm{M}$ & Merck KGaA, Darmstadt, Deutschland \\
\hline TEMED & AppliChem GmbH, Darmstadt, Deutschland \\
\hline
\end{tabular}




\begin{tabular}{|l|l|}
\hline Tris ultrapure & AppliChem GmbH, Darmstadt, Deutschland \\
\hline Trypanblau & Merck KGaA, Darmstadt, Deutschland \\
\hline Tween 20 & Sigma-Aldrich, St. Louis, MO, USA \\
\hline Xylol & $\begin{array}{l}\text { Mallinckrodt Baker B. V., Deventer, } \\
\text { Niederlande }\end{array}$ \\
\hline
\end{tabular}

\subsubsection{Geräte}

\begin{tabular}{|c|c|}
\hline Autoklav, HST 32/25 & $\begin{array}{l}\text { Zirbus technology GmbH, Bad Grund/ Harz, } \\
\text { Deutschland }\end{array}$ \\
\hline CCD Kamera, ImageQuant LAS 4000 mini & $\begin{array}{l}\text { GE Healthcare Life Sciences, Uppsala, Schwe- } \\
\text { den }\end{array}$ \\
\hline Elektroblotter, semi-dry & Peqlab, Erlangen, Deutschland \\
\hline Färbeautomat BenchMark XT & $\begin{array}{l}\text { Ventana Medical Systems, Tucson, Arizona, } \\
\text { USA }\end{array}$ \\
\hline $\begin{array}{l}\text { Freezing Container, } 5100 \mathrm{Cryo} 1^{\circ} \mathrm{C}, " \mathrm{Mr} \text {. } \\
\text { Frosty" }\end{array}$ & $\begin{array}{l}\text { Thermo Fisher Scientific Inc., Waltham, MA, } \\
\text { USA }\end{array}$ \\
\hline $\begin{array}{l}\text { Gelelektrophoresekammer, Minigel- } \\
\text { Twin }\end{array}$ & Biometra GmbH, Göttingen, Deutschland \\
\hline Glasplatte, ausgeschnitten, für Minigele & Biometra GmbH, Göttingen, Deutschland \\
\hline $\begin{array}{l}\text { Glasplatte, fixe Spacer, 1,0 mm, für Mi- } \\
\text { nigele }\end{array}$ & Biometra GmbH, Göttingen, Deutschland \\
\hline Heißluftsterilisator, Heraeus ST6060 & $\begin{array}{l}\text { Thermo Fisher Scientific Inc., Waltham, MA, } \\
\text { USA }\end{array}$ \\
\hline Inkubator $\mathrm{CO}_{2}$, Incubator $\mathrm{C} 200$ & Labotect GmbH, Göttingen, Deutschland \\
\hline $\begin{array}{l}\text { Inkubator, Water-Jacketed Incubator } \\
3250\end{array}$ & Forma Scientific Inc., Marietta, OH, USA \\
\hline $\begin{array}{l}\text { Kämme (10- und 16-zähnig), für Minige- } \\
\text { le }\end{array}$ & Biometra GmbH, Göttingen, Deutschland \\
\hline Magnetrührer & $\begin{array}{l}\text { IKA }- \text { Werke GmbH \& Co. KG, Staufen, } \\
\text { Deutschland }\end{array}$ \\
\hline
\end{tabular}




\begin{tabular}{|c|c|}
\hline Membranpumpe, Miniport & KNF Neuberger GmbH, Freiburg, Deutschland \\
\hline Mikroskop Axio Imager II & Carl Zeiss Microlmaging GmbH, Deutschland \\
\hline Mikroskop, Leica S6 E & Leica AG, Wetzlar, Deutschland \\
\hline Mikroskopkamera, High-speed Leica EC3 & Leica AG, Wetzlar, Deutschland \\
\hline Multilabel Plate Reader, Victor ${ }^{\mathrm{TM}} \mathrm{X} 4$ & PerkinElmer, Waltham, MA, USA \\
\hline Netzgerät, PowerPac 3000 & $\begin{array}{l}\text { Bio-Rad Laboratories GmbH, München, } \\
\text { Deutschland }\end{array}$ \\
\hline pH-Meter, PB-11 & Sartorius AG, Göttingen, Deutschland \\
\hline $\begin{array}{l}\text { Pipette, elektrisch, 8-Kanal Research pro } \\
50-1200 \mu \mathrm{l} \text { und } 12-\text { Kanal pro } 10-100 \mu \mathrm{l}\end{array}$ & Eppendorf AG, Hamburg, Deutschland \\
\hline Pipette, Multipette Stream & Eppendorf AG, Hamburg, Deutschland \\
\hline Pipetten, Eppendorf Reference & Eppendorf AG, Hamburg, Deutschland \\
\hline Pipettierhelfer, accu-jet & $\begin{array}{l}\text { Brand GmbH \& Co. KG, Wertheim, } \\
\text { Deutschland }\end{array}$ \\
\hline Präzisionswaage, BP 610 & Sartorius AG, Göttingen, Deutschland \\
\hline Präzisionswaage, ED224S & Sartorius AG, Göttingen, Deutschland \\
\hline Schlittenmikrotom Microm HM 430 & $\begin{array}{l}\text { MICROM International, Walldorf, } \\
\text { Deutschland }\end{array}$ \\
\hline Schüttler, MS 3 digital & $\begin{array}{l}\text { IKA }{ }^{\oplus} \text {-Werke GmbH \& Co. KG, Staufen, } \\
\text { Deutschland }\end{array}$ \\
\hline Silikonabdichtung, 1,0 mm, für Minigel & Biometra GmbH, Göttingen, Deutschland \\
\hline $\begin{array}{l}\text { Sterilbank, SterilGARD Hood Class II Typ } \\
\text { A/B3 }\end{array}$ & The Baker Company, Sanford, ME, USA \\
\hline Sterilbank Biowizard Xtra LINE & Kojair, Vilppula, Finnland \\
\hline Thermomixer, comfort & Eppendorf AG, Hamburg, Deutschland \\
\hline $\begin{array}{l}\text { Ultraschallhomogenisator SONOPULS } \\
\text { HD } 3100\end{array}$ & BANDELIN electronic GmbH \& Co. KG \\
\hline VICTOR $^{\mathrm{TM}}$ X4 Multilable Plate Reader & PerkinElmer, Wiesbaden, Deutschland \\
\hline Vortexer, IKA ${ }^{\oplus}$ MS1 Shaker & $\begin{array}{l}\text { IKA }{ }^{\oplus} \text {-Werke GmbH \& Co. KG, Staufen, } \\
\text { Deutschland }\end{array}$ \\
\hline Wärmeplatte & MEDAX Nagel GmbH, Kiel, Deutschland \\
\hline
\end{tabular}




\begin{tabular}{|c|c|}
\hline Wärmeschrank & Memmert GmbH, Schwabach, Deutschland \\
\hline Wasserbad, GFL 1003 & $\begin{array}{l}\text { Gesellschaft für Labortechnik mbH, Burgwe- } \\
\text { del, Deutschland }\end{array}$ \\
\hline $\begin{array}{l}\text { Water Purification System, Milli-Q Refe- } \\
\text { rence Ultrapure }\end{array}$ & Merck Millipore, Billerica, MA, USA \\
\hline Wippschüttler, WS42 & $\begin{array}{l}\text { A. Hartenstein Gesellschaft für Labor- und } \\
\text { Medizintechnik mbH, Würzburg/Versbach, } \\
\text { Deutschland }\end{array}$ \\
\hline Zählkammer, Neubauer improved & $\begin{array}{l}\text { Brand GmbH \& Co. KG, Wertheim, Deutsch- } \\
\text { land }\end{array}$ \\
\hline Zentrifuge, Heraeus Fresco 17 & $\begin{array}{l}\text { Thermo Fisher Scientific Inc., Waltham, MA, } \\
\text { USA }\end{array}$ \\
\hline Zentrifuge, Heraeus Labofuge $400 \mathrm{R}$ & $\begin{array}{l}\text { Thermo Fisher Scientific Inc., Waltham, MA, } \\
\text { USA }\end{array}$ \\
\hline Zentrifuge, Mini, Rotilabo & $\begin{array}{l}\text { Carl Roth GmbH \& Co. KG, Karlsruhe, } \\
\text { Deutschland }\end{array}$ \\
\hline Zentrifuge, Shandon Cytospin 4 & $\begin{array}{l}\text { Thermo Fisher Scientific Inc., Waltham, MA, } \\
\text { USA }\end{array}$ \\
\hline
\end{tabular}




\subsubsection{Zelllinien}

\begin{tabular}{|c|c|c|c|c|c|}
\hline Zelllinie & $\delta / 9$ & Ursprung & Medium & $\mathrm{CO}_{2}$ & ATCC-Nr. \\
\hline Caco-2 & $\overline{0}$ & Adenokarzinom, Kolon & Minimum essential medium & $5 \% \mathrm{CO}_{2}$ & HTB-37 \\
\hline НСT 116 & $\hat{0}$ & Adenokarzinom, Kolon & McCoy's 5a & $5 \% \mathrm{CO}_{2}$ & CCL-247 \\
\hline HT-29 & q & Adenokarzinom, Kolon & McCoy's 5a & $5 \% \mathrm{CO}_{2}$ & HTB-38 \\
\hline LS1034 & $\hat{\sigma}$ & Adenokarzinom, Kolon & RPMI 1640 Custom & $5 \% \mathrm{CO}_{2}$ & CRL-2158 \\
\hline LS411N & 0 & Adenokarzinom, Kolon & RPMI 1640 Custom & $5 \% \mathrm{CO}_{2}$ & CRL-2159 \\
\hline LS513 & 0 & Adenokarzinom, Kolon & RPMI 1640 Custom & $5 \% \mathrm{CO}_{2}$ & CRL-2134 \\
\hline SW1116 & 0 & Adenokarzinom, Kolon & Leibovitz's L-15 & $0 \% \mathrm{CO}_{2}$ & CCL-233 \\
\hline SW1463 & P & Adenokarzinom, Rektum & Leibovitz's L-15 & $0 \% \mathrm{CO}_{2}$ & CCL-234 \\
\hline SW403 & 우 & Adenokarzinom, Kolon & Leibovitz's L-15 & $0 \% \mathrm{CO}_{2}$ & CCL-230 \\
\hline SW480 & $0^{\pi}$ & Adenokarzinom, Kolon & Leibovitz's L-15 & $0 \% \mathrm{CO}_{2}$ & CCL-228 \\
\hline SW620 & 0 & LK-Metastase v. SW480 & Leibovitz's L-15 & $0 \% \mathrm{CO}_{2}$ & CCL-227 \\
\hline sW837 & $\hat{\sigma}$ & Adenokarzinom, Rektum & Leibovitz's L-15 & $0 \% \mathrm{CO}_{2}$ & CCL-235 \\
\hline
\end{tabular}

Tabelle 2: Übersicht der verwendeten kolorektalen Karzinomzelllinien

\subsubsection{Zellkulturreagenzien}

\begin{tabular}{|l|l|}
\hline $0,25 \%$ Trypsin-EDTA (1x) & $\begin{array}{l}\text { Gibco by life technologies } \\
\text { UM }\end{array}$ \\
\hline BSA Carlsbad, CA,
\end{tabular}




\begin{tabular}{|l|l|}
\hline Nährmedium, RPMI Medium 1640 & $\begin{array}{l}\text { Gibco }{ }^{\circ} \text { by life technologies } \\
\text { USA }\end{array}$ \\
\hline Phosphate Carlsbad, CA, $^{\text {Buffered Saline (PBS) pH 7,2 }}$ & $\begin{array}{l}\text { Gibco }{ }^{\circ} \text { by life technologies } \\
\text { US }\end{array}$ \\
\hline USA
\end{tabular}

\subsubsection{Inhibitoren, Antikörper und Chemotherapeutika}

\begin{tabular}{|l|l|}
\hline Afatinib & BIOMOL GmbH, Hamburg, Deutschland \\
\hline Lapatinib & LC Laboratories, Woburn, MA, USA \\
\hline Pertuzumab & Roche, Penzberg, Deutschland \\
\hline T-DM1 & Roche, Penzberg, Deutschland \\
\hline Trastuzumab & Roche, Penzberg, Deutschland \\
\hline 5-Fluorouracil & Sigma, München, Deutschland \\
\hline Oxaliplatin & Sigma, München, Deutschland \\
\hline
\end{tabular}

\subsubsection{Puffer und Lösungen}

Tris-buffered saline (TBS) Puffer

Reagenzien

Tris ultrapure

$\mathrm{NaCl}$
Endkonzentration

$50 \mathrm{mM}$

$150 \mathrm{mM}$
Für $1000 \mathrm{ml}$

$6,057 \mathrm{~g}$

$8,766 \mathrm{~g}$

Die Reagenzien wurden in Aqua bidest. gelöst und der pH-Wert auf 7,5 eingestellt. Dann wurde Aqua bidest. hinzugefügt, bis das Zielvolumen von $1000 \mathrm{ml}$ erreicht war.

Tris-buffered saline $+0,1 \%$ Tween $^{\circledR} 20$ (TBS-T) Puffer

Reagenzien

TBS

Tween 20

\section{Endkonzentration}

$0,1 \%$
Für $1000 \mathrm{ml}$

$999 \mathrm{ml}$

$1 \mathrm{ml}$ 
RIPA (Radio Immuno Precipitation Assay) Zelllysepuffer

Reagenzien

Tris ultrapure

$\mathrm{NaCl}$

Natrium Deoxycholat

Nonidet ${ }^{\circledast} \mathrm{P} 40$

$0,5 \mathrm{M}$ EDTA $, \mathrm{pH}=8,0$

\section{Endkonzentration}

$50 \mathrm{mM}$

$150 \mathrm{mM}$

$0,5 \%$

$1 \%$

$2 \mathrm{mM}$
Für $100 \mathrm{ml}$

$606 \mathrm{mg}$

$877 \mathrm{mg}$

$500 \mathrm{mg}$

$1 \mathrm{ml}$

$400 \mu \mathrm{l}$

Die Reagenzien wurden in Aqua bidest. gelöst und der pH-Wert auf 8 eingestellt. Dann wurde Aqua bidest. hinzugefügt, bis das Zielvolumen von $100 \mathrm{ml}$ erreicht war.

SDS-PAGE Sammelgelpuffer

Reagenzien

Tris ultrapure
Endkonzentration

$1 \mathrm{M}$
Für $250 \mathrm{ml}$

$30,29 \mathrm{~g}$

Die Reagenzien wurden in Aqua bidest. gelöst und der pH-Wert auf 6,8 eingestellt. Dann wurde Aqua bidest. hinzugefügt, bis das Zielvolumen von $250 \mathrm{ml}$ erreicht war.

\section{4x SDS-PAGE Ladepuffer}

Reagenzien

$0,5 \mathrm{M}$ Tris- $\mathrm{HCl}, \mathrm{pH} 6,8$

Glycerin

$\beta$-Mercaptoethanol

Bromphenol Blau

SDS

Aqua bidest.

\begin{tabular}{|c|c|}
\hline Endkonzentration & Für $10 \mathrm{ml}$ \\
\hline $250 \mathrm{mM}$ & $5 \mathrm{ml}$ \\
\hline $40 \%$ & $4 \mathrm{ml}$ \\
\hline $8 \%$ & $0,8 \mathrm{ml}$ \\
\hline $0,4 \%$ & $0,04 \mathrm{~g}$ \\
\hline $8 \%$ & $0,8 \mathrm{~g}$ \\
\hline
\end{tabular}

$0,2 \mathrm{ml}$

Der Ladepuffer wurde in $1 \mathrm{ml}$ Aliquots bei $-20^{\circ} \mathrm{C}$ eingefroren. 
SDS-PAGE Trenngelpuffer

Reagenzien

Tris ultrapure
Endkonzentration

$1,5 \mathrm{M}$
Für $250 \mathrm{ml}$

$45,43 \mathrm{~g}$

Die Reagenzien wurden in Aqua bidest. gelöst und der pH-Wert auf 8,8 eingestellt. Dann wurde Aqua bidest. hinzugefügt, bis das Zielvolumen von $250 \mathrm{ml}$ erreicht war.

\section{SDS-PAGE Laufpuffer}

Reagenzien

Tris ultrapure

Glycin
Endkonzentration

$25 \mathrm{mM}$

$192 \mathrm{mM}$
Für $1000 \mathrm{ml}$

$3,03 \mathrm{~g}$

$14,41 \mathrm{~g}$

Die Reagenzien wurden in Aqua bidest. gelöst und der pH-Wert auf 8,3 eingestellt. Dann wurde Aqua bidest. hinzugefügt, bis das Zielvolumen von $1000 \mathrm{ml}$ erreicht war.

\section{Western Blot Transferpuffer}

Reagenzien

Tris ultrapure

Glycin

SDS-Lösung, $10 \%$

Methanol

Endkonzentration

$48 \mathrm{mM}$

$39 \mathrm{mM}$

$0,037 \%$

$20 \%$
Für $1000 \mathrm{ml}$

$5,8 \mathrm{~g}$

$2,9 \mathrm{~g}$

$3,7 \mathrm{ml}$

$200 \mathrm{ml}$

Beim Transferpuffer ist eine Einstellung des pH-Wertes nicht nötig. Den Reagenzien wurde Aqua bidest. hinzugefügt, bis das Zielvolumen von $1000 \mathrm{ml}$ erreicht war.

\section{Blockierpuffer für Western Blot Membranen, Lösungspuffer für Antikörper}

Reagenzien

TBS-T

Milchpulver Blotting grade, pulv., fettarm
Endkonzentration

$5 \%$
Für $100 \mathrm{ml}$ $100 \mathrm{ml}$

$5 \mathrm{~g}$ 
Lösungspuffer für Antikörper

Reagenzien

TBS-T

Bovines Serum Albumin

\section{Coomassie Färbelösung für Gele}

Reagenzien

Methanol

Coomassie Brilliant Blue

Eisessig

Aqua bidest.

Coomassie Fixierlösung für Gele

Reagenzien

Methanol

Eisessig

Aqua bidest.

Coomassie Entfärbelösung für Gele

Reagenzien

Methanol

Eisessig

Aqua bidest.
Endkonzentration

Für $10 \mathrm{ml}$

$10 \mathrm{ml}$

$5 \%$

$0,5 \mathrm{~g}$

Endkonzentration

$50 \%$

Für $1000 \mathrm{ml}$

$500 \mathrm{ml}$

$0,05 \%$

$500 \mathrm{mg}$

$10 \%$

$100 \mathrm{ml}$

$40 \%$

$400 \mathrm{ml}$

Endkonzentration

Für $1000 \mathrm{ml}$

$50 \%$

$500 \mathrm{ml}$

$10 \%$

$100 \mathrm{ml}$

$40 \%$

$400 \mathrm{ml}$

Endkonzentration

Für $1000 \mathrm{ml}$

$5 \%$

$50 \mathrm{ml}$

$7 \%$

$70 \mathrm{ml}$

$88 \%$

$880 \mathrm{ml}$ 


\subsubsection{Antikörper für den Western Blot}

\begin{tabular}{|c|c|c|c|c|c|c|c|}
\hline Primärantikörper & Hersteller & Ursprung & Proteingewicht & Verdünnung & Lösungspuffer & Inkubationszeit & Temperatur \\
\hline Anti-Actin (A2066) & Sigma-Aldrich, St. Louis, MO, USA & Kaninchen & $42 \mathrm{kDa}$ & $1: 2000$ & $5 \%$ Milch-TBS-T & $2 \mathrm{~h}$ & Raumtemperatur \\
\hline Anti-Akt & Cell Signaling, Danvers, MA, USA & Kaninchen & $60 \mathrm{kDa}$ & $1: 1000$ & 5\%-BSA-TBS-T & über Nacht & $4^{\circ} \mathrm{C}$ \\
\hline Anti-p44/42 MAPK (Erk1/2) & Cell Signaling, Danvers, MA, USA & Kaninchen & $42,44 \mathrm{kDa}$ & $1: 2000$ & $5 \%-B S A-T B S-T$ & über Nacht & $4^{\circ} \mathrm{C}$ \\
\hline Anti-Phospho-Akt & Cell Signaling, Danvers, MA, USA & Kaninchen & $60 \mathrm{kDa}$ & $1: 1000$ & $5 \%-B S A-T B S-T$ & über Nacht & $4^{\circ} \mathrm{C}$ \\
\hline Anti-Phospho-p44/42 MAPK (Erk1/2) & Cell Signaling, Danvers, MA, USA & Kaninchen & $42,44 \mathrm{kDa}$ & $1: 1000$ & $5 \%$-BSA-TBS-T & über Nacht & $4^{\circ} \mathrm{C}$ \\
\hline Sekundärantikörper & Hersteller & Ursprung & Proteingewicht & Verdünnung & Lösungspuffer & Inkubationszeit & Temperatur \\
\hline $\begin{array}{c}\text { Polyclonal Antibody to Rabbit IgG } \\
{[H \& L]-H R P, R 1364 H R P}\end{array}$ & $\begin{array}{l}\text { Acris Antibodies } \mathrm{GmbH} \text {, Herford, } \\
\text { Deutschland }\end{array}$ & Ziege & $40 \mathrm{kDa}$ & $1: 30000$ & $5 \%$ Milch-TBS-T & $2 \mathrm{~h}$ & Raumtemperatur \\
\hline
\end{tabular}

\subsubsection{Substanzen und Protokolle für den Färbeautomaten BenchMark XT}

\subsubsection{Antikörper}

\begin{tabular}{|c|c|c|c|c|c|c|}
\hline Primärantikörper & Hersteller & Ursprung & Proteingewicht & Verdünnung & Vorbehandlung & Inkubationszeit \\
\hline PATHWAY anti-HER-2/neu (4B5) & $\begin{array}{c}\text { Ventana Medical Systems/ Roche, Mannheim, } \\
\text { Deutschland }\end{array}$ & Kaninchen & $185 \mathrm{kDa}$ & konzentriert & $\mathrm{CC} 160 \mathrm{~min}$ bei $100^{\circ} \mathrm{C}$ & $32 \mathrm{~min}$ bei $37^{\circ} \mathrm{C}$ \\
\hline
\end{tabular}




\subsubsection{Substanzen}

Antibody Diluent

Protease III

Bluing Reagent

Reaction Buffer

CC1 (Cell Conditioner)

Silverwash

CC2 (Cell Conditioner)

SSC

EZ Prep

ultraView Universal DAB Detection Kit

Hämatoxilin II ultraView SISH DNP Detection Kit

INFORM HER2 Dual ISH DNS Probe Cocktail ultraView AP Red ISH DIG Detection Kit LCS

(von Ventana Medical Systems/ Roche, Mannheim, Deutschland)

\subsubsection{Computer-Software}

\begin{tabular}{|l|l|}
\hline Adobe Reader X & Adobe, San Jose, CA, USA \\
\hline EndNote X7 & Thomson Reuters, New York, NY, USA \\
\hline Grapher $^{\text {TM }} 8$ & Golden Software Inc., Golden, CO, USA \\
\hline Image J & $\begin{array}{l}\text { National Institutes of Health (NIH), Bethesda, } \\
\text { MD, USA }\end{array}$ \\
\hline ImageQuant ${ }^{\text {TM }}$ LAS 4000 mini 1.2 & $\begin{array}{l}\text { GE Healthcare Life Sciences, Little Chalfont, } \\
\text { United Kingdom }\end{array}$ \\
\hline Microsoft Office 2011 & Microsoft Corporation, Redmond, WA, USA \\
\hline Wallac 1420 Manager & PerkinElmer, Wiesbaden, Deutschland \\
\hline
\end{tabular}

\subsection{Methoden}

\subsubsection{Zellkultur}

Alle Zellkulturarbeiten wurden unter sterilen Bedingungen an einer Zellkulturwerkbank durchgeführt. Die verwendeten zwölf humanen kolorektalen Adenokarzinom-Zelllinien (s. 2.1.4, Tabelle 2) stammen von der American Type Culture Collection (ATCC, Manasas, USA) und wurden in Stocks bei $-150^{\circ} \mathrm{C}$ asserviert. Gemäß den Empfehlungen der ATCC 
wurden für jede Zelllinie die entsprechenden Kulturmedien eingesetzt, die mit 10 bzw. $20 \%$ FBS und $1 \%$ Glutamin angereichert wurden.

Um Zellen aus diesem Stock aufzutauen, wurde ein Kryoröhrchen im Wasserbad bei $37^{\circ} \mathrm{C}$ angetaut. Danach wurde der Inhalt zügig in Kulturmedium aufgenommen, in ein $15 \mathrm{ml}$ Röhrchen überführt und bei 800 rpm für fünf Minuten abzentrifugiert. Das Zellpellet wurde nach Absaugen des Überstandes in frischem Medium resuspendiert und in eine Kulturflasche pipettiert, welche bei $37^{\circ} \mathrm{C}$ und ggf. unter Zusatz von $5 \% \mathrm{CO}_{2}$ zum wasserdampfgesättigten Raumluftgemisch inkubiert wurde. Am nächsten Tag erfolgte ein Mediumwechsel, welcher fortan alle zwei bis drei Tage durchgeführt wurde.

Bei einer Zelldichte von etwa $70 \%$ der Kulturflasche wurde eine Verdünnung der Population durchgeführt, um eine gegenseitige Wachstumshemmung und Konkurrenz um Nährstoffe zu vermeiden. Dafür wurde das Medium abgesaugt. Dann wurden die Zellen mit PBS gewaschen und anschließend mit 0,25\% Trypsin-EDTA für etwa fünf Minuten im Brutschrank inkubiert. Nach Ablösen der adhärenten Zellen wurden diese wiederum in Kulturmedium resuspendiert und in ein Röhrchen zum Zentrifugieren überführt. Das in frischem Medium gelöste Zellpellet wurde entsprechend den Wachstumseigenschaften der jeweiligen Zelllinie in einem Verhältnis von 1:2 bis 1:6 verdünnt und in neuer Passage im Kulturgefäß subkultiviert oder für Experimente weiterverwendet.

Um die Zellen für Experimente einzuzählen, wurde die Neubauer-Zählkammer genutzt. Hierzu wurde die Zellsuspension im Verhältnis 1:10 mit einer Trypanblau-Lösung gemischt. Davon wurden jeweils $10 \mu$ lauf beide Seiten der Zählkammer pipettiert. Eine Seite enthält vier genormte Quadrate, sogenannte Leukozytenfelder, die jeweils wiederum 16 kleine Quadrate enthalten. Da es sich um eine Lebendzellzahlbestimmung handelt, werden dabei nur die vitalen Zellen nach einem bestimmten Schema ausgezählt. Tote Zellen färben sich aufgrund eines Membranbarrieredefektes stark blau an und werden vernachlässigt. Das arithmetische Mittel der Zellen wird berechnet, woraus sich durch Multiplikation mit dem Faktor $10^{5}$ die Zellzahl pro Milliliter errechnen lässt. 
Zum Einfrieren wurden die Zellen nach dem Zentrifugieren in einem speziellen Einfriermedium (10\% DMSO, $20 \%$ FBS, 70\% Nährmedium) gelöst und in $2 \mathrm{ml}$-Kryoröhrchen in einem mit Isopropanol gefüllten Behältnis für 24 Stunden bei $-80^{\circ} \mathrm{C}$ zwischengelagert, bevor sie zur endgültigen Lagerung bei $-150^{\circ} \mathrm{C}$ eingefroren wurden.

\subsubsection{Proteinisolation}

Um den Proteingehalt einer Zelle quantitativ und qualitativ zu untersuchen, muss die Zelle lysiert werden. Dazu wurden $1 \times 10^{6}$ Zellen pro Well in 6-Well-Platten zusammen mit den Anti-HER-2-Substanzen (s. 2.1.6) ausgesetzt. Diese wurden in aufsteigender Konzentration eines bestimmten Konzentrationsbereiches gewählt (s. Tabelle 3), welcher an Vorexperimenten unserer Arbeitsgruppe orientiert war. Ebenfalls wurden zum Vergleich unbehandelte Zellen ausgesetzt.

Anti-HER-2 Substanz

Konzentrationen

\begin{tabular}{|l|cccccc|}
\hline Trastuzumab & $0 \mu \mathrm{g} / \mathrm{ml}$ & $1 \mu \mathrm{g} / \mathrm{ml}$ & $5 \mu \mathrm{g} / \mathrm{ml}$ & $20 \mu \mathrm{g} / \mathrm{ml}$ & $50 \mu \mathrm{g} / \mathrm{ml}$ & $100 \mu \mathrm{g} / \mathrm{ml}$ \\
Pertuzumab & $0 \mu \mathrm{g} / \mathrm{ml}$ & $1 \mu \mathrm{g} / \mathrm{ml}$ & $5 \mu \mathrm{g} / \mathrm{ml}$ & $20 \mu \mathrm{g} / \mathrm{ml}$ & $50 \mu \mathrm{g} / \mathrm{ml}$ & $100 \mu \mathrm{g} / \mathrm{ml}$ \\
T-DM1 & $0 \mu \mathrm{g} / \mathrm{ml}$ & $1 \mu \mathrm{g} / \mathrm{ml}$ & $5 \mu \mathrm{g} / \mathrm{ml}$ & $20 \mu \mathrm{g} / \mathrm{ml}$ & $50 \mu \mathrm{g} / \mathrm{ml}$ & $100 \mu \mathrm{g} / \mathrm{ml}$ \\
Lapatinib & $0 \mu \mathrm{M}$ & $0,1 \mu \mathrm{M}$ & $1 \mu \mathrm{M}$ & $5 \mu \mathrm{M}$ & $10 \mu \mathrm{M}$ & - \\
Afatinib & $0 \mu \mathrm{M}$ & $0,1 \mu \mathrm{M}$ & $1 \mu \mathrm{M}$ & $5 \mu \mathrm{M}$ & $10 \mu \mathrm{M}$ & - \\
\hline
\end{tabular}

Tabelle 3: Konzentrationsreihen der Anti-HER-2-Substanzen für die Proteinisolation

Um ausreichend phosphoryliertes Akt im Western Blot nachzuweisen, wurden die Zellen vor der Proteinisolation am nächsten Tag mit $100 \mathrm{ng} / \mu \mathrm{l}$ Neuregulin-1, einem direkten Liganden von HER-3, für 5 Minuten stimuliert. Dies betraf sowohl die behandelten Zellen als auch unbehandelte Zellen als Negativkontrolle. Eine weitere Negativkontrolle blieb unstimuliert. Anschließend wurde das Medium abgesaugt, die Zellen wurden mit PBS gewaschen und mit RIPA-Proteinlysepuffer für 5 Minuten auf Eis inkubiert. Die Ablösung der Zellen erfolgte mechanisch mit Hilfe eines Zellspachtels. Das Lysat wurde in ein 1,5 mlEppendorfgefäß pipettiert und zur weiteren Zelllyse für 45 Minuten auf Eis gelagert. Danach wurde das Lysat mit Hilfe eines Ultraschallhomogenisators sonifiziert, um ggf. noch vorhandene Bindungen zwischen Membranen und Proteinen aufzubrechen. Im Anschluss 
wurde die Probe bei $4^{\circ} \mathrm{C}$ zentrifugiert und der Überstand entweder sofort verwendet oder für spätere Experimente bei $-80^{\circ} \mathrm{C}$ gelagert.

\subsubsection{Photometrische Proteinkonzentrations-Messung}

Um den Gehalt des Gesamtproteins in einer Probe zu quantifizieren, kann der Bicinchoninsäure (BCA)-Test durchgeführt werden. In Anwesenheit von Proteinen erfolgt in alkalischem Milieu eine Reduktion von $\mathrm{Cu}^{2+} \mathrm{zu} \mathrm{Cu}^{1+}-$ Ionen als sogenannte Biuret-Reaktion. Anschließend bilden die reduzierten Kupferionen mit Bicinchoninsäure einen Chelatkomplex, welcher zu einem violetten Farbumschlag führt. Der Komplex weist eine hohe Absorption bei $562 \mathrm{~nm}$ auf und kann folglich photometrisch analysiert werden. Als Referenz dient eine Standardkurve in Form einer BSA-Verdünnungsreihe (s. Tabelle 4).

BSA-Konzentration $(\mu \mathrm{g} / \mathrm{ml}) \quad$ BSA $(\mu \mathrm{l}) \quad$ Aqua dest. $(\mu \mathrm{l})$

\begin{tabular}{|c|ccc|}
\hline A & 2000 & 300 aus Stock & 0 \\
B & 1500 & 375 aus Stock & 125 \\
C & 1000 & 325 aus Stock & 325 \\
D & 750 & 175 aus B & 175 \\
E & 500 & 325 aus C & 325 \\
F & 250 & 325 aus E & 325 \\
G & 125 & 325 aus F & 325 \\
H & 25 & 100 aus G & 400 \\
I & 0 & 0 & 400 \\
\hline
\end{tabular}

Tabelle 4: BSA-Standardkurve für den BCA-Test

Diese Verdünnungsreihe wurde auf eine 96-Well-Platte in Tripletts mit je $25 \mu$ pipettiert. Ebenso wurde mit Verdünnungen der Proteinproben (1:25) verfahren. Über alle Proben wurden nun $200 \mu$ l des oben genannten Reagenz gegeben, bestehend aus 50 Teilen BCAReagenz A und einem Teil BCA-Reagenz B. Nach 30 Minuten Inkubation bei $37^{\circ} \mathrm{C}$ erfolgte die photometrische Messung im Victor X4 Multilabel Reader. Die quantitativen Werte des Gesamtproteins der Proben wurden anhand der Standardkurve ausgerechnet. Zur weiteren Verwendung in der Gelelektrophorese wurden die Proteinproben mit vierfachem SDSPAGE-Ladepuffer versetzt und bei $95^{\circ} \mathrm{C}$ für 5 Minuten denaturiert. Entweder wurden die Proben sofort weiter verarbeitet oder bei $-20^{\circ} \mathrm{C}$ asserviert. 


\subsubsection{Gelelektrophorese}

Zunächst wurden die Proteine hinsichtlich ihrer Molekulargröße mittels SDSPolyacrylamid-Gelelektrophorese (SDS-PAGE) aufgetrennt, um im Anschluss im Western Blot genauer untersucht werden zu können. Das Gel, bestehend aus einer Trenn- und einer Sammelgelphase, wurde entsprechend der gewünschten Porengröße in Abhängigkeit von der zu erwartenden Proteingröße hergestellt. Die Gele wurden zwischen zwei speziell abgedichtete Glasplatten gegossen und härteten durch Polymerisation aus. Ein spezieller Kamm wurde in die obere Phase eingebracht, um Taschen für die Proteinproben zu formen. Die Gele wurden in eine Apparatur, die Western-Blot-Laufkammer, eingesetzt und diese mit SDS-Laufpuffer befüllt. Schließlich erfolgte die Beladung mit den Proteinproben, deren Volumen sich aus dem BCA-Test errechnen ließ. Als Referenz für die Proteinmasse wurden noch zusätzlich $5 \mu \mathrm{l}$ Spectra Broad Range Protein Ladder und $1 \mu \mathrm{l}$ Magic Mark ${ }^{T M}$ aufgetragen. Die Laufkammer wurde mit dem zugehörigen Deckel abgeschlossen und mit Hilfe eines Stromversorgungsgerätes an ein elektrisches Feld mit einer Stromstärke von $20 \mathrm{~mA}$ pro Gel für etwa zwei Stunden angeschlossen, wobei die Dauer nach optischer Kontrolle der Elektrophorese variiert wurde.

\subsubsection{Western Blot}

Nach Auftrennung der Probe durch die Natriumdodecylsulfat-Polyacrylamidgelelektrophorese (sodium dodecyl sulfate polyacrylamide gel electrophoresis, SDS-PAGE) wurden die Proteine auf eine Polyvinylidenfluoridmembran (PVDF-Membran) übertragen, um die Zielproteine, welche von Interesse waren, durch Immunodetektion sichtbar zu machen. Die PVDF-Membran wurde hierbei für wenige Sekunden in $100 \%$ igem Methanol aktiviert und drei Minuten in destilliertem Wasser gewaschen. Anschließend wurden Membran, SDS-Gel und die Filterpapiere 15 Minuten in Western Blot Transferpuffer äquilibriert und schließlich in der Blotapparatur zusammengesetzt. Das verschlossene System wurde für eine Stunde an eine Stromquelle mit $100 \mathrm{~mA}$ pro Membran angeschlossen. Durch diesen Vorgang hafteten die Proteine fest an der Membran und konnten durch spezifische Antikörper detektiert werden. Freie Proteinbindestellen wurden durch Inkubation eines Puffers, Tris-buffered saline with Tween ${ }^{\circledR} 20$ (TBS-T) in einer Lösung mit entfettetem Milchpulver (5\%), für eine Stunde blockiert. Anschließend erfolgte die Beladung mit dem Pri- 
märantikörper über Nacht, gefolgt von der Bindung des mit horseradish-Peroxidase (HRP) gekoppelten Sekundärantikörpers für zwei Stunden (s. 2.1.8). Die HRP katalysierte eine Chemolumineszenzreaktion (enhanced chemoluminescece, ECL) durch Zugabe des Substrates Luminata ${ }^{T M}$ Forte, wobei die enthaltene Verbindung Luminol oxidiert wurde. Die Detektion der Proteinbanden erfolgte mit Hilfe der ImageQuant LAS 4000 Kamera.

Sofern noch andere Proteine auf derselben Membran immunodetektiert werden sollten, mussten die gebundenen Primär- und Sekundärantikörper entfernt werden. Dies geschah durch Lösen der Protein-Antikörperbindungen (,stripping“) mit $1 \mathrm{M}$ Natronlauge ( $\mathrm{NaOH})$ für 5 Minuten bei Raumtemperatur. Hiernach wiederholte sich die Behandlung der Membran, beginnend mit der Blockierung freier Proteinstellen.

\subsubsection{Anfertigung von Paraffinblöcken und -schnitten}

Zur Anfertigung von Paraffinblöcken wurden in großen Zellkulturflaschen die jeweiligen Zelllinien kultiviert. Die Zellen wurden durch Trypsin abgelöst, in PBS aufgenommen und für 5 Minuten 1500 U/min zentrifugiert. Nach Absaugen des Überstandes wurde das Zellpellet in $4 \%$ igem Formalin (gepuffert) über Nacht bei Raumtemperatur inkubiert. Am Folgetag wurde die Suspension abermals zentrifugiert und das Zellpellet jeweils in $8 \mathrm{ml}$ einer aufsteigenden Alkoholreihe (Aqua bidest., $60 \%, 85 \%, 100 \%$ Ethanol) für 30 Minuten bei Raumtemperatur inkubiert. Nun wurde das Zellpellet nach erneuter Zentrifugation in $1 \mathrm{ml}$ Isopropanol aufgenommen und bei Raumtemperatur weitere 30 Minuten inkubiert. Im Anschluss erfolgte ein weiterer Zentrifugationsschritt, nach dem das Pellet in $1 \mathrm{ml}$ Xylol resuspendiert, für 30 Minuten inkubiert und abzentrifugiert wurde. Danach wurde das Zellpellet in heißem Paraffin aufgenommen und in einem Eppendorfgefäß auf dem Thermoblock bei $70^{\circ} \mathrm{C}$ für etwa 20 Minuten inkubiert, damit sich die Zellen am Boden des Gefäßes absetzen. Abschließend folgte ein Kühlschritt auf Eis, bei dem das ausgehärtete Paraffin mitsamt den Zellen ausgelöst wurde, um danach die Zellen in einen Paraffinblock auszugießen. Mit Hilfe eines Schlittenmikrotoms wurden aus dem Block $2 \mu \mathrm{m}$ starke Schnitte angefertigt. Die Paraffinschnitte wurden auf Glasobjektträger transferiert und bei $40^{\circ} \mathrm{C}$ über Nacht zum Trocknen in einem Wärmeschrank aufbewahrt. 


\subsubsection{Immunzytochemie und Auswertung}

Die Paraffinschnitte wurden im Färbeautomaten Ventana IHC-BENCHMARK XT System mit spezifischen Antikörpern angefärbt. Hierfür wurden die Objektträger mit gerätespezifischen Färbeprotokollen behandelt, welche ein vergleichbares Ergebnis aller Zelllinien für den Antikörper produzierten. Die Protokolle enthielten die folgenden Schritte:

- $\quad$ Entparaffinierung

- Zellaufbereitung mit einem Cell-Conditioner (Antigendemaskierung)

- Inkubation mit dem Primärantikörper (Inkubationsbedingungen s. 2.1.9.1)

- $\quad$ ultraVIEW Universal DAB Detection Kit (Bindung der Sekundärantikörper und Bildung eines braunen Niederschlags aus Wasserstoffperoxid und Kupfer)

- $\quad$ Kernfärbung

Nachdem das Färbeprogramm beendet war, wurden die Objektträger mit Wasser gespült und in einer aufsteigenden Alkoholreihe mit Xylol entwässert. Schlussendlich wurden die Schnitte dann mit Vitro-Clud ${ }^{\oplus}$ eingedeckelt.

Da es für die Zellkultur bisher kein etabliertes Scoringsystem hinsichtlich der Auswertung der HER-2-Expression gibt, erfolgte die Auswertung der immunzytochemischen Schnitte analog dem HER-2-Scoring-System beim Magenkarzinom innerhalb der ToGA-Studie (Bang et al. 2010) und wurde gemeinsam mit einem erfahrenen Pathologen durchgeführt. Die Membranfärbung wurde als stark (3+) gewertet, wenn sich mindestens 5 kohäsive Karzinomzellen im Biopsat bzw. mindestens 10\% der Karzinomzellen im chirurgischen Resektat basolateral und lateral bei 2,5- bis 5-facher Vergrößerung bereits als deutlich angefärbt darstellten. War die Membranfärbung eher schwach bis mittelgradig bei $10-$ bis 20-facher Vergrößerung zu detektieren, wurde der Expressionsgrad als 2+ gewertet. Wenn erst bei 40-facher Vergrößerung eine schwache Membranfärbung zu erkennen war, lag ein Expressionsgrad von 1+ vor. Keine Membranfärbung oder eine sehr schwache Färbung bei starker Vergrößerung außerhalb der o.g. Referenzbereiche wurde als IHC 0 gewertet (Rüschoff et al. 2010) (s. Abb. 6). Ein HER-2-Expressionsgrad von 3+ wurde als HER-2-positiv gewertet. Ein Grad von 2+ galt als grenzwertig positiv und musste mittels 
In-situ-Hybridisierung (ISH) verifiziert werden (s. 2.2.8). Ein Grad von 1+ oder 0 galt als negativ.

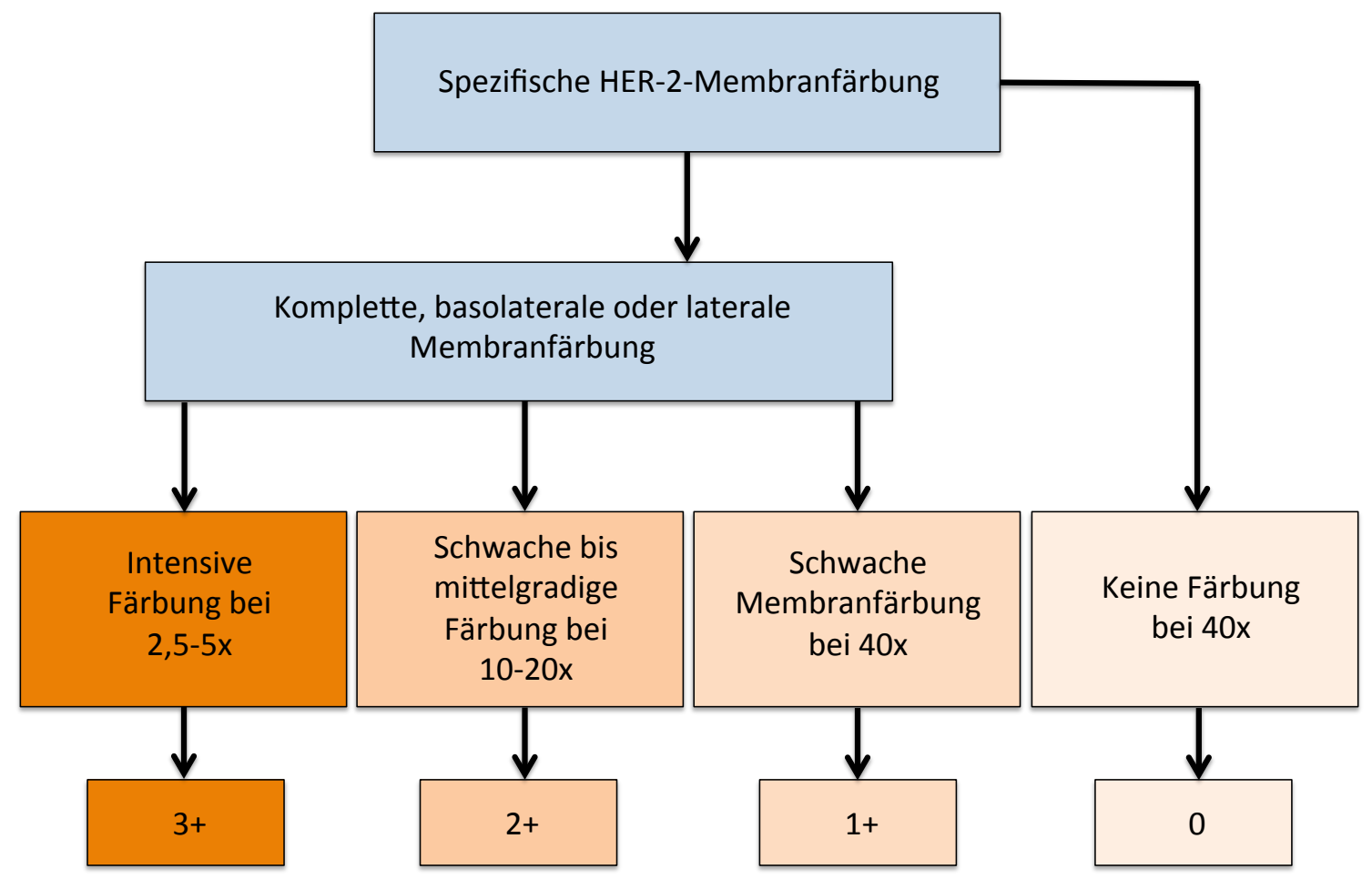

Abbildung 6: Beurteilung der spezifischen Membranfärbung für HER-2 in der Immunzytochemie

Ein Ausbleiben der spezifischen Membranfärbung wird bei maximaler Vergrößerung von 40-fach mit einem Scoring von " 0 “ beziffert. Eine schwache Membranfärbung bei dieser Vergrößerung wird mit dem Scoring "1+“ beziffert, bei geringerer Vergrößerung und stärkerer Färbung mit „2+“ oder „3+“. Die Membranfärbung kann bei Zellverbänden komplett, basolateral oder lateral ausgebildet sein.

Die Abbildung wurde von der Autorin der vorliegenden Arbeit selbst erstellt. Inhaltlich wurde sich bezogen auf Bang et al. 2010 (S. 688, Tabelle 1) für chirurgische Resektate/Biopsien. In diesem Fall jedoch wurde die Methodik modifiziert für die Zellkultur.

\subsubsection{Silber-in-situ-Hybridisierung (SISH)}

Zum direkten Nachweis von Nukleinsäuren in Form von DNA oder RNA im zytologischen oder histologischen Schnittpräparat wurde die Methode der In-situ-Hybridisierung verwendet. Hier binden Sonden aus künstlich hergestellten Nukleinsäuren durch Basenpaarung an die zu untersuchende Sequenz. Verschiedene Substanzen, die an die Sonde gekoppelt sind, können durch Detektoren sichtbar gemacht werden. Hierdurch können z. B. Chromosomen, Gene, DNA- oder RNA-Sequenzen lokalisiert werden. Bei der Silber-insitu-Hybidisierung (SISH) sind die Sonden mit Dinitrophenyl (DNP) gekoppelt und somit durch das Detektionssystem im Lichtmikroskop darstellbar. Diese Methode ist vollautomatisiert in der Handhabung und kostengünstig bezogen auf die benötigten Geräte. Wei- 
terhin erlaubt sie die Asservierung von gefärbten Schnitten und erlaubt einen genauen Vergleich HER-2-positiver Areale mit der Immunhisto-/zytochemie, was insbesondere in sehr heterogen HER-2-exprimierenden Tumoren wie dem Magenkarzinom von Vorteil ist (Rüschoff et al. 2010). Es konnte gezeigt werden, dass der Nachweis einer HER-2Genamplifikation durch SISH vergleichbar mit dem durch Fluoreszenz-in-situHybridisierung (FISH) war, sowohl im Mamma- (Dietel et al. 2007) als auch im Magenkarzinom (Rüschoff et al. 2012). In der vorliegenden Arbeit wurde die SISH verwendet, da diese Methode in der Arbeitsgruppe bereits etabliert ist und einen genauen Vergleich der Zellareale erlaubt, welche sich in der Immunzytochemie angefärbt zeigten.

Die Anfärbung der Paraffinschnitte erfolgte im Färbeautomat BenchMark XT (Ventana). Eine spezifische DNP-markierte Sonde (Teil des INFORM HER-2 Dual ISH DNA Probe Cocktail) bindet nach Denaturierung und Hybridisierung der DNA-Probe am Genlokus von HER-2, welcher auf dem Chromosom 17q21 lokalisiert ist, und wird durch das Detektionssystem VENTANA ultraView Silber ISH DNP Detection Kit lichtmikroskopisch als dunkler Punkt sichtbar gemacht. Diese Reaktion ist schematisch in Abbildung 7 dargestellt. Der Primärantikörper (Anti-DNP-Kaninchen-Antikörper) bindet an DNP, während der Sekundärantikörper (Ziege-anti-Kaninchen-Antikörper), welcher mit horseradish peroxidase (HRP) gekoppelt ist, an das Fab-Segment des Primärantikörpers bindet. Es folgt die Reduktion von Silberionen aus Silberacetat (Chromogen A) zu metallischem Silber durch Hydrochinon (Chromogen B), enzymatisch gesteuert durch die HRP und deren Substrat Wasserstoffperoxid (Chromogen C) (Dietel et al. 2007). 


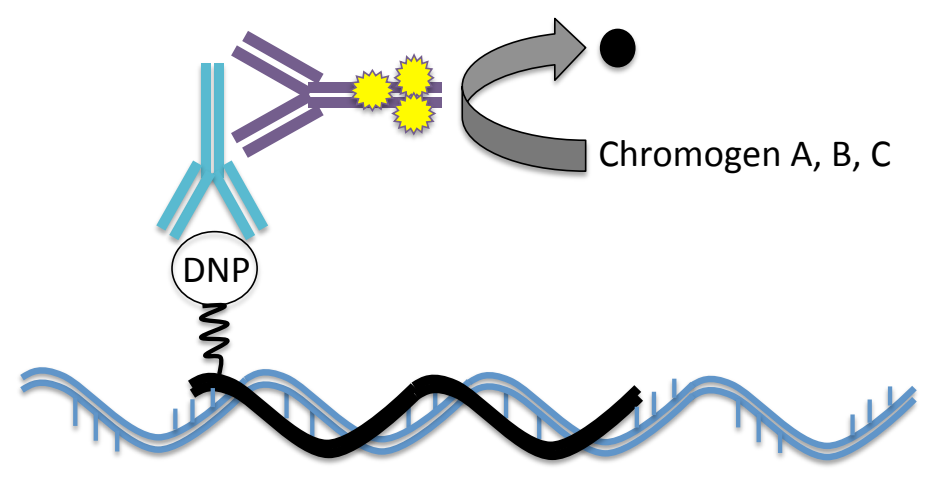

\section{Abbildung 7: SISH-Reaktion}

In türkis dargestellt ist der Primärantikörper, welcher an DNP bindet. Der daran bindende Sekundärantikörper (lila) ist gekoppelt an die HRP (gelb). Diese katalysiert die Reaktion der Substrate (Chromogen A-C) zu metallischem Silber (schwarzer Punkt, sichtbares Signal).

Diese Abbildung wurde von der Autorin der vorliegen Arbeit selbst erstellt und modifiziert anhand des Manuals, VENTANA ultraView Silber ISH DNP Detection Kit 760-098, 05572037001, 2012-03-05, S.1.

Gleichzeitig wird eine Digoxigenin (DIG)-markierte Sonde als Kontrolle verwendet, welche am Zentromer des Chromosoms 17 bindet, und mit dem VENTANA ultraView Red ISH DIG Detektion Kit visualisiert wird (s. Abb. 8). Es bindet ein Primärantikörper (Anti-DIG-MausAntikörper) an DIG, an diesen bindet ein Sekundärantikörper (Ziege-anti-MausAntikörper), welcher an eine alkalische Phosphatase gekoppelt ist. Als Substrat dieses Enzyms wird Naphthol zusammen mit einem roten Farbstoff zugegeben. Es bildet sich ein roter Niederschlag, welcher lichtmikroskopisch als roter Punkt gesehen werden kann.

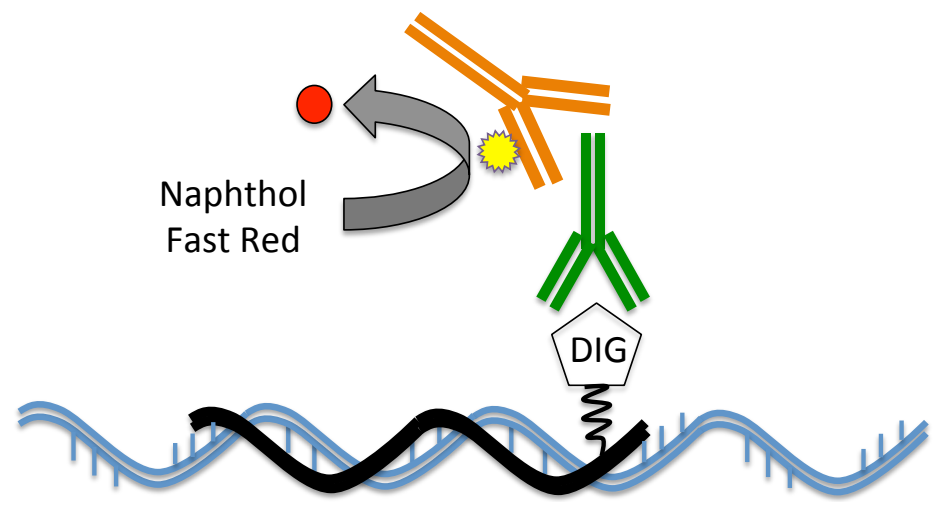

\section{Abbildung 8: Red-ISH-Reaktion}

In grün dargestellt ist der Primärantikörper, welcher an DIG bindet. Der daran bindende Sekundärantikörper (orange) ist gekoppelt an die alkalische Phosphatase (gelb). Diese katalysiert die Reaktion der Substrate (Naphthol, Fast Red) zu einem roten Niederschlag (roter Punkt, sichtbares Signal).

Diese Abbildung wurde von der Autorin der vorliegen Arbeit selbst erstellt und modifiziert anhand des Manuals, VENTANA ultraView Silber ISH DNP Detection Kit 760-505, 05587778001, 2012-03-05, S.1. 
Man spricht daher in diesem Zusammenhang auch von einer Dual-ISH. Durch Auszählen der schwarzen Punkte (Genkopien des HER-2-Gens) und der roten Punkte (Kopien des Chromosoms 17) kann eine Ratio der HER-2-Genkopien zu den Kopien des Chromosoms 17 gebildet werden. Es müssen mindestens 20 kohäsive Tumorzellen ausgewertet werden. Liegt hierbei die Ratio zwischen 1,8 und 2,2, müssen weitere 20 kohäsive Tumorzellen ausgezählt werden. Eine Ratio von $\geq 2$ entspricht einer Genamplifikation (Rüschoff et al. 2012). Dabei ist auf die Qualität der Färbung sowie auf etwaige Verschmutzungen zu achten, welche das Ergebnis verfälschen könnten.

\subsubsection{Messung der Zellviabilität nach Anti-HER-2-Therapie}

Die Wirkung von Inhibitoren, Antikörpern und/oder zytotoxischen Substanzen auf lebende Zellen kann u. a. durch Messung der Stoffwechselaktivität untersucht werden. Dabei stellt der CellTiter-Blue ${ }^{\circledR}$ Cell Viability Assay eine geeignete Methode dar. Metabolisch aktive Zellen reduzieren den Fluoreszenzfarbstoff Resazurin zu Resorufin, welcher anschließend mittels Extinktion bei $595 \mathrm{~nm}$ im Victor X4 Multilabel Reader gemessen werden kann. Dabei ist das Signal umso stärker, je mehr Farbstoff metabolisiert wird. Von den Rohdaten wird der mittlere Leerwert subtrahiert und anschließend ein Mittelwert gebildet, der prozentual ins Verhältnis zur Negativkontrolle gesetzt wird. Die Daten der Replikate wurden graphisch mit Hilfe der Software Grapher ${ }^{\mathrm{TM}} 8$ als Dosis-Wirkungs-Kurven dargestellt.

\subsubsection{Verwendete Anti-HER-2-Substanzen}

Es wurden die Auswirkungen einer Behandlung mit Trastuzumab, Pertuzumab, T-DM1, Lapatinib und Afatinib auf kolorektale Karzinomzelllinien untersucht. Des Weiteren wurden die Antikörper Trastuzumab und Pertuzumab miteinander kombiniert. Alle Substanzen wurden in einem weiteren Schritt mit den Chemotherapeutika 5-Fluorouracil (5-FU) und Oxaliplatin kombiniert.

Trastuzumab (Herceptin ${ }^{\circledR}$ ) ist ein rekombinanter humanisierter monoklonaler Antikörper vom Immunglobulin-G-Typ, welcher 1998 durch die Food and Drug Administration (FDA) 
für die Therapie des metastasierten Mammakarzinoms zugelassen wurde. Der Antikörper bindet mit seinen Antigen-spezifischen Bindestellen an der extrazellulären Domäne des HER-2-Transmembranproteins nahe der Zellmembran (Subdomäne IV, s. Abb. 5, S. 16) (Cho et al. 2003) und blockiert die Rezeptorstimulation (Hudis 2007; Valabrega et al. 2007). Obwohl der exakte Wirkmechanismus nicht vollständig erschlossen ist, deuten Untersuchungen darauf hin, dass die Signalweiterleitung durch fehlende Dimerisierung verhindert, der endozytotische Rezeptorabbau gesteigert und das körpereigene Immunsystem aktiviert wird. Ebenfalls wird die proteolytische Spaltung der extrazellulären Domäne des Rezeptors und konsekutive Entstehung eines Tyrosinkinase-aktiven membranständigen Fragmentes (p95) vermindert (Molina et al. 2001).

Pertuzumab (Perjeta ${ }^{\circledR}$ ) bindet als humanisierter monoklonaler Antikörper vom IgG-Typ ebenfalls an der extrazellulären Domäne von HER-2 (Subdomäne II, s. Abb. 5, S. 16), jedoch nicht an derselben Stelle wie Trastuzumab (Franklin et al. 2004). Durch direkte Blockade im Bereich der Dimerisationsstelle verhindert die Substanz die Fusion von HER-2 mit den übrigen Mitgliedern der EGFR-Familie, insbesondere mit HER-3 (Adams et al. 2006), und verhindert so die Aktivierung nachgeschalteter Signalwege. Es gibt Hinweise, dass Pertuzumab aufgrund dieses Wirkmechanismus selbst bei moderatem Expressionslevel von HER-2 aktiv ist, da einer ligandenabhängigen Dimerisation entgegengewirkt wird (Agus et al. 2005).

T-DM1 (Trastuzumab-Maytansinoid, Trastuzumab-Emtansin, Kadcyla ${ }^{\circledR}$ ) stellt ein Konjugat des monoklonalen Antikörpers Trastuzumab mit einem zytotoxischen Wirkstoff, dem Maytansinderivat Mertansin (DM1), dar (LoRusso et al. 2011). Dieser gegen Mikrotubuli gerichtete Inhibitor wirkt ähnlich wie ein Vincaalkaloid und weist für sich genommen eine hohe systemische Toxizität auf (Okines und Cunningham 2012; Remillard et al. 1975). Jedoch ist das DM1 über stabile linker (Thioether-Brücken) an den Antikörper gebunden und zeigt daher nur geringfügige systemische Nebenwirkungen. Zielstruktur ist - entsprechend dem unkonjugierten Antikörper - die extrazelluläre Domäne von HER-2. Neben den oben genannten Wirkmechanismen von Trastuzumab selbst wird durch Internalisierung des Rezeptors samt T-DM1 unter anderem das Zytostatikum in der HER-2- 
überexprimierenden Zelle vermehrt freigesetzt und ein Zellzyklusarrest bewirkt (Erickson et al. 2006).

Als Vertreter kleinmolekularer Inhibitoren ist Lapatinib (Tykerb ${ }^{\circledR}$ oder Tyverb $^{\circledR}$ ) in der Lage, die Zellmembran zu überwinden und wirkt als reversibler, selektiver Tyrosinkinaseinhibitor an der intrazellulären Domäne von EGFR und HER-2 (s. Abb. 5, S. 16) (Spector et al. 2005). Die Bindung erfolgt an den einzelnen Transmembranrezeptoren und verhindert deren Phosphorylierung durch Bildung von Dimeren (Wood et al. 2004). Dadurch werden auch die nachgeschalteten Signalkaskaden über Proteine wie PI3K/Akt und Ras/MAPK nicht aktiviert. Hierdurch kommt es in den Tumorzellen vermehrt zur Zytostase aber auch zur Apoptose (Xia et al. 2002).

Ähnlich wie Lapatinib bewirkt auch Afatinib (Giotrif ${ }^{\circledR}$ ) als kleinmolekularer Tyrosinkinaseinhibitor durch potente Hemmung der intrazellulären Kinasedomäne die Aktivitätsminderung der nachgeordneten Signalwege des HER-2. Als pan-HERTyrosinkinaseinhibitor sind in diesem Fall jedoch ebenfalls EGFR und HER-4 Angriffspunkt, und auch die Transphosphorylierung von HER-3 wird verhindert (Li et al. 2008). Eine weitere Besonderheit liegt darin, dass die Inaktivierung der enzymatischen Funktion durch kovalente Bindung irreversibel ist und auch im aktivierten Zustand des Rezeptors greift, welcher beispielsweise durch Mutationen stabilisiert ist und Resistenzen gegen andere Substanzen hervorruft (Solca et al. 2012).

Für die Dosierungen der Substanzen orientierten wir uns an Vorversuchen unserer Arbeitsgruppe bezüglich der Therapie mit den Chemotherapeutika 5-FU und Oxaliplatin sowie Trastuzumab und Lapatinib. Ergänzend planten wir die Verdünnung von Pertuzumab und T-DM1 anhand von Trastuzumab, da es sich um einen weiteren Antikörper und ein Antikörperwirkstoffkonjugat handelt. Die Verdünnungsreihe für Afatinib orientierten wir an den Konzentrationen von Lapatinib, da es sich hierbei ebenfalls um einen kleinmolekularen Inhibitor mit ähnlichem Wirkmechanismus handelt. Tabelle 5 zeigt die Verdünnungsreihen für die Zelllinien LS513 und LS1034, Tabelle 6 für die Zelllinie SW837. Die Dosierungen unterscheiden sich insbesondere hinsichtlich des Chemotherapeutikums Oxaliplatin. 
$\begin{array}{ll}\text { Substanz Konzentration } & \text { Kontion }\end{array}$

\begin{tabular}{|c|c|c|c|c|c|c|c|c|c|c|c|c|}
\hline 5-FU $(\mu \mathrm{M})$ & 0 & 0,1 & 0,5 & 1 & 2,5 & 5 & 7,5 & 10 & 25 & 50 & - & - \\
\hline Oxaliplatin $(\mu \mathrm{M})$ & 0 & 0,001 & 0,01 & 0,05 & 0,1 & 0,5 & 1 & 5 & 10 & 25 & - & - \\
\hline $\begin{array}{l}\text { Trastuzumab } \\
(\mu \mathrm{g} / \mathrm{ml})\end{array}$ & 0 & 0,2 & 0,4 & 2 & 4 & 20 & 50 & 100 & 200 & - & - & - \\
\hline Pertuzumab ( $\mu \mathrm{g} / \mathrm{ml})$ & 0 & 0,2 & 0,4 & 2 & 4 & 20 & 50 & 100 & 200 & - & - & - \\
\hline T-DM1 $(\mu \mathrm{g} / \mathrm{ml})$ & 0 & 0,2 & 0,4 & 2 & 4 & 7,5 & 20 & 50 & 100 & 200 & 400 & - \\
\hline Lapatinib $(\mu \mathrm{M})$ & DMSO & 0,01 & 0,05 & 0,1 & 0,5 & 1 & 2,5 & 7,5 & 5 & 10 & 25 & 50 \\
\hline Afatinib $(\mu \mathrm{M})$ & DMSO & 0,01 & 0,05 & 0,1 & 0,5 & 1 & 2,5 & 7,5 & 5 & 10 & 25 & 50 \\
\hline
\end{tabular}

Tabelle 5: Dosierungen der Chemotherapeutika und Anti-HER-2-Substanzen für den Viabilitätsassay mit den Zelllinien LS513 und LS1034

Substanz Konzentration

\begin{tabular}{|c|c|c|c|c|c|c|c|c|c|c|c|c|}
\hline $5-\mathrm{FU}(\mu \mathrm{M})$ & 0 & 0,1 & 0,5 & 1 & 2,5 & 5 & 7,5 & 10 & 25 & 50 & - & - \\
\hline Oxaliplatin ( $\mu \mathrm{M})$ & 0 & 0,1 & 0,5 & 1 & 1,5 & 2 & 3,25 & 6,5 & 12,5 & 25 & - & - \\
\hline Trastuzumab $(\mu \mathrm{g} / \mathrm{ml})$ & 0 & 0,2 & 0,4 & 2 & 4 & 20 & 50 & 100 & 200 & - & - & - \\
\hline Pertuzumab ( $\mu \mathrm{g} / \mathrm{ml})$ & 0 & 0,2 & 0,4 & 2 & 4 & 20 & 50 & 100 & 200 & - & - & - \\
\hline T-DM1 ( $\mu \mathrm{g} / \mathrm{ml})$ & 0 & 0,2 & 0,4 & 2 & 4 & 20 & 50 & 100 & 200 & - & - & - \\
\hline Lapatinib $(\mu \mathrm{M})$ & DMSO & 0,01 & 0,05 & 0,1 & 0,5 & 1 & 2,5 & 7,5 & 5 & 10 & 25 & 50 \\
\hline Afatinib $(\mu \mathrm{M})$ & DMSO & 0,01 & 0,05 & 0,1 & 0,5 & 1 & 2,5 & 7,5 & 5 & 10 & 25 & 50 \\
\hline
\end{tabular}

Tabelle 6: Dosierungen der Chemotherapeutika und Anti-HER-2-Substanzen für den Viabilitätsassay mit der Zelllinie SW837

\subsubsection{Zellviabilitätsassay}

Für den CellTiter-Blue ${ }^{\circledR}$ Cell Viability Assay wurde eine für jede Zelllinie optimale Anzahl an Zellen ausgewählt, bei der sich die Zellen in einer exponentiellen Wachstumsphase befinden (LS513: 8000 Zellen, LS1034/SW837: 6000 Zellen). Diese Zellzahl wurde in $100 \mu l$ Medium pro Well in einer schwarzen 96-Well-Platte ausgesetzt. Dabei wurden für jede Konzentration der zu untersuchenden Substanz drei Wells als technische Replikate vorgesehen. Die äußeren Wells wurden nur mit Medium in äquivalenter Menge befüllt und dienten der Evaporation sowie der späteren Ermittlung eines Leerwertes (s. Abb. 9).

Es wurden für jede Substanz bzw. Kombination von Substanzen jeweils Zellen auf drei separaten Platten ausgesetzt, um durch verschiedene Messzeitpunkte (24, 48 und 72 
Stunden) den Einfluss der Inhibierung über die Zeit zu untersuchen. Dieser Versuch wurde insgesamt dreimal mit Zellen aus verschiedenen Passagen wiederholt (biologische Replikate). So konnten Standardabweichungen für alle Werte erhoben und die Reproduzierbarkeit der Ergebnisse überprüft werden. Die Zellen wuchsen über 24 Stunden im Inkubator bei $37^{\circ} \mathrm{C}$ an, und am nächsten Tag wurden $10 \mu \mathrm{l}$ der zu testenden Substanzen in aufsteigenden Verdünnungsreihen zugegeben. Als Negativkontrolle wurden Zellen mit den entsprechenden Lösungsmitteln der Substanzen inkubiert. Hierbei handelte es sich entweder um Wasser für Trastuzumab, Pertuzumab, T-DM1, 5-FU und Oxaliplatin oder um das organische Lösungsmittel Dimethylsulfoxid (DMSO) für Lapatinib und Afatinib.

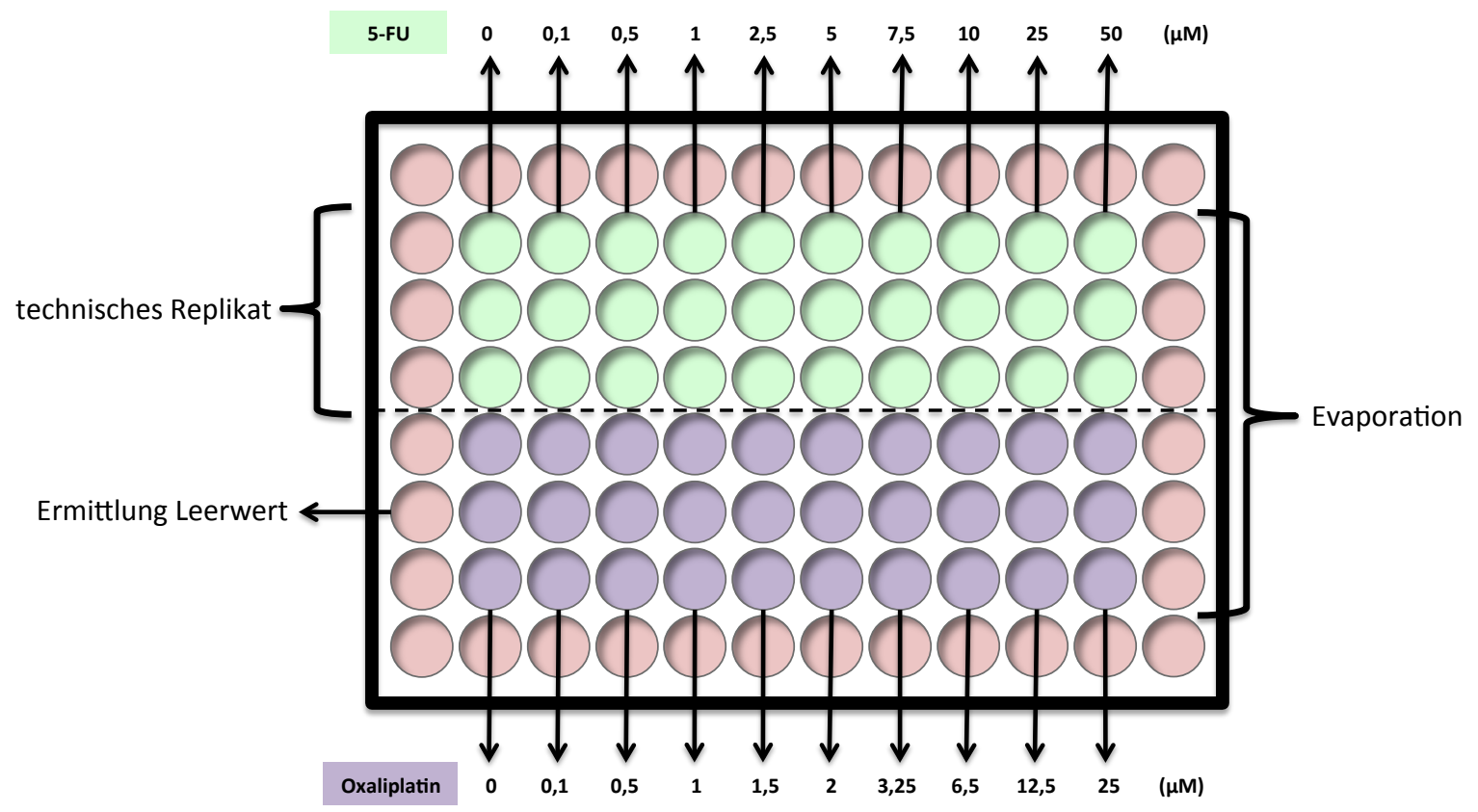

\section{Abbildung 9: Schema einer 96-Well-Platte}

Die äußeren Wells (rosa) der 96-Well-Platte werden mit Medium in äquivalenter Menge befüllt und dienen linksseitig zur Ermittlung des Leerwertes und allgemein zur Evaporation. In allen anderen Wells (hellgrün, lila) werden Zellen der jeweiligen kolorektalen Karzinomzelllinie in idealer Zellzahl ausgesetzt. In aufsteigender Konzentration werden 3 technische Replikate der Inhibitoren/Antikörper (hier am Beispiel 5-FU in den hellgrünen Wells und Oxaliplatin in den lila Wells) in vertikaler Ausrichtung angefertigt.

Die Abbildung wurde von der Autorin der vorliegenden Arbeit selbst erstellt.

Nach 24, 48 und 72 Stunden Inkubation mit den Anti-HER-2-Substanzen bzw. den Chemotherapeutika wurde das CellTiter-Blue ${ }^{\circledR}$ Cell Viability Assay-Reagenz im Verhältnis 1:5 hinzu pipettiert und für eine Stunde bei $37^{\circ} \mathrm{C}$ inkubiert. Danach wurden die Platten im Victor X4 Multilabel Reader die Extinktion bei $595 \mathrm{~nm}$ gemessen und ausgewertet. 


\subsubsection{Statistische Analysen}

Zum Nachweis signifikanter Unterschiede zwischen Zellviabilitätsänderungen als Effekt auf die untersuchten Mono- und Kombinationstherapien wurden Regressionsanalysen anhand von Generalisierten Linearen Modellen (GLM) durchgeführt. Im Modell wurde die Zielvariable Zellviabilität abhängig von der Dauer einer Behandlung (Messzeitpunkte bei 24, 48 und 72 Stunden), der Dosis einer Substanz oder Substanzkombination und der Dosis-zu-Dauer-Interaktion beschrieben. Für eine Signifikanzbeurteilung der Prädiktorvariablen wurde jeweils ein p-Wert berechnet. Ferner wurde für einen Vergleich der GLM mit verschiedenen Substanzen ein F-Test im Rahmen einer Varianzanalyse (ANOVA) durchgeführt. Die Analyse erfolgte in der statistischen Programmierumgebung R. Die effektive Konzentration bei einer Viabilitätsverringerung von $50 \%\left(E_{50}\right)$ wird aus den Kurven einer jeden Messung im Rahmen der Regressionsanalyse bestimmt. Hier sei jedoch darauf hingewiesen, dass die Extrapolation einer größeren Ungenauigkeit unterworfen ist und $z u$ nicht eindeutigen Schätzungen führt, sofern die $E_{50}$ weit außerhalb des Messbereichs liegt. 


\section{Ergebnisse}

Ziel der vorliegenden Arbeit war es zu überprüfen, ob eine HER-2-Inhibierung beim KRK sinnvoll ist. Dazu wurde anhand von kolorektalen Karzinomzelllinien getestet, ob eine gegen HER-2 gerichtete Therapie Auswirkungen auf nachgeschaltete Signalwege sowie die Zellviabilität hat. Dabei wurden verschiedene Substanzen eingesetzt. Zudem wurde untersucht, ob eine Kombination der einzelnen Substanzen mit den Chemotherapeutika 5-FU und Oxaliplatin zu einer gesteigerten Effektivität der Therapie führt.

\subsection{HER-2 Status}

Insgesamt wurden 12 kolorektale Karzinomzelllinien untersucht, welche in der Vergangenheit intensiv hinsichtlich ihrer molekulargenetischen Charakteristika sowie ihrer (Radio-) Chemotherapiesensibilität durch unsere Arbeitsgruppe untersucht wurden (Camps et al. 2009; Camps et al. 2013; Grade et al. 2011; Spitzner et al. 2010). Tabelle 7 zeigt für alle verwendeten Zelllinien den Mutationsstatus hinsichtlich der Gene HER-2, TP53, KRAS und APC sowie den Status des DNA-Mismatch-Reparatur-Systems (MMR) durch Unterscheidung von Mikrosatellitenstabilität (MSS) und -instabilität (MSI).

\begin{tabular}{|c|c|c|c|c|c|}
\hline Zelllinie & HER-2 Mutation & TP53 Mutation & KRAS Mutation & APC Mutation & MMR Status \\
\hline Caco-2 & - & + & - & + & MSS \\
\hline НCT 116 & - & - & + & - & MSI \\
\hline HT-29 & - & + & - & + & MSS \\
\hline LS1034 & - & + & + & + & MSS \\
\hline LS411N & + & + & - & + & MSS \\
\hline LS513 & - & - & + & - & MSS \\
\hline SW1116 & - & + & + & + & MSS \\
\hline SW1463 & - & + & + & + & MSS \\
\hline SW403 & - & + & + & + & MSS \\
\hline SW480 & + & + & + & + & MSS \\
\hline SW620 & - & + & + & + & MSS \\
\hline SW837 & - & + & + & + & MSS \\
\hline
\end{tabular}

Tabelle 7: Molekulargenetische Charakteristika der kolorektalen Karzinomzellinien Die Abbildung wurde modifiziert nach Spitzner et al. 2010 (S. 1185, Tabelle 1). 


\subsubsection{Immunzytochemische Färbungen von HER-2 an Paraffinschnitten}

Für alle 12 KRK-Zelllinien wurden Paraffinschnitte angefertigt, immunzytochemisch für HER-2 angefärbt und analog dem HER-2-Scoring beim Magenkarzinom lichtmikroskopisch in Zusammenarbeit mit einem erfahrenen Pathologen ausgewertet (s. 2.2.7) (Rüschoff et al. 2012). Dabei galt ein Expressionsgrad von 3+, wenn die Membranfärbung basolateral und lateral bei 2,5- bis 5-facher Vergrößerung bereits deutlich sichtbar war. War die Membranfärbung eher schwach bis mittelgradig bei 10- bis 20-facher Vergrößerung, wurde der Expressionsgrad als 2+ gewertet. Wenn erst bei 40-facher Vergrößerung eine schwache Membranfärbung zu erkennen war, lag ein Expressionsgrad 1+ vor. Keine Membranfärbung oder eine sehr schwache Färbung bei starker Vergrößerung außerhalb der o.g. Referenzbereiche wurde als ICC-Grad 0 gewertet.

Ein HER-2-Expressionsgrad von 3+ zeigte sich lediglich in der Zelllinie LS513 (s. Abb. 10). Hier konnte somit entsprechend dem o.g. Scoring von einer Positivität für HER-2 ausgegangen werden. Die Zelllinien CaCo-2, LS1034, LS411N, SW1116 und SW837 wiesen einen Expressionsgrad von 2+ auf. Gemäß der Diagnostik des HER-2 Status beim Magenkarzinom bedurften diese Zelllinien also einer weiteren Färbung mittels In-situ-Hybridisierung, um eine HER-2 Positivität zu bestätigen oder auszuschließen (s. Tabelle 8, S. 51). Die übrigen Zelllinien zeigten für HER-2 einen Expressionsgrad von 1+ (HT-29, SW1463, SW403) oder 0 (HCT116, SW480, SW620) und galten somit als negativ. 
LS513 - ICC 3+

A

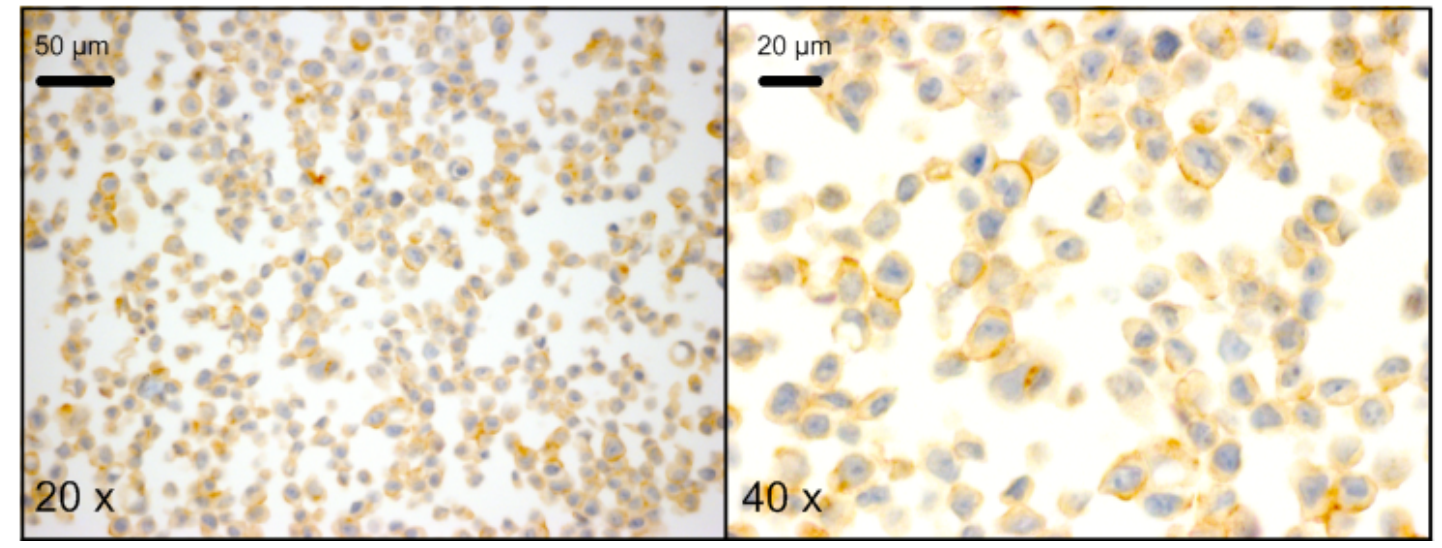

SW837 - ICC 2+

B

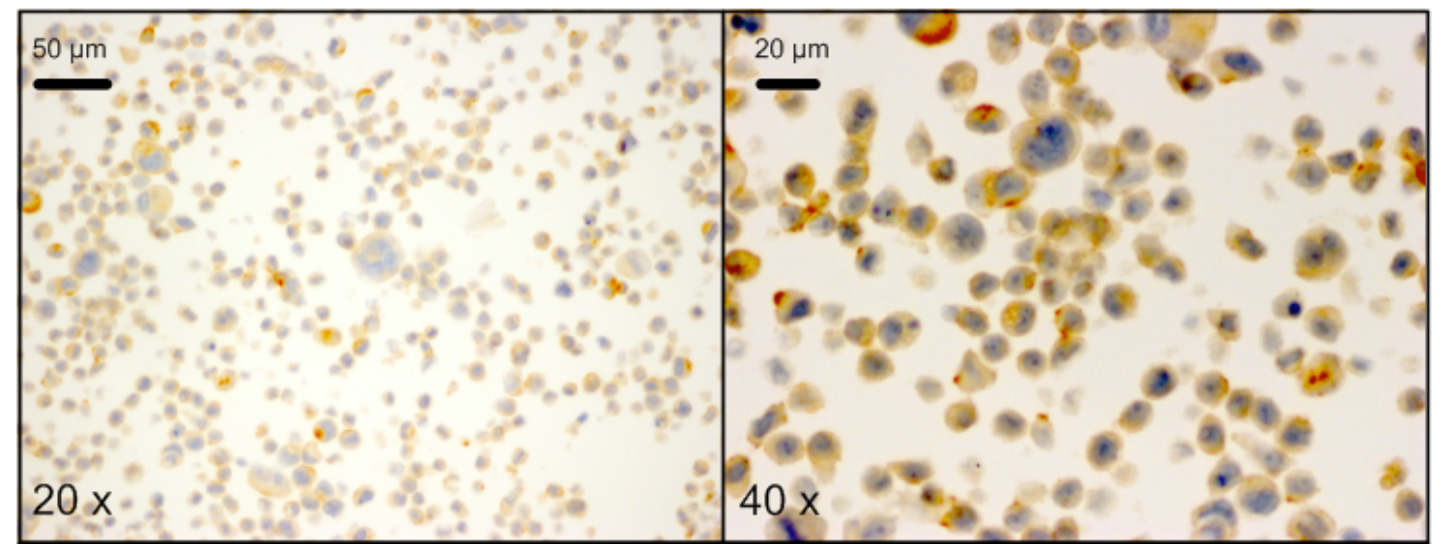

Abbildung 10: Immunzytochemische Färbungen von HER-2 und Scoring am Beispiel der Zelllinien LS513 (A) und SW837 (B)

\subsubsection{Silber-in-situ-Hybridisierung}

Analog dem HER-2-Scoring beim Magenkarzinom wurde zusätzlich zur Immunzytochemie eine In-situ-Hybridisierung durchgeführt, um einen positiven HER-2 Status zu verifizieren, insbesondere im Fall eines Scorings von 2+ (Rüschoff et al. 2012). Als „HER-2-positiv“ gelten Tumorgewebe, deren basolaterale oder laterale Zellmembranen sich in einem bestimmten Anteil der Karzinomzellen immunhistochemisch für HER-2 stark anfärben lassen (Expressionsgrad 3+). Fällt diese immunhistochemische Anfärbung schwächer aus (Expressionsgrad 2+), sollte durch In-situ-Hybridisierung die Genkopie-Anzahl von HER-2 untersucht werden. Dies gelingt methodisch vergleichbar sowohl mit einer FISH als auch einer SISH (Rüschoff et al. 2012). Hierdurch erfolgt der Nachweis einer Genamplifikation. 
Liegt eine Genamplifikation von HER-2 zusammen mit einem immunzytochemischen Scoring von 2+ (oder 3+) vor, kann ebenfalls von einer HER-2-Positivität gesprochen werden.

Für die vorliegende Arbeit wurden die zytologischen Paraffinschnitte spezifisch anhand des unter 2.2.8. aufgeführten Protokolls angefärbt und durch einen erfahrenen Pathologen lichtmikroskopisch ausgewertet. Eine Genamplifikation lag per Definition vor, wenn das Verhältnis des sondenmarkierten HER-2-Genlokus zur Anzahl des Chromosoms $17 \geq 2$ betrug. Dies bedeutet, dass mindestens zwei Genkopien auf dem Chromosom vorhanden waren. Einen entsprechenden Wert erreichten die Zelllinien LS1034 (SISH Ratio 2,1), LS513 (SISH Ratio 2,2) und SW837 (SISH Ratio 2,1). Die übrigen Zelllinien wiesen keine Genamplifikation auf (s. Tabelle 8).

\subsubsection{Vergleich und Auswahl der Zelllinien}

In Zusammenschau der Immunzytochemie und der Silber-in-situ-Hybridisierung hinsichtlich der Proteinexpression bzw. Genamplifikation von HER-2 zeigten sich folgende Ergebnisse, hier tabellarisch für alle 12 KRK-Zelllinien dargestellt.

\begin{tabular}{|ccc|}
$\begin{array}{c}\text { kolorektale } \\
\text { Karzinomzelllinie }\end{array}$ & $\begin{array}{c}\text { Immunzytochemie } \\
\text { (HER-2) }\end{array}$ & $\begin{array}{c}\text { SISH Ratio } \\
\text { (HER-2) }\end{array}$ \\
\hline Caco-2 & $2+$ & 1,3 \\
\hline HCT 116 & 0 & 1,1 \\
\hline HT-29 & $1+$ & 1,2 \\
\hline LS1034 & $2+$ & 2,1 \\
\hline LS411N & $2+$ & 1,0 \\
\hline LS513 & $3+$ & 2,2 \\
\hline SW1116 & $2+$ & 1,3 \\
\hline SW1463 & $1+$ & 1,2 \\
\hline SW403 & $1+$ & 1,2 \\
\hline SW480 & 0 & 1,2 \\
\hline SW620 & 0 & 1,0 \\
\hline SW837 & $2+$ & 2,1 \\
\hline
\end{tabular}

Tabelle 8: Ergebnisse der Immunzytochemie und SISH für die kolorektalen Karzinomzelllinien.

In roter Schrift hervorgehoben sind die HER-2-positiven Zelllinien. 
Somit wurde ein formal positiver HER-2 Status (ICC 3+ oder ICC 2+ mit SISH Ratio $\geq 2$ ) für die Zelllinien LS513, LS1034 und SW837 erhoben. Für die weiteren Versuche wurden daher nur diese drei Zelllinien eingesetzt. Die übrigen Zelllinien wiesen einen negativen HER-2-Status auf.

\subsection{Behandlung mit Anti-HER-2-Substanzen}

\subsection{1 pAkt-Level und Zellviabilitätsmessung}

Um den Einfluss der Anti-HER-2-Substanzen auf die nachgeschalteten Signalwege des HER-2-Rezeptors nachzuweisen, führten wir Western Blots nach der Behandlung mit den jeweiligen Substanzen durch. Als Zielprotein wählten wir Akt in seiner aktivierten, phosphorylierten Form (pAkt) (s. Abb. 5, S. 16). Gemäß der Literatur ist die Abnahme an pAkt ein sensitiver Indikator für eine Blockierung des Signalweges (Moasser 2007). Die Zellen wurden zuvor mit Neuregulin-1 (NRG) stimuliert, damit eine ausreichende Menge an Protein zur Detektion im Western Blot vorhanden war. Verglichen wurden Inhibitorbehandelte NRG-stimulierte Zellen und unbehandelte stimulierte Zellen. Als Ladekontrolle wurde das Protein Actin verwendet.

Zur Untersuchung der Wirksamkeit von Anti-HER-2 Substanzen auf den Zellstoffwechsel wurde die relative Zellviabilität mittels CellTiter-Blue ${ }^{\circledR}$ Assay gemessen. Es wurden gemäß dem Versuchsprotokoll (s. 2.2.9) Fluoreszenz-Messungen durchgeführt und als DosisWirkungs-Kurven dargestellt. Auf der y-Achse aufgetragen wurde die Zellviabilität in Prozent bezogen auf einen konstruierten relativen Wert von $100 \%$, welcher aus dem Mittelwert der Messungen von Zellen im jeweiligen Versuchssetting errechnet wurde, die dem jeweiligen Lösungsmittel der Anti-HER-2-Substanzen (Wasser oder DMSO) ausgesetzt waren. Auf der x-Achse wurden die Konzentrationen der jeweiligen Wirkstoffe dargestellt. 


\subsubsection{Anti-HER-2-Substanzen}

\subsubsection{Trastuzumab}

Trastuzumab ist ein spezifisch gegen HER-2 gerichteter monoklonaler Antikörper, welcher an der extrazellulären Domäne des Membranrezeptors bindet (s. Abb. 5, S. 16) (Valabrega et al. 2007). Diese Substanz wird bereits erfolgreich in der Therapie des HER-2positiven Mammakarzinoms und des HER-2-positiven metastasierten Magen- und Kardiakarzinoms eingesetzt (Bang et al. 2010; Romond et al. 2005; Slamon et al. 2001).

Zur Proteinisolation für den Western Blot wurde Trastuzumab in einer Konzentration von $1-100 \mu \mathrm{g} / \mathrm{ml}$ auf die Zellen gegeben. Für die Messungen der Zellviabilität wählten wir einen breiteren Konzentrationsbereich von 0,2-200 $\mu \mathrm{g} / \mathrm{ml}$ Trastuzumab. Im Western Blot für die Zelllinien LS513 und LS1034 zeigte sich allenfalls bei der höchsten Konzentration von Trastuzumab ein milder Einfluss auf das Zielprotein pAkt (s. Abb. 11A). Im Gegensatz dazu war in der Zelllinie SW837 bereits bei niedrigen Konzentrationen $(5 \mu \mathrm{g} / \mathrm{ml})$ eine Verminderung von pAkt zu sehen. Die Menge an Akt war etwa gleichbleibend. In der Zellviabilitätsmessung nach Behandlung mit Trastuzumab zeigte sich in keiner Zelllinie ein phänotypisch relevanter Effekt, obgleich die Unterschiede mathematisch signifikant waren bezüglich der Dosis (LS513: $p=4.1 \mathrm{e}-10$, LS1034: $p=7.6 \mathrm{e}-11$, SW837: $p=5 \mathrm{e}-06$ ) und der Zeit (LS513: $p=5.2 \mathrm{e}-18$, LS1034: $p=0.00011$, SW837: $p=0.0058$ ) (s. Abb. 11B).

LS513

A

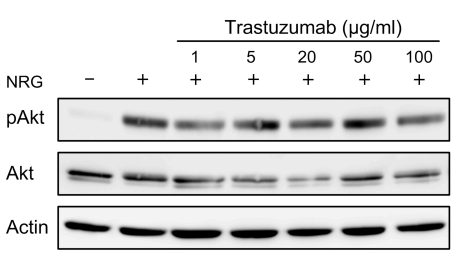

B

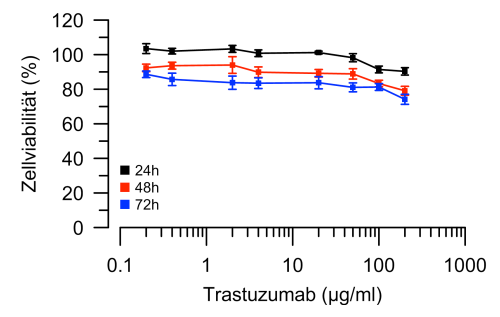

LS1034
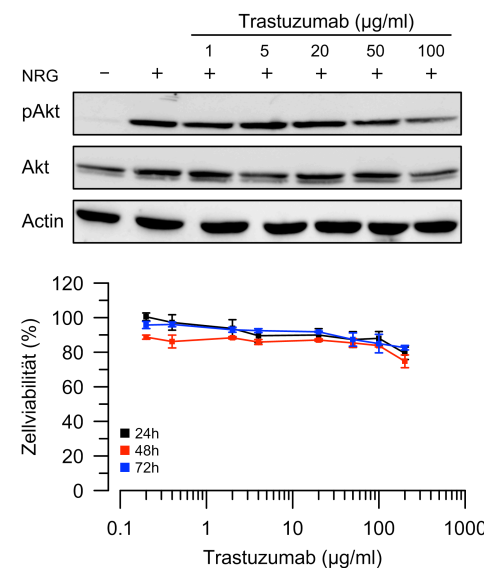

SW837
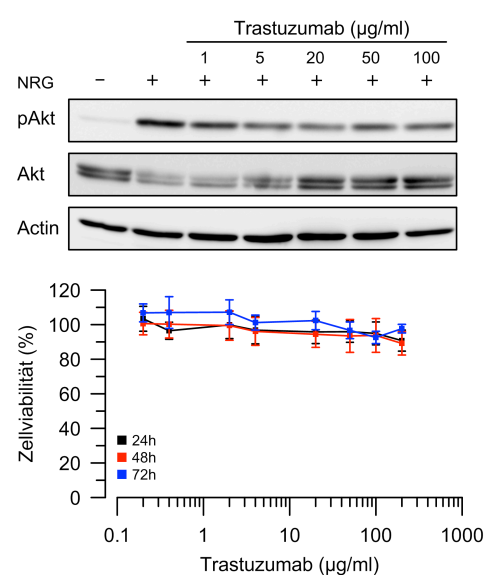

Abbildung 11: Western Blot (A) und Zellviabilitätsmessung (B) nach der Behandlung mit Trastuzumab 


\subsubsection{Pertuzumab}

Der monoklonale Antikörper Pertuzumab bindet ebenfalls spezifisch an HER-2, jedoch an einer anderen extrazellulären Bindungsdomäne des Rezeptors (s. Abb. 5, S. 16). Dadurch wird eine Homo- bzw. Heterodimerisation und nachfolgende Aktivierung der intrazellulären Tyrosinkinasedomäne verhindert (Adams et al. 2006). Pertuzumab wird in der Therapie des HER-2-positiven metastasierten Mammakarzinoms eingesetzt (Baselga et al. 2014).

Um den Einfluss von Pertuzumab auf das pAkt-Level zu untersuchen, wählten wir für die Behandlung den gleichen Konzentrationsbereich wie für Trastuzumab. Auch für den Zellviabilitätsassay wurden die gleichen Konzentrationen wie für Trastuzumab verwendet. Im Western Blot war nach der Behandlung mit Pertuzumab eine deutliche Abnahme von pAkt in den Zelllinien LS513 und LS1034 nachzuweisen, welche sich bereits bei sehr niedrigen Konzentrationen einstellte (s. Abb. 12A). In der Zelllinie SW837 wurde die Aktivierung von pAkt erst bei höheren Dosen inhibiert. Der Zellviabilitätsassay nach Behandlung mit Pertuzumab zeigte in allen Zelllinien - ähnlich der Monotherapie mit Trastuzumab einen signifikanten, aber phänotypisch nicht relevanten Einfluss mit zunehmender Dosis (LS513: $p=2 \mathrm{e}-13$, LS1034: $p=2.1 \mathrm{e}-15$, SW837: $p=1.6 \mathrm{e}-13$ ) und Behandlungsdauer (LS513: $p=4.7 \mathrm{e}-07, \mathrm{LS1034}: p=9.9 \mathrm{e}-06, \mathrm{SW} 837: p=1.5 \mathrm{e}-10)$ (s. Abb. 12B).

LS513

A

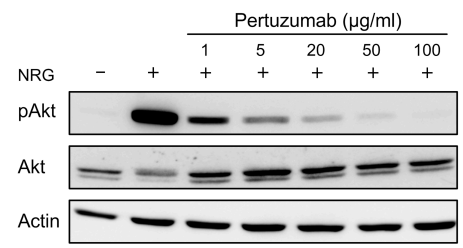

B

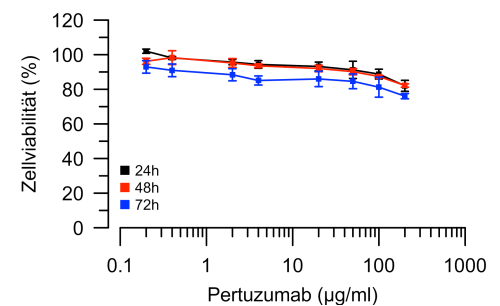

LS1034
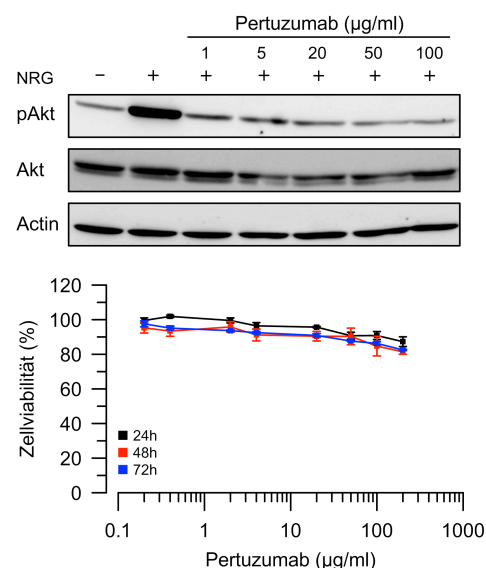

SW837
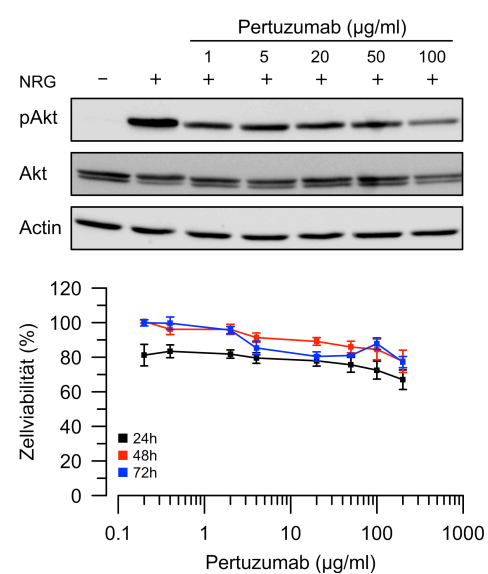

Abbildung 12: Western Blot (A) und Zellviabilitätsmessung (B) nach der Behandlung mit Pertuzumab 


\subsubsection{T-DM1}

Trastuzumab-Emtansin (T-DM1) ist ein Antikörper-Wirkstoff-Konjugat des monoklonalen Antikörpers Trastuzumab und dem Maytansin-Derivat DM1. Durch stabile Kopplung wird der Mitosehemmstoff erst nach Internalisierung in der Zelle freigesetzt und führt zur Apoptose (LoRusso et al. 2011). Neben den Wirkmechanismen des Antikörpers wird somit eine Zytotoxizität unter Reduktion systemischer Nebenwirkungen erreicht. Therapeutisch wird T-DM1 aufgrund der Ergebnisse der EMILIA-Studie beim lokal fortgeschrittenen oder metastasierten HER-2-positiven Mammakarzinom eingesetzt (Verma et al. 2012).

Für die Proteinisolation und im Zellviabilitätsassay wurden die gleichen Konzentrationen wie für Trastuzumab gewählt. In der Zelllinie LS513 zeigte sich nach der Behandlung mit T-DM1 kein Einfluss auf pAkt (s. Abb. 13A). Hingegen war in den Zelllinien LS1034 und SW837 eine starke Verminderung der pAkt-Level bereits bei sehr niedrigen Konzentrationen von T-DM1 zu erkennen (s. Abb. 13A). Die T-DM1-Behandlung minderte die Zellviabilität in allen Zelllinien deutlich dosis- (LS513: $p=4.1 \mathrm{e}-28$, LS1034: $p=1.5 \mathrm{e}-33$, SW837: $p=$ 2.9e-34) und zeitabhängig (LS513: $p=2.1 \mathrm{e}-09$, LS1034: $p=1.2 \mathrm{e}-10$, SW837: $p=5.6 \mathrm{e}-08$ ). Dieser Effekt war wesentlich stärker ausgeprägt als bei Trastuzumab oder Pertuzumab. Während bei LS513 und LS1034 der phänotypische Effekt erst bei T-DM1-Konzentrationen ab etwa $4 \mu \mathrm{g} / \mathrm{ml}$ beobachtet wurde, zeigte sich für SW837 bereits bei $0,4 \mu \mathrm{g} / \mathrm{ml}$ ein deutlicher Effekt auf die Zellviabilität (s. Abb. 13B).

LS513

A

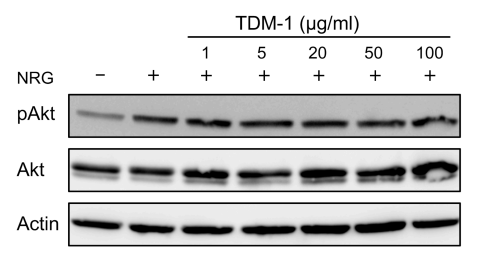

B

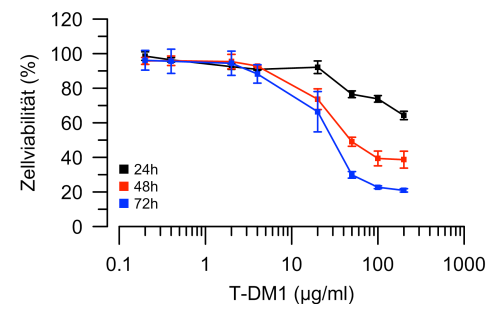

LS1034
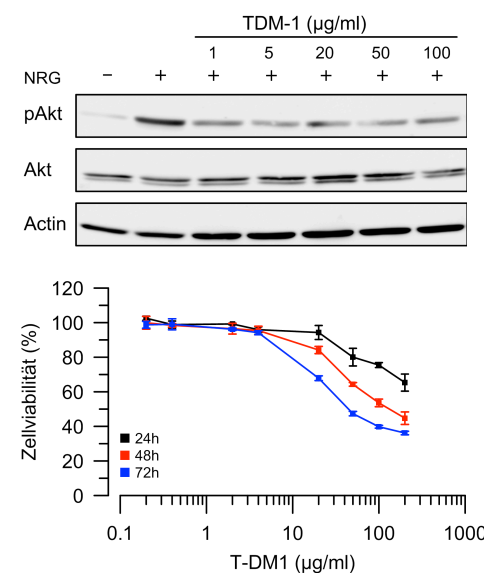

SW837
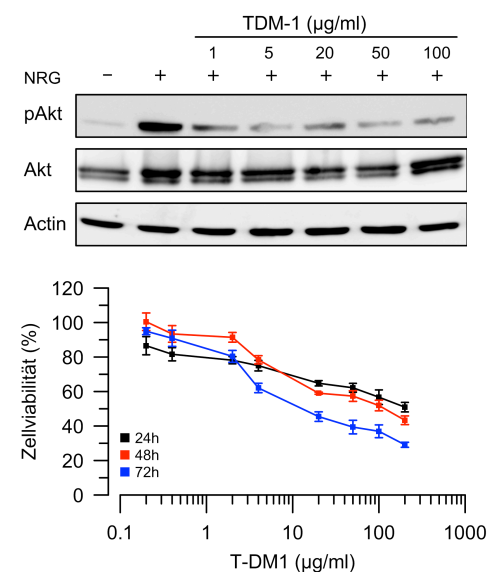

Abbildung 13: Western Blot (A) und Zellviabilitätsmessung (B) nach der Behandlung mit T-DM1 


\subsubsection{Lapatinib}

Lapatinib ist ein kleinmolekularer Inhibitor, der eine reversible Hemmung der intrazellulären Tyrosinkinasedomäne der Membranrezeptoren EGFR und HER-2 bewirkt (Spector et al. 2005). Die Substanz führt zur Zytostase und letztlich zur Apoptose der Zelle (Xia et al. 2002). Klinisch wird Lapatinib in der Therapie des metastasierten HER-2-positiven Mammakarzinoms eingesetzt (Geyer et al. 2006).

Die Konzentrationen von Lapatinib für die Proteinisolation wählten wir, basierend auf früheren Experimenten der Arbeitsgruppe, im Bereich zwischen 0,01-10 $\mu \mathrm{M}$. Für den Zellviabilitätsassay wurden Konzentrationen von 0,01-50 $\mu \mathrm{M}$ verwendet. Alle Zelllinien zeigten im Western Blot bereits bei sehr niedrigen Konzentrationen von Lapatinib eine deutliche Verminderung von pAkt (s. Abb. 14A). In allen Zelllinien zeigte sich auch im Zellviabilitätsassay nach der Behandlung mit Lapatinib ein signifikanter und phänotypisch sehr starker Effekt auf die Zellviabilität bezogen auf die Dosis (LS513: $p=7.2 \mathrm{e}-32$, LS1034: $p=6.1 \mathrm{e}$ 27, SW837: $p=1.4 \mathrm{e}-27$ ) und die Zeit (LS513: $p=0.00065$, LS1034: $p=0.00016$, SW837: $p=6.3 \mathrm{e}-07)$. Die stärkste Abnahme der Zellviabilität wurde in allen Zelllinien bei einer Konzentration von 1-50 $\mu \mathrm{M}$ detektiert. Nach 48 und 72 Stunden waren alle Zellen bei der Maximaldosis von $50 \mu \mathrm{M}$ depletiert, bei LS513 sogar schon nach 24 Stunden (s. Abb. 14B).

LS513

A

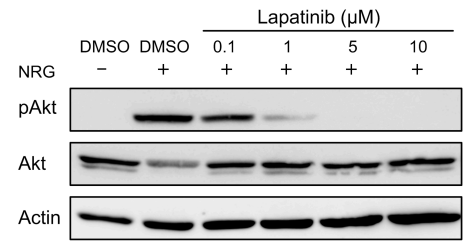

B

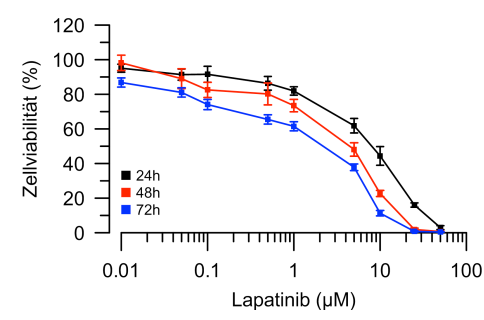

LS1034
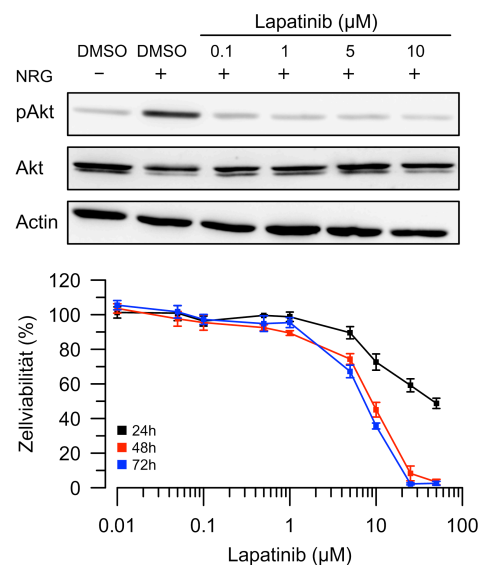

SW837
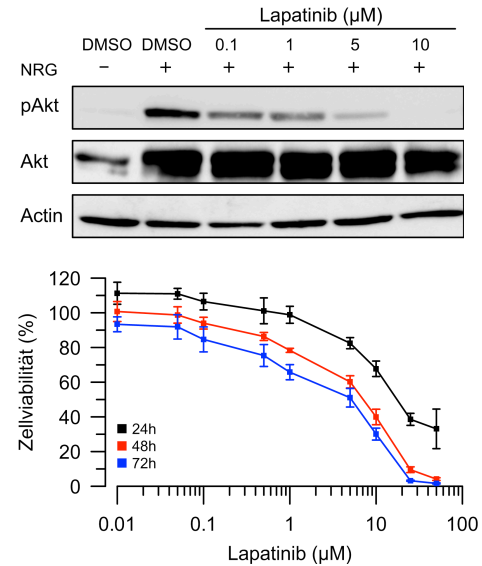

Abbildung 14: Western Blot (A) und Zellviabilitätsmessung (B) nach der Behandlung mit Lapatinib 


\subsubsection{Afatinib}

Afatinib ist, wie auch Lapatinib, ein kleinmolekularer Inhibitor der intrazellulären Domäne der Rezeptortyrosinkinasen. Neben HER-1 und HER-2 stellt jedoch auch HER-4 eine Zielstruktur dieses Wirkstoffes dar (Li et al. 2008). Da HER-3 keine eigene Tyrosinkinaseaktivität zeigt, jedoch aufgrund der Hemmung der anderen Mitglieder durch Afatinib vermindert transphosphoryliert wird, spricht man auch von einem pan-HER-Inhibitor. Im Gegensatz zu Lapatinib bindet Afatinib irreversibel an die intrazelluläre Domäne der Membranrezeptoren (Solca et al. 2012). Afatinib wird therapeutisch in der Erstlinientherapie beim metastasierten nicht-kleinzelligen Lungenkarzinom (NSCLC) mit EGFR-Mutationen eingesetzt (Dungo und Keating 2013).

Für Afatinib wurden sowohl für die Proteinisolation als auch für die Zellviabilitätsversuche die gleichen Konzentrationen wie für Lapatinib ausgewählt. Nach Behandlung mit Afatinib war im Western Blot ein deutlicher Einfluss auf das aktivierte, phosphorylierte Zielprotein Akt zu erkennen (s. Abb. 15A). Bereits eine geringe Konzentration bewirkte in allen Zelllinien eine Verminderung von pAkt, wobei der Effekt in der Zelllinie SW837 am stärksten war (s. Abb. 15A). Die Behandlung mit Afatinib zeigte einen phänotypischen Einfluss auf die Zellviabilität. Dieser war in allen Zelllinien sowohl bezogen auf die Dosis (LS513: $p=$ 1.7e-31, LS1034: $p=4.7 \mathrm{e}-34$, SW837: $p=1.9 \mathrm{e}-30$ ) als auch auf die Zeit (LS513: $p=1.7 \mathrm{e}-$ 31, LS1034: $p=0.00061$, SW837: $p=0.00076$ ) signifikant. Ähnlich der Therapie mit Lapatinib war der deutlichste Einfluss auf die Zellviabilität ab einer Konzentration von $1 \mu \mathrm{M} z \mathrm{u}$ beobachten. Bei den höchsten Dosierungen war auch nach der Behandlung mit Afatinib kaum noch eine messbare Zellviabilität vorhanden (s. Abb. 15B). 
LS513

A

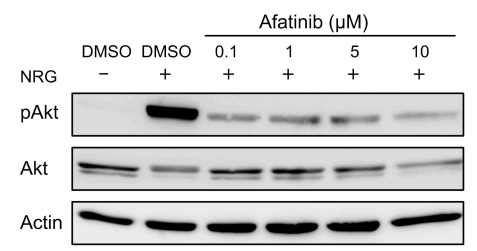

B

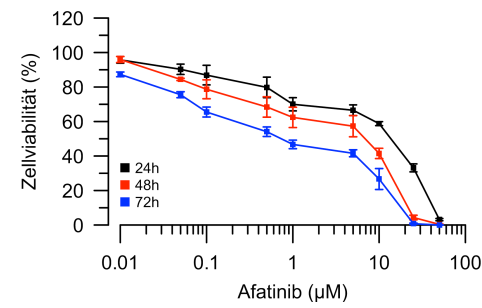

LS1034
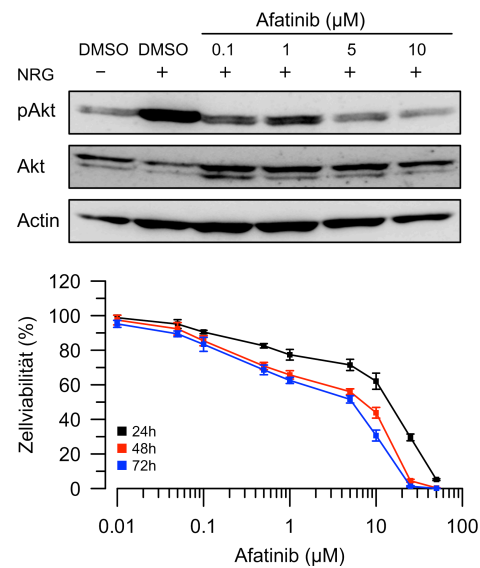

SW837
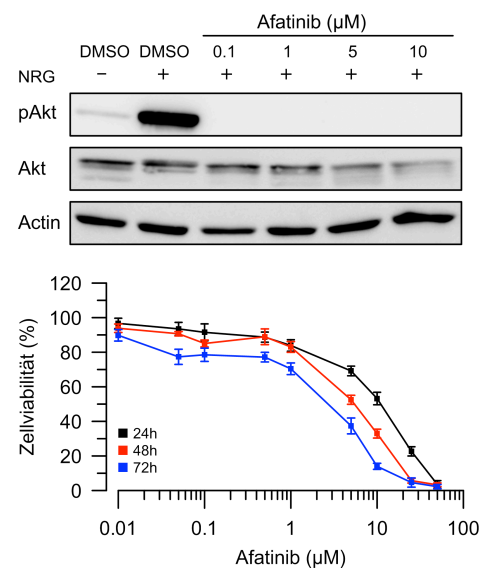

Abbildung 15: Western Blot (A) und Zellviabilitätsmessung (B) nach der Behandlung mit Afatinib

\subsubsection{Kombination Trastuzumab und Pertuzumab}

Wie zuvor aufgeführt, zeigten sich in der Monotherapie mit Trastuzumab und Pertuzumab keine phänotypisch relevanten Effekte auf die Zellviabilität und auch nur ein moderater Effekt auf die pAkt-Level (s. Abb. 11 und 12). Da beim Mammakarzinom bereits eine duale Antikörpertherapie gegen den HER-2-Rezeptor mittels Trastuzumab und Pertuzumab zur Anwendung kommt (Swain et al. 2015a), wurde die Kombinationstherapie auch in der vorliegenden Arbeit überprüft. Im Folgenden wurden daher aus den Ergebnissen der Western Blots (s. Abb. 11A und 12A) für jeden der beiden Antikörper eine niedrige und eine hohe Konzentration gewählt, welche dann mit ansteigenden Konzentrationen des anderen Antikörpers kombiniert wurden. Als niedrige Konzentration wurde für beide Antikörper $1 \mu \mathrm{g} / \mathrm{ml}$ gewählt. Die hohe Konzentration orientierte sich daran, dass im Western Blot ein deutlicher Einfluss auf das pAkt-Level zu sehen war. Folgende Dosierungen wurden ausgewählt:

- LS513: 1 bzw. $20 \mu \mathrm{g} / \mathrm{ml}$ Trastuzumab, 1 bzw. $20 \mu \mathrm{g} / \mathrm{ml}$ Pertuzumab

- LS1034: 1 bzw. $100 \mu \mathrm{g} / \mathrm{ml}$ Trastuzumab, 1 bzw. $50 \mu \mathrm{g} / \mathrm{ml}$ Pertuzumab

- $\quad$ SW837: 1 bzw. $20 \mu \mathrm{g} / \mathrm{ml}$ Trastuzumab, 1 bzw. $100 \mu \mathrm{g} / \mathrm{ml}$ Pertuzumab. 
Beide Konzentrationen des einen Antikörpers wurden nun sowohl für den Western Blot als auch im Zellviabilitätsassay mit der Verdünnungsreihe des anderen Antikörpers kombiniert.

\subsubsection{Trastuzumab kombiniert mit Pertuzumab}

Im Western Blot zeigte die Kombination einer festen Konzentration von $1 \mu \mathrm{g} / \mathrm{ml}$ Trastuzumab mit einer Pertuzumab-Verdünnungsreihe in allen drei Zelllinien einen dosisabhängigen deutlichen Einfluss auf pAkt (s. Abb. 16A). Im Zellviabilitätsassay waren die Ergebnisse in allen drei Zelllinien dosisabhängig zwar statistisch signifikant (LS513: $p=1.8 \mathrm{e}-25$, LS1034: $p=6.3 \mathrm{e}-24$, SW837: $p=6.8 \mathrm{e}-20)$, jedoch gab es keine phänotypisch relevante Reduktion der Zellviabilität (s. Abb. 16B). Auch über die verschiedenen Messzeitpunkte konnten für die Zelllinien LS513 und SW837 zwar signifikante Unterschiede errechnet werden (LS513: $p=1.2 \mathrm{e}-12$, SW837: $p=1.4 \mathrm{e}-08$ ), jedoch erschien die Zellviabilität nicht deutlich verändert. Für LS1034 ergab sich kein signifikanter Unterschied über die Zeit ( $p=$ 0.02) (s. Abb. 16B).

LS513

A

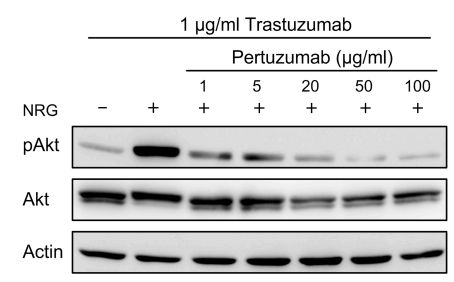

B

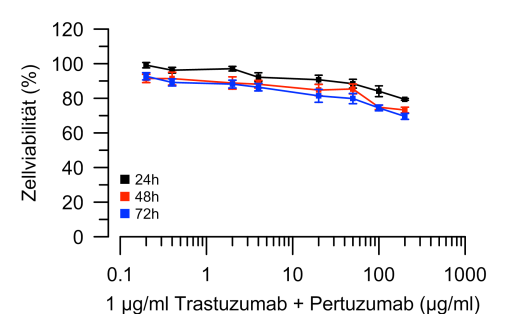

LS1034
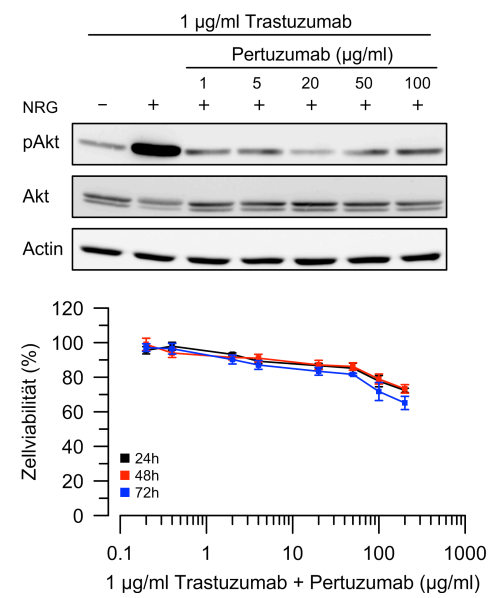

SW837

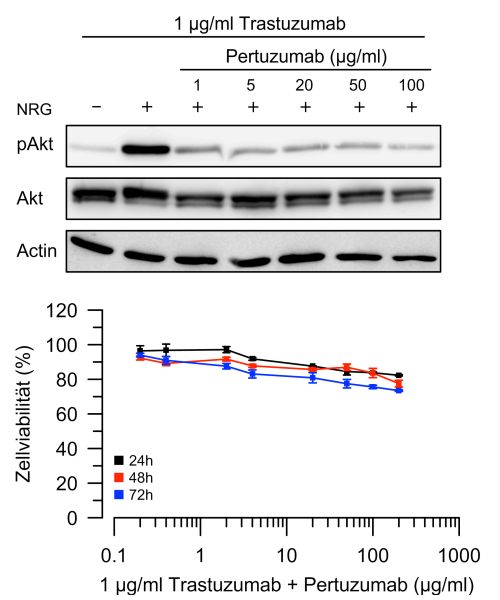

Abbildung 16: Western Blots (A) und Zellviabilitätsmessungen (B) nach Behandlung mit $1 \mu \mathrm{g} / \mathrm{ml}$ Trastuzumab und Pertuzumab

Wie erwartet, zeigte sich auch für die höhere Dosierung von Trastuzumab $(20 \mu \mathrm{g} / \mathrm{ml}$ bei LS513 und SW837 bzw. $100 \mu \mathrm{g} / \mathrm{ml}$ bei LS1034) in Verbindung mit einer PertuzumabVerdünnungsreihe im Western Blot eine deutliche Reduzierung der pAkt-Level in den drei 
Zelllinien (s. Abb. 17A). Es zeigte sich kein relevanter Unterschied zwischen der Behandlung mit der niedrigen $(1 \mu \mathrm{g} / \mathrm{ml})$ und der hohen Konzentration (20 bzw. $100 \mu \mathrm{g} / \mathrm{ml})$ Trastuzumab mit der Pertuzumab-Verdünnungsreihe. Folglich ist auch durch Erhöhung der Konzentration kein stärkerer Effekt auf den untergeordneten Signalweg zu erzielen. Im Zellviabilitätsversuch führte die Kombination von $20 \mu \mathrm{g} / \mathrm{ml}$ Trastuzumab mit aufsteigenden Konzentrationen Pertuzumab für die Zelllinien LS513 und SW837 zu signifikanten, jedoch phänotypisch lediglich kleinen Unterschieden über die Dosis (LS513: $p=1.1 \mathrm{e}-19$, SW837: $p=5.6 \mathrm{e}-22$ ) und Dauer der Therapie (LS513: $p=9.9 \mathrm{e}-10$, SW837: $p=1.1 \mathrm{e}-09$ ). Für LS1034 zeigte sich nach Behandlung mit $100 \mu \mathrm{g} / \mathrm{ml}$ Trastuzumab in Kombination mit Pertuzumab eine dosisabhängig signifikante, jedoch minimale Reduktion der Zellviabilität ( $p=8.9 \mathrm{e}$ 16). Zeitabhängig lag für LS1034 kein signifikanter Effekt vor ( $p=0.18)$ (s. Abb. 17B). Es konnte also auch durch Dosissteigerung von Trastuzumab keine phänotypisch relevante Effektivitätssteigerung auf Ebene der Zellviabilität erzielt werden.

LS513

A

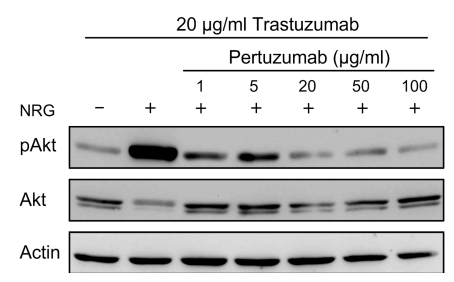

B

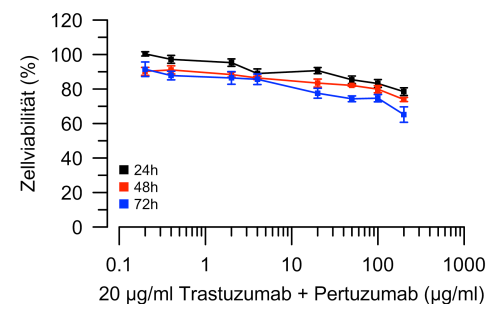

LS1034
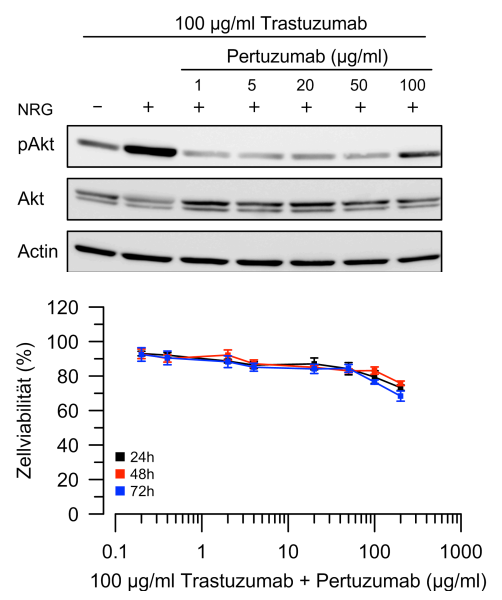

SW837
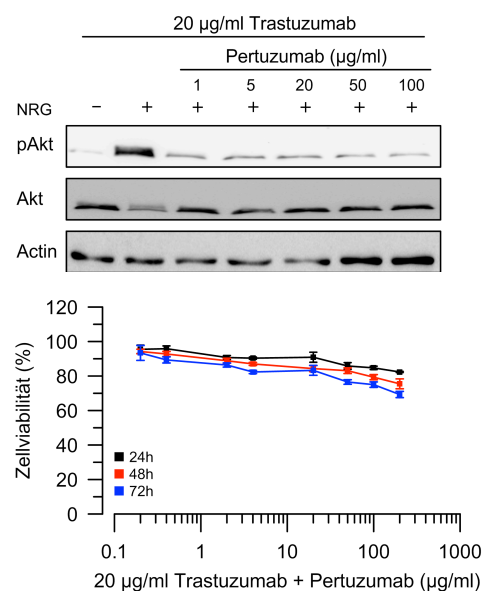

Abbildung 17: Western Blots (A) und Zellviabilitätsmessungen (B) nach Behandlung mit $20 \mathrm{bzw} .100 \mathrm{\mu g} / \mathrm{ml}$ Trastuzumab und Pertuzumab

\subsubsection{Pertuzumab kombiniert mit Trastuzumab}

Bei der Kombination von $1 \mu \mathrm{g} / \mathrm{ml}$ Pertuzumab mit einer Trastuzumab-Verdünnungsreihe stellte sich in allen Zelllinien eine deutliche dosisabhängige Verminderung von pAkt im Western Blot dar (s. Abb. 18A). Die alleinige Therapie mit einer TrastuzumabVerdünnungsreihe war im Vergleich dazu nicht effektiv (s. Abb. 11, S. 53). Im Zellviabili- 
tätsassay erbrachte die Behandlung mit $1 \mu \mathrm{g} / \mathrm{ml}$ Pertuzumab und der TrastuzumabVerdünnungsreihe für alle Zelllinien signifikante, aber phänotypisch nur geringe Unterschiede der Zellviabilität über die Dosierung (LS513: $p=1.1 \mathrm{e}-16$, LS1034: $p=8.7 \mathrm{e}-15$, SW837: $p=1.8 \mathrm{e}-20$ ) und die Messzeitpunkte (LS513: $p=0.015$, LS1034: $p=0.006$, SW837: $p=3 \mathrm{e}-04)$ (s. Abb. 18B).

LS513

A

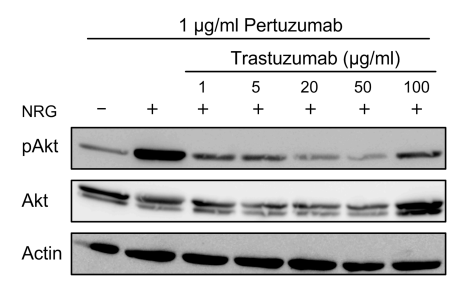

B

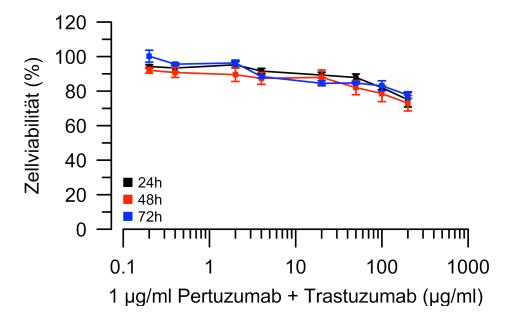

LS1034
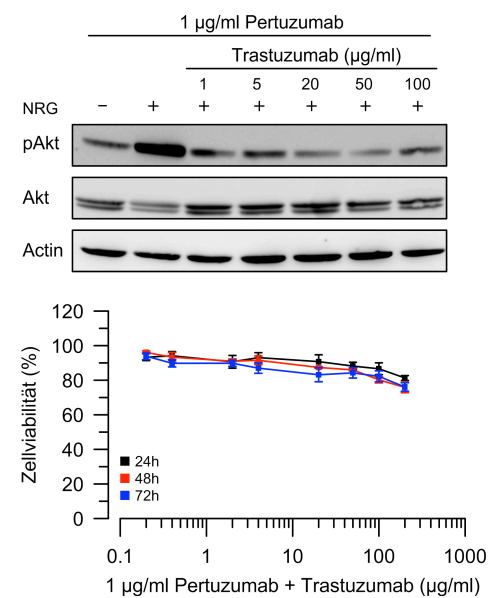

SW837
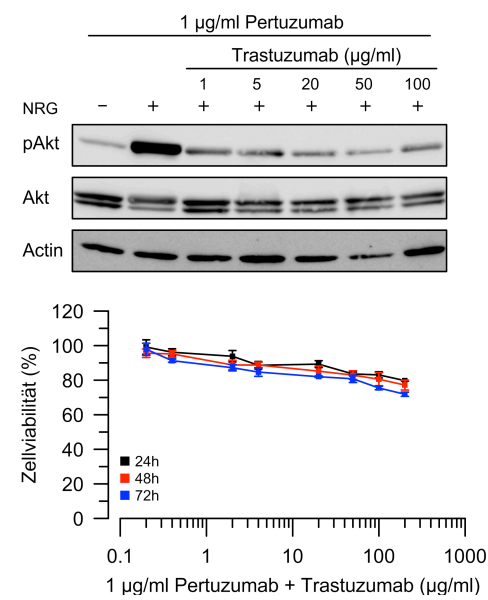

Abbildung 18: Western Blots (A) und Zellviabilitätsmessungen (B) nach Behandlung mit $1 \mu \mathrm{g} / \mathrm{ml}$ Pertuzumab und Trastuzumab

Im Western Blot zeigte sich in allen Zelllinien ein deutlicher Unterschied zwischen der niedrigen $(1 \mu \mathrm{g} / \mathrm{ml})$ und der hohen Dosis Pertuzumab $(20 \mu \mathrm{g} / \mathrm{ml}$ für LS513, $50 \mu \mathrm{g} / \mathrm{ml}$ für LS1034 und $100 \mu \mathrm{g} / \mathrm{ml}$ für SW837) in Kombination mit einer TrastuzumabVerdünnungsreihe (s. Abb. 18A und 19A). Das bedeutet, dass eine Steigerung der Pertuzumab-Dosis zu einer Effektivitätssteigerung in der Inhibierung von pAkt führte. Die Kombination von $20 \mu \mathrm{g} / \mathrm{ml}$ Pertuzumab mit Trastuzumab führte bei LS513 zu einem dosisabhängigen ( $p=5.4 \mathrm{e}-20)$, nicht jedoch zeitabhängigen $(p=0.49)$ signifikanten Unterschied in der Zellviabilität. LS1034 wurde mit 50 $\mathrm{gg} / \mathrm{ml}$ Pertuzumab und SW837 mit $100 \mu \mathrm{g} / \mathrm{ml}$ Pertuzumab in Kombination mit Trastuzumab behandelt. Dies führte über die Dosis (LS1034: $p=8.5 \mathrm{e}-16$, SW837: $p=6.3 \mathrm{e}-22$ ) und die Zeit (LS1034: $p=0.015$, SW837: $p=$ 1.3e-05) zu einem signifikanten, jedoch phänotypisch nur geringen Unterschied der Zellviabilität (s. Abb. 19B). Im Vergleich zur Kombination von $1 \mu \mathrm{g} / \mathrm{ml}$ Pertuzumab mit Trastuzumab konnte auf Ebene der Zellviabilität keine Effektivitätssteigerung durch Dosissteigerung gezeigt werden (s. Abb. 18B und 19B). 
LS513

A

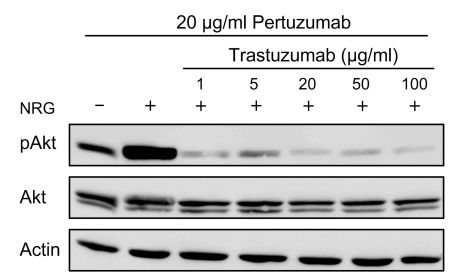

B

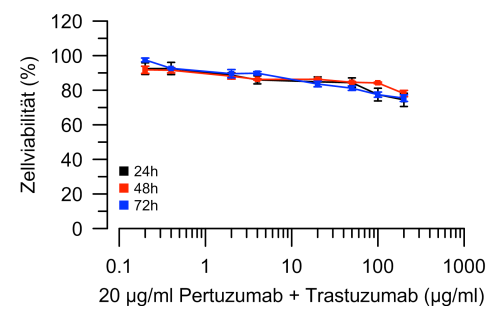

LS1034
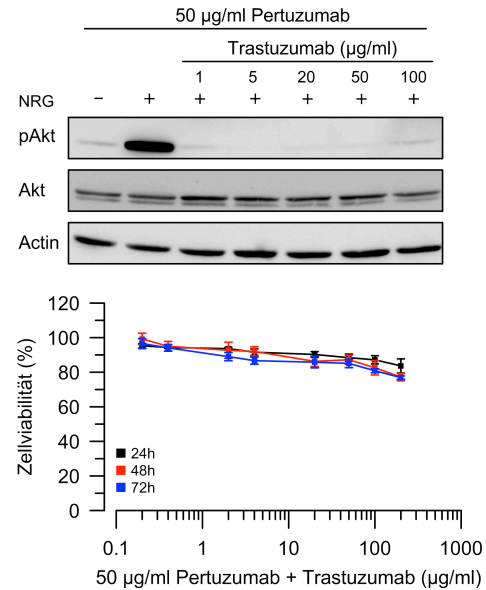

SW837
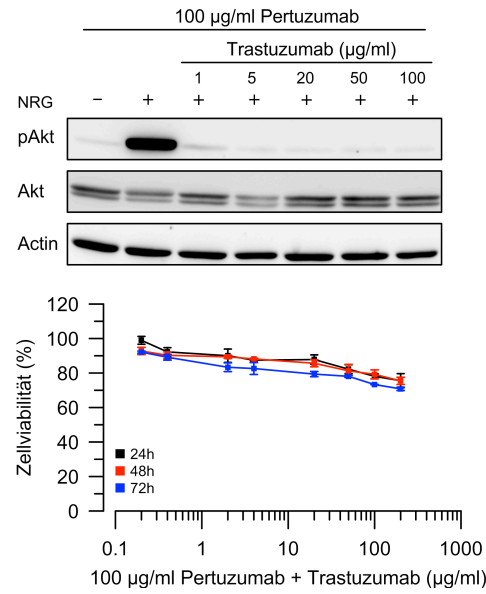

Abbildung 19: Western Blots (A) und Zellviabilitätsmessungen (B) nach Behandlung mit 20, 50 bzw. $100 \mu \mathrm{g} / \mathrm{ml}$ Pertuzumab und Trastuzumab

Zusammenfassend zeigte sich im Western Blot also ein deutlicher Einfluss durch Kombination von Pertuzumab und Trastuzumab auf das pAkt-Level. Im Fall der festen Konzentration von Trastuzumab gab es keinen relevanten Unterschied zwischen einer niedrigen und hohen Konzentration (s. Abb. 16A und 17A). Im Fall der festen Konzentration von Pertuzumab zeigte die höhere Konzentration einen deutlicheren Einfluss auf pAkt (s. Abb. 18A und 19A). Im Zellviabilitätsassay wurde zusammenfassend in allen Zelllinien nach der Behandlung mit einer Kombinationen aus Trastuzumab und Pertuzumab kein maßgeblicher Einfluss beobachtet. Selbst bei sehr hohen Antikörperkonzentrationen zeigte sich die Zellviabilität nur geringfügig vermindert. Es konnte kein relevanter Unterschied zwischen einer niedrigen und hohen Konzentration eines Antikörpers dargestellt werden (s. Abb. 16B und 17B sowie 18B und 19B).

An dieser Stelle sollte darauf hingewiesen werden, dass eine statistische Varianzanalyse der einzelnen Regressionskurven zum Vergleich der Effektivität zwischen einer Monotherapie und einer Kombinationstherapie, wie nachfolgend für einige Kombinationen der Anti-HER-2-Substanzen mit 5-FU und Oxaliplatin durchgeführt, an dieser Stelle nicht sinnvoll erscheint. Die effektive Konzentration, die theoretisch zu einer Viabilitätsverringerung von $50 \%\left(\mathrm{EC}_{50}\right)$ führen würde, liegt zu jedem Zeitpunkt weit außerhalb des Messbereichs und hätte daher nur mathematisch geschätzt werden können. 


\subsubsection{Kombination der Anti-HER-2-Substanzen mit 5-FU und Oxaliplatin}

\subsubsection{Etablierung eines Chemotherapie-Protokolls}

Die gängigen Chemotherapieprotokolle in der Therapie des fortgeschrittenen kolorektalen Karzinoms beinhalten in der Regel die Chemotherapeutika 5-FU und Oxaliplatin (Schmiegel et al. 2017). Diese Substanzen wurden daher nachfolgend in Kombination mit den Anti-HER-2-Substanzen verwendet.

In früheren Experimenten unserer Arbeitsgruppe wurden Dosis-Wirkungs-Kurven von 5FU für alle drei Zelllinien erstellt (daher hier nicht dargestellt). Anhand dieser Daten wurden die Dosierungen für 5-FU festgelegt (Spitzner et al. 2010). Für diese Arbeit wurde nun eine Monotherapie mit Oxaliplatin durchgeführt. Nach der Behandlung mit Oxaliplatin zeigten alle Zelllinien eine deutliche und signifikante dosisabhängige Reduktion der Zellviabilität (LS513: $p=2 \mathrm{e}-37$, LS1034: $p=2.3 \mathrm{e}-31$, SW837: $p=1.2 \mathrm{e}-26)$. Über die Messzeitpunkte waren die Ergebnisse signifikant für LS513 und LS1034, nicht jedoch für SW837 (LS513: $p=2.3 \mathrm{e}-15$, LS1034: $p=4.5 \mathrm{e}-13$; SW837: $p=0.1$ ) (s. Abb. 20). Dies bedeutet, dass sich für SW837 keine Zunahme des Effektes mit längerer Inkubationszeit zeigte (s. Abb. 20).

LS513

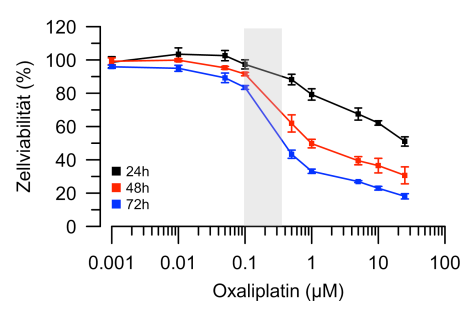

LS1034

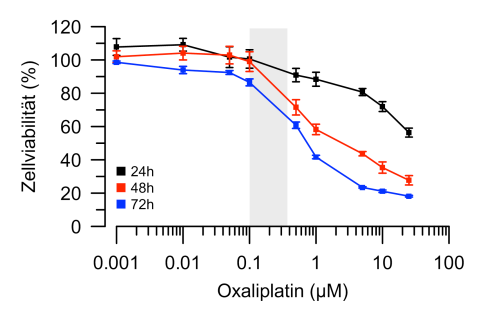

SW837

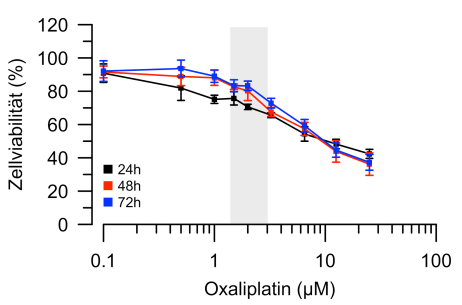

Abbildung 20: Zellviabilitätsmessungen nach Behandlung mit Oxaliplatin

Der graue Balken markiert den Konzentrationsbereich, bei welchen die Zellviabilität auf etwa $60-80 \%$ reduziert ist.

Aus den Ergebnissen dieser Zellviabilitätsmessungen wurden zwei Konzentrationen 5-FU und zwei Konzentrationen Oxaliplatin ausgewählt, zwischen denen die Zellviabilität auf etwa 60 bis $80 \%$ reduziert war. In diesem Bereich wiesen die Messungen einen relativ deutlichen Abfall der Viabilität auf, weshalb jeweils zwei Dosierungen zum Vergleich ausgewählt wurden. Für die Zelllinien LS513 und LS1034 handelte es sich jeweils um 0,25 und 


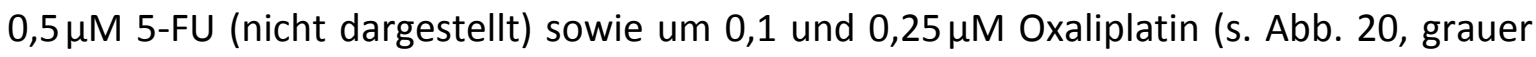
Längsbalken). Für die Zelllinie SW837 wurden Konzentrationen von 3 und $6 \mu \mathrm{M}$ 5-FU (nicht dargestellt) sowie 1,5 und $3 \mu \mathrm{M}$ Oxaliplatin (s. Abb. 20, grauer Längsbalken) gewählt. Diese Konzentrationen wurden nun mit einer Verdünnungsreihe des jeweils anderen Chemotherapeutikums kombiniert (s. Abb. 21 und 22). Anschließend wurde für jedes Chemotherapeutikum eine Konzentration ausgewählt, die dann für die Kombinationsexperimente mit den Anti-HER-2-Substanzen (5-FU + Oxalipaltin + Anti-HER-2-Substanz) eingesetzt wurden.

Grundsätzlich zeigte sich, dass die Chemotherapeutika auf die Zelllinien LS513 und LS1034 deutlich toxischer wirkten als auf die Zelllinie SW837, weshalb die Dosierungen insgesamt in einem niedrigeren Konzentrationsbereich gewählt wurden (s. Tabelle 5 und 6, S. 45). Die Behandlung mit der festen Konzentration Oxaliplatin kombiniert mit einer 5-FU-Verdünnung zeigte signifikante Effekte über die Dosis (LS513: 0,1 $\mu \mathrm{M}, p=6.3 \mathrm{e}-54$; $0,25 \mu \mathrm{M}, p=9.7 \mathrm{e}-44 /$ LS1034: 0,1 $\mu \mathrm{M}, p=1.6 \mathrm{e}-53 ; 0,25 \mu \mathrm{M}, p=1.4 \mathrm{e}-47 /$ SW837: 1,5 $\mu \mathrm{M}$, $p=4.3 \mathrm{e}-20 ; 3 \mu \mathrm{M}, p=2.7 \mathrm{e}-20$ ) und die Zeit (LS513 0,1 $\mu \mathrm{M}, p=1.2 \mathrm{e}-34 ; 0,25 \mu \mathrm{M}, p=9.6 \mathrm{e}-$ 31/ LS1034: 0,1 $\mu \mathrm{M}, p=3.1 \mathrm{e}-32 ; 0,25 \mu \mathrm{M}, p=1.6 \mathrm{e}-29 / \mathrm{SW} 837: 1,5 \mu \mathrm{M}, p=9 \mathrm{e}-04 ; 3 \mu \mathrm{M}$, $p=4.2 \mathrm{e}-16)$ (s. Abb. 21A und B).

LS513

A

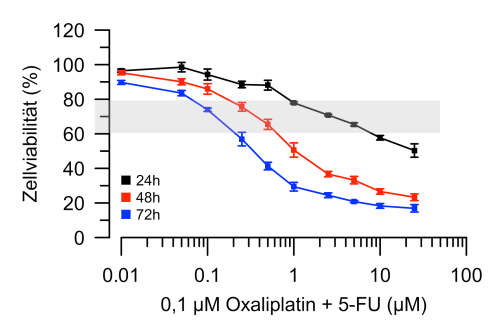

B

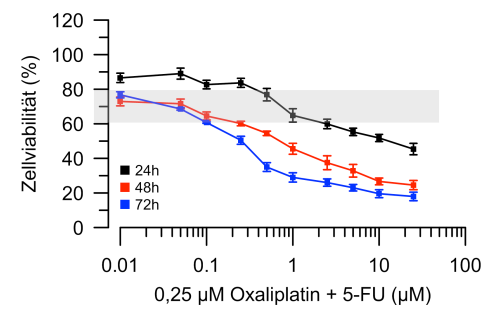

LS1034
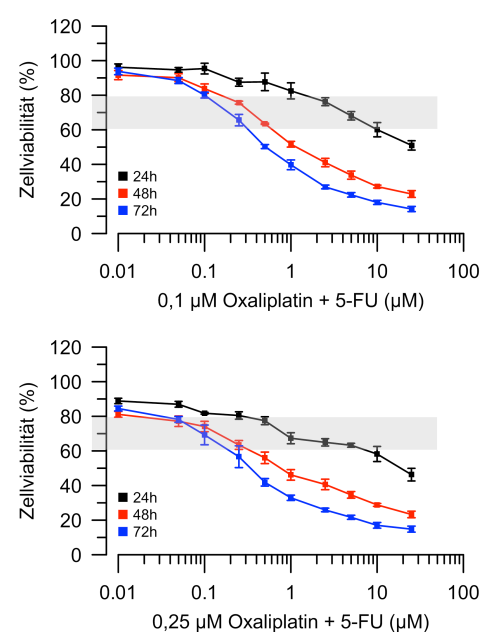

SW837
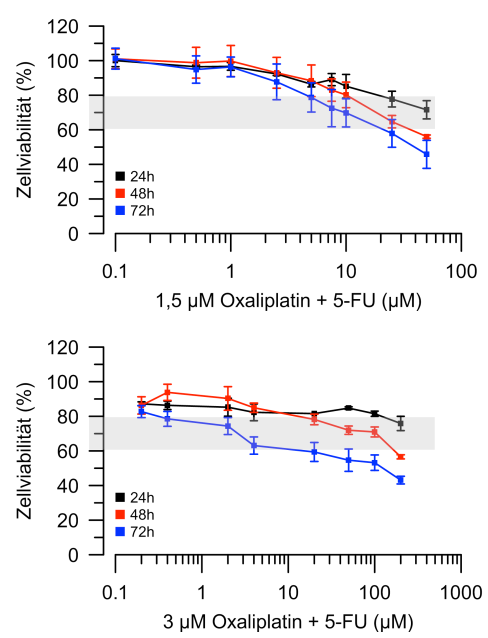

Abbildung 21: Zellviabilitätsmessungen nach Behandlung mit 0,1 bzw 1,5 $\mu \mathrm{M}$ Oxaliplatin + 5-FU (A) sowie 0,25 bzw. $3 \mu \mathrm{M}$ Oxaliplatin + 5-FU (B)

Der graue Balken markiert den Bereich der Zellviabilität bei $60-80 \%$. 
Ebenfalls zeigten sich signifikante Effekte für die Kombination der festen Konzentration 5-FU mit Oxaliplatin über Dosis (LS513: 0,25 $\mu \mathrm{M}, p=2 \mathrm{e}-49 ; 0,5 \mu \mathrm{M}, p=5.8 \mathrm{e}-51 / \mathrm{LS} 1034$ : $0,25 \mu \mathrm{M}, p=7.6 \mathrm{e}-52 ; 0,5 \mu \mathrm{M}, p=2 \mathrm{e}-53 / \mathrm{SW} 837: 3 \mu \mathrm{M}, p=2.9 \mathrm{e}-26 ; 6 \mu \mathrm{M}, p=4.6 \mathrm{e}-24)$ und Zeit (LS513: $0,25 \mu \mathrm{M}, p=7.8 \mathrm{e}-26 ; 0,5 \mu \mathrm{M}, p=3.8 \mathrm{e}-42 /$ LS1034: $0,25 \mu \mathrm{M}, p=2.6 \mathrm{e}-25$; $0,5 \mu \mathrm{M}, p=1.3 \mathrm{e}-39 / \mathrm{SW} 837: 3 \mu \mathrm{M}, p=7.4 \mathrm{e}-11 ; 6 \mu \mathrm{M}, p=5.3 \mathrm{e}-09)$ (s. Abb. 22A und B).

LS513

A

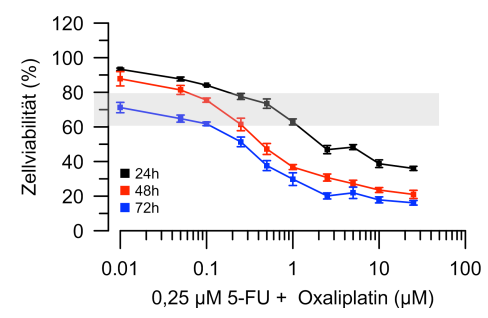

B

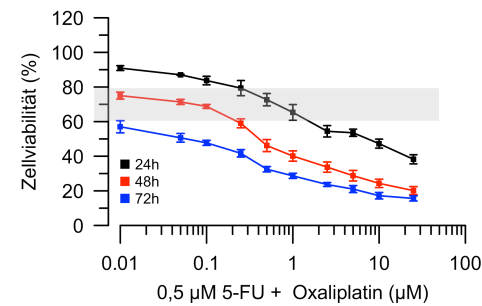

LS1034
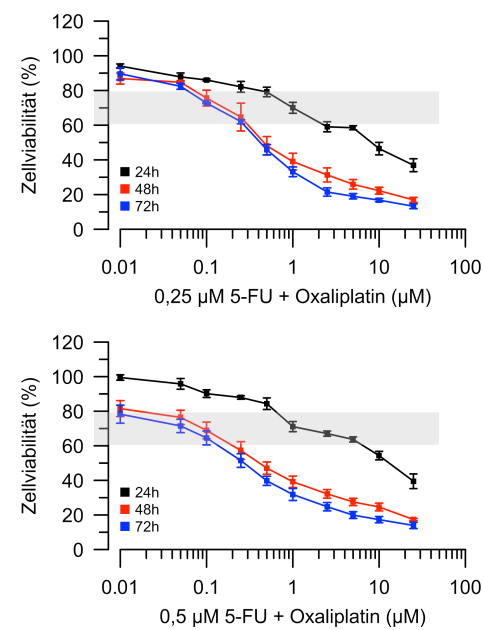

SW837
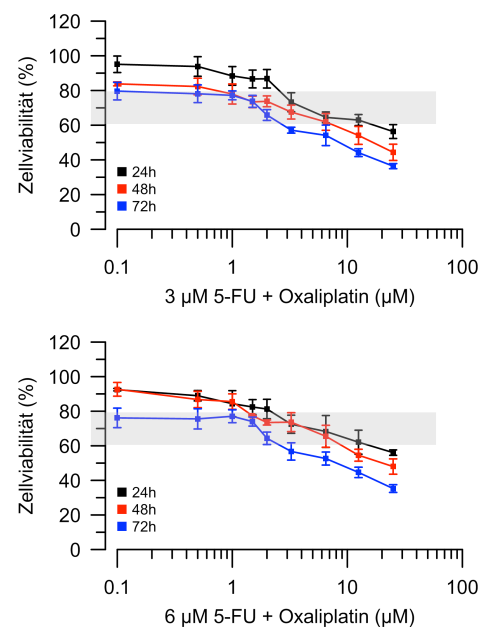

Abbildung 22: Zellviabilitätsmessungen nach Behandlung mit 0,25 bzw. $3 \mu \mathrm{M}$ 5-FU + Oxaliplatin (A) sowie 0,5 bzw. $6 \mu \mathrm{M}$ 5-FU + Oxaliplatin (B)

Der graue Balken markiert den Bereich der Zellviabilität bei $60-80 \%$.

Erneut wurden nun anhand der Dosis-Wirkungs-Kurven Konzentrationen der Chemotherapeutika ausgewählt, welche als Kombinationschemotherapie mit den Anti-HER-2Substanzen für die folgenden Experimente verwendet werden sollten. Dabei wurde als Ziel die Zellviabilität im Bereich von etwa 60-80\% nach Behandlung mit 5-FU und Oxaliplatin angestrebt (s. Abb. 21 und 22, grauer Querbalken). Für die weiteren Experimente wurden folgende Konzentrationen ausgewählt:

- LS513: 0,25 $\mu \mathrm{M}$ 5-FU und 0,1 $1 \mu \mathrm{M}$ Oxaliplatin

- LS1034: 0,25 $\mu \mathrm{M}$ 5-FU und 0,25 $\mu \mathrm{M}$ Oxaliplatin

- SW837: $6 \mu \mathrm{M}$ 5-FU und $3 \mu \mathrm{M}$ Oxaliplatin. 


\subsubsection{Trastuzumab mit 5-FU und Oxaliplatin}

Nach der Kombinationsbehandlung mit 5-FU, Oxaliplatin und Trastuzumab zeigte sich zwar ein statistisch signifikanter dosisabhängiger Einfluss auf die Zellviabilität (LS513: $p=$ 5.1e-13, LS1034: $p=1.3 \mathrm{e}-09$, SW837: $p=1.1 \mathrm{e}-08)$, der aber wie auch nach alleiniger Antikörpertherapie phänotypisch nicht relevant war (s. Abb. 23). Es war eine Parallelverschiebung über die Zeit bei den Zelllinien LS513 und LS1034 zu erkennen. Der phänotypische Unterschied über die Messzeitpunkte war gering, jedoch statistisch signifikant für die Zelllinien LS513 ( $p=8.4 \mathrm{e}-28)$ und LS1034 ( $p=5 \mathrm{e}-28)$.

LS513

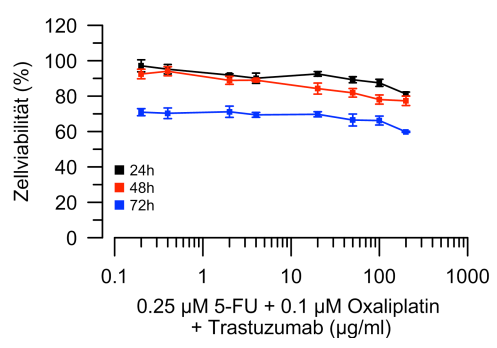

LS1034

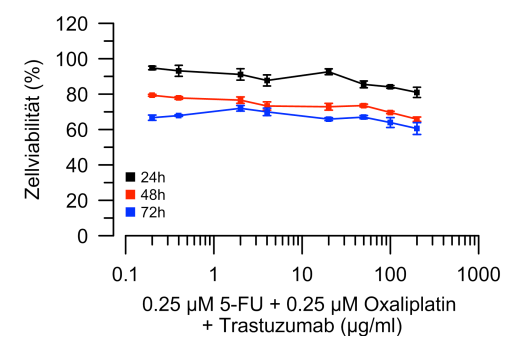

SW837

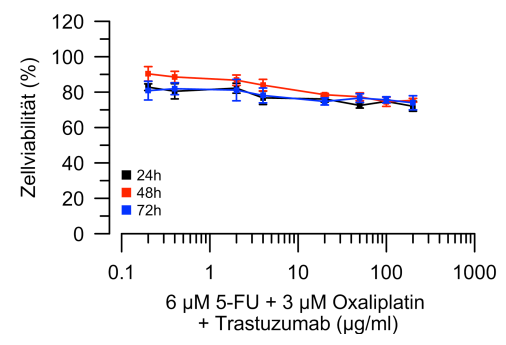

Abbildung 23: Zellviabilitätsmessung nach der Behandlung mit Trastuzumab, 5-FU und Oxaliplatin

Eine statistische Auswertung der Regressionskurven der Monotherapie mit Trastuzumab im Vergleich zur Kombinationstherapie mit 5-FU und Oxaliplatin wurde nicht durchgeführt, da die halbmaximale effektive Konzentration $\left(\mathrm{EC}_{50}\right)$ hätte geschätzt werden müssen und weit außerhalb des Messbereichs läge.

\subsubsection{Pertuzumab mit 5-FU und Oxaliplatin}

Die Kombination des Antikörpers Pertuzumab mit den Chemotherapeutika 5-FU und Oxaliplatin bewirkte wie bei Trastuzumab keinen phänotypisch relevanten, jedoch mathematisch signifikanten Einfluss auf die Zellviabilität der Zelllinien LS513 und LS1034 in Bezug auf die Dosis (LS513: $p=3.3 \mathrm{e}-07$, LS1034: $p=4.6 \mathrm{e}-10$ ) und die Therapiedauer (LS513: $p=1.9 \mathrm{e}-28$, LS1034: $p=5.5 \mathrm{e}-36)$ (s. Abb. 24). 
LS513

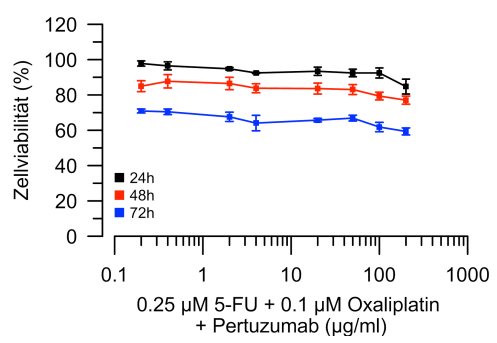

LS1034

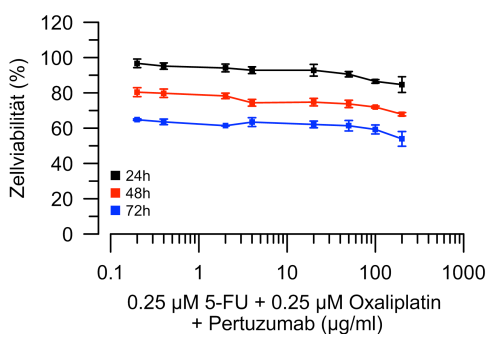

SW837

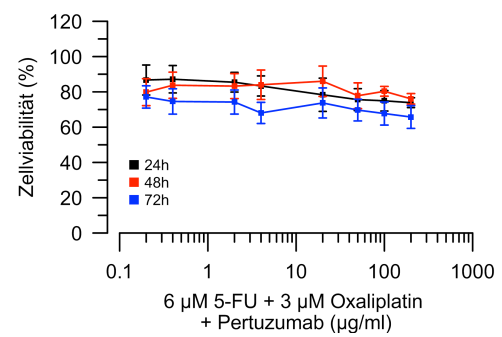

Abbildung 24: Zellviabilitätsmessung nach der Behandlung mit Pertuzumab, 5-FU und Oxaliplatin

Für den Vergleich der Regressionskurven der Monotherapie mit Pertuzumab und der Kombinationstherapie mit 5-FU und Oxaliplatin gilt ebenfalls, dass die mathematisch errechneten $\mathrm{EC}_{50}$-Werte weit außerhalb des Messbereichs lägen, so dass auf eine Darstellung verzichtet wurde.

\subsubsection{T-DM1 mit 5-FU und Oxaliplatin}

Aufgrund des starken Abfalls der Zellviabilität im Bereich zwischen etwa 4 und $20 \mu \mathrm{g} / \mathrm{ml}$ T-DM1 (s. Abb. 13, S. 55) wurde für die Kombination mit 5-FU und Oxaliplatin für die Zelllinien LS513 und LS1034 mit 7,5 $\mu \mathrm{g} / \mathrm{ml}$ ein zusätzlicher Messpunkt ergänzt. Auch wurden diese Zelllinien mit einer neuen Höchstdosis von $400 \mu \mathrm{g} / \mathrm{ml}$ inkubiert, um den weiteren dosisabhängigen Einfluss auf die Zellviabilität genauer beobachten zu können.

Auch nach der Kombinationstherapie mit T-DM1, 5-FU und Oxaliplatin zeigte sich ein signifikanter dosisabhängiger Effekt (LS513: $p=3.9 \mathrm{e}-36$, LS1034: $p=8.9 \mathrm{e}-37$, SW837: $p=$ 2.9e-19), insbesondere ab einer T-DM1-Konzentration von $4 \mu \mathrm{g} / \mathrm{ml}$ (s. Abb. 25). Ebenfalls ergab sich ein deutlicher zeitabhängiger Effekt in allen drei Zelllinien (LS513: $p=5 e-28$, LS1034: $p=3.8 \mathrm{e}-31$, SW837: $p=2.1 \mathrm{e}-17)$, welcher phänotypisch relevant war. 
LS513

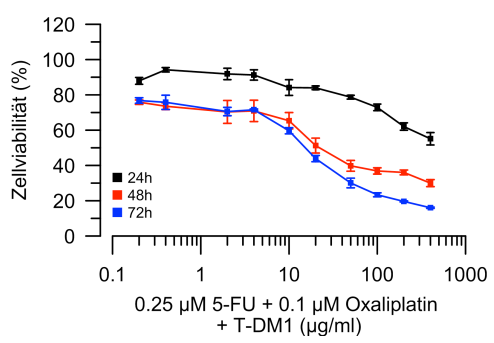

LS1034

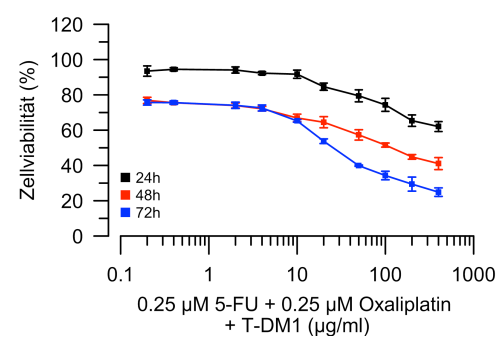

SW837

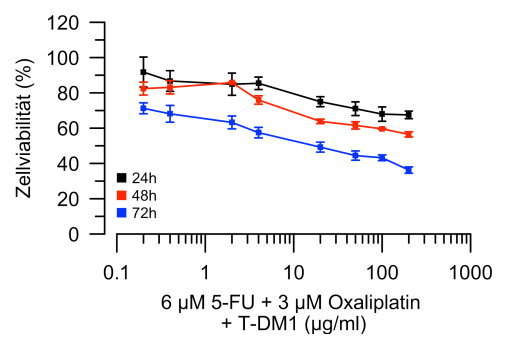

Abbildung 25: Zellviabilitätsmessung nach der Behandlung mit T-DM1, 5-FU und Oxaliplatin

Für die Substanz T-DM1 erfolgte nun anhand der logistischen Regressionskurven ein statistischer Vergleich der Effektivität zwischen der Monotherapie und der Kombinationstherapie. Hierfür wurde eine Varianzanalyse mittels ANOVA durchgeführt, und es wurden p-Werte für die Signifikanzbeurteilung errechnet. Dies bedeutet, dass die effektive Konzentration von T-DM1 bei einer Viabilitätsverringerung von $50 \%\left(\mathrm{EC}_{50}\right)$ zwischen der Monotherapie und der Kombination mit 5-FU und Oxaliplatin verglichen wurde.

Im Vergleich zur Monotherapie bewirkte die Kombinationstherapie eine signifikante Änderung der Zellviabilität. Eine Steigerung der Effektivität zugunsten der Kombinationstherapie zeigte sich in den Zelllinien LS513 und LS1034 bei 48 und 72 Stunden sowie in der Zelllinie SW837 bei 72 Stunden (LS513: $p=2.5 \mathrm{e}-58$, LS1034: $p=7 \mathrm{e}-69$, SW837: $p=1.2 \mathrm{e}-$ 54). Zu den anderen Zeitpunkten erschien die Monotherapie der Kombinationstherapie überlegen (s. Abb. 26). Durch die Kombinationstherapie konnte die Effektivität der Therapie mit T-DM1 also teilweise gesteigert werden, was sich durch eine niedrigere $\mathrm{EC}_{50}$ über bestimmte Zeitpunkte zeigte.

LS513: Nach 24 Stunden sowohl Mono- als auch Kombinationstherapie lagen die mathematisch errechneten $\mathrm{EC}_{50}$-Werte weit außerhalb des Messbereichs. Nach 48 Stunden ergab sich für die Monotherapie eine $\mathrm{EC}_{50}$ von $72,4 \mu \mathrm{g} / \mathrm{ml}$, für die Kombinationstherapie von $27,7 \mu \mathrm{g} / \mathrm{ml}$. Bei 72 Stunden lag die $\mathrm{EC}_{50}$ der Monotherapie bei 25,8 $\mu \mathrm{g} / \mathrm{ml}$ und für die Kombinationstherapie bei $11,7 \mu \mathrm{g} / \mathrm{ml}$ (s. Tabelle 10, S. 99). Somit zeigte sich die Kombinationstherapie effektiver. LS1034: Nach 24 Stunden konnten auch hier nur EC 50 -Werte geschätzt werden. Nach 48 Stunden ergaben sich eine $\mathrm{EC}_{50}$ von $159 \mu \mathrm{g} / \mathrm{ml}$ für die Monotherapie und $142 \mu \mathrm{g} / \mathrm{ml}$ für die Kombinationstherapie. Nach 72 Stunden betrug die $\mathrm{EC}_{50}$ 
$61,7 \mu \mathrm{g} / \mathrm{ml}$ nach Monotherapie und $23,3 \mu \mathrm{g} / \mathrm{ml}$ nach Kombinationstherapie. Die Kombinationstherapie war somit der Monotherapie überlegen (s. Tabelle 11, S. 99). Für die Zelllinie SW837 waren nach 24 und 48 Stunden die EC $_{50}$-Werte geringer nach Monotherapie, wobei die Kombinationstherapie nach 24 und 48 Stunden $E_{50}$-Werte außerhalb des Messbereichs lagen. Nach 72 Stunden war jedoch die Kombinationstherapie mit einer $\mathrm{EC}_{50}$ von $18,2 \mu \mathrm{g} / \mathrm{ml}$ geringfügig niedriger als die der Monotherapie mit 19,8 $\mathrm{gg} / \mathrm{ml}$ (s. Tabelle 12, S. 100).

LS513

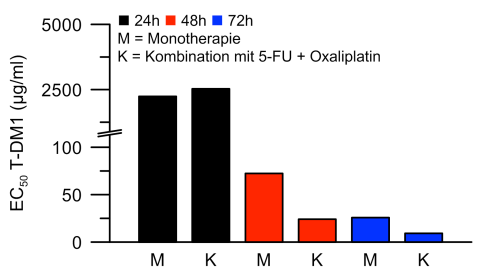

LS1034

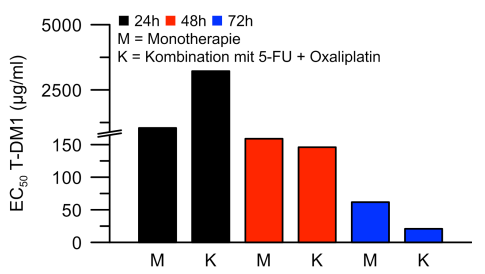

SW837

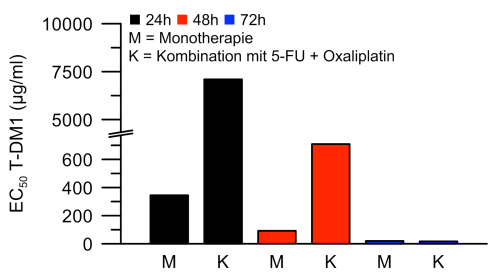

Abbildung 26: Vergleich der $\mathrm{EC}_{50}$ zwischen Mono- und Kombinationstherapie mit T-DM1, 5-FU und Oxaliplatin

\subsubsection{Kombination von Lapatinib mit 5-FU und Oxaliplatin}

Für die Kombination von Lapatinib mit 5-FU und Oxaliplatin wurden die geringste sowie die höchste Konzentration von Lapatinib vernachlässigt, da hier in der Monotherapie zum einen kein Effekt und zum anderen ein nahezu vollständiger Verlust der Zellviabilität zu sehen war (s. Abb. 14, S. 56). Dafür wurde die Konzentrationsreihe um 2,5 und 7,5 $\mu \mathrm{M}$ ergänzt.

Auch durch die Kombinationstherapie ließ sich ein signifikanter dosis- (LS513: $p=2.1 \mathrm{e}-32$, LS1034: $p=1.3 \mathrm{e}-24$, SW837: $p=1.2 \mathrm{e}-24$ ) und zeitabhängiger (LS513: $p=1.3 \mathrm{e}-08$, LS1034: $p=2.9 \mathrm{e}-10$, SW837: $p=0.0034)$ Einfluss auf die Zellviabilität erkennen, welcher phänotypisch bis zu einem nahezu vollständigen Verlust der Zellviabilität führte (s. Abb. 27). 
LS513

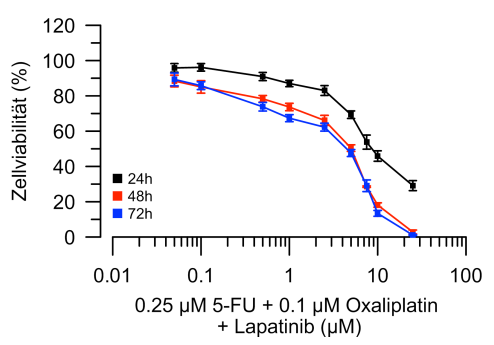

LS1034

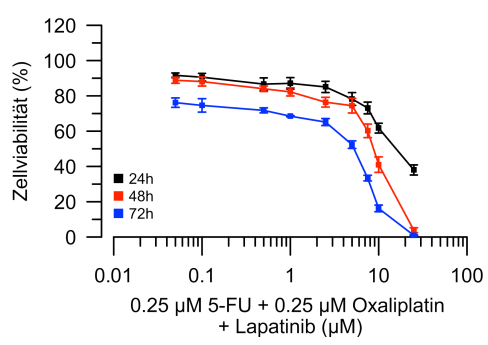

SW837

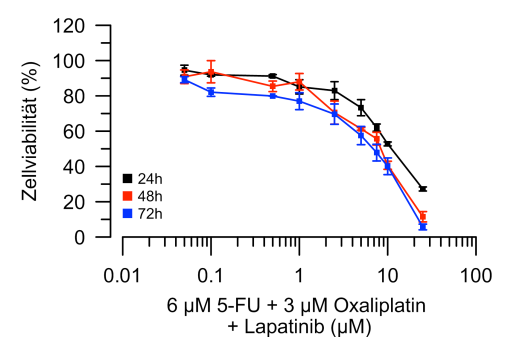

Abbildung 27: Zellviabilitätsmessung nach der Behandlung mit Lapatinib, 5-FU und Oxaliplatin

Basierend auf den Regressionsanalysen (s. Abb. 28) zeigte sich, dass der Effekt der Monotherapie bei LS513 und SW837 stärker war als durch eine Kombinationstherapie (LS513: $p=1.2 \mathrm{e}-59$, SW837: $p=2.4 \mathrm{e}-50)$. Durch Hinzunahme von 5-FU und Oxaliplatin konnte keine konstante weitere Reduktion der Zellviabilität erzielt werden, sondern vereinzelt zeigte sich sogar ein gegenteiliger Effekt. Die Zelllinie LS1034 zeigte nach der Kombinationstherapie bei 24 und 72 Stunden einen stärkeren Effekt als nach der Monotherapie (LS1034: $p=3.9 \mathrm{e}-47$ ). Die Zelllinie LS513 zeigte nach 24 Stunden Monotherapie eine $\mathrm{EC}_{50}$ von $4 \mu \mathrm{M}$, was im Vergleich zur Kombinationstherapie mit 10,2 $\mu \mathrm{M}$ effektiver war. Nach 48 Stunden ergab sich nach Monotherapie eine $\mathrm{EC}_{50}$ von 1,7 $\mu \mathrm{M}$, nach Kombinationstherapie von $2,5 \mu \mathrm{M}$. Auch nach 72 Stunden blieb die Monotherapie mit einer EC $_{50}$ von $0,7 \mu \mathrm{M}$ effektiver als die Kombinationstherapie mit einer $\mathrm{EC}_{50}$ von 2,1 $\mu \mathrm{M}$ (s. Tabelle $10, \mathrm{~S}$. 99). Die Zelllinie LS1034 zeigte nach 24 und 72 Stunden Monotherapie Werte von 102 bzw. 4,6 $\mu \mathrm{M}$, was im Vergleich zur Kombinationstherapie mit einer $\mathrm{EC}_{50}$ von 22,6 bzw. 2,1 $\mu \mathrm{M}$ für eine Effektivitätssteigerung zugunsten der Hinzunahme von 5-FU und Oxaliplatin spricht. Nach 48 Stunden war die Monotherapie mit einer EC $_{50}$ von 5,3 $\mu \mathrm{M}$ der Kombinationstherapie mit einer $\mathrm{EC}_{50}$ von 7,4 $\mu \mathrm{M}$ überlegen (s. Tabelle 11, S. 99). Für SW837 galt wiederum, das nur nach 24 Stunden die Kombinationstherapie mit einer $\mathrm{EC}_{50}$ von $14,8 \mu \mathrm{M}$ im Vergleich zur Monotherapie mit 23,6 $\mu \mathrm{M}$ überlegen war. Nach 48 und 72 Stunden war die Effektivität einer Monotherapie mit einer $\mathrm{EC}_{50}$ von 3,5 $\mu \mathrm{M}$ bzw. 1,6 $\mu \mathrm{M}$ stärker als die Kombinationstherapie mit einer $\mathrm{EC}_{50}$ von 6,3 und 4,3 $\mathrm{MM}$ (s. Tabelle 12, S. 100). 
LS513

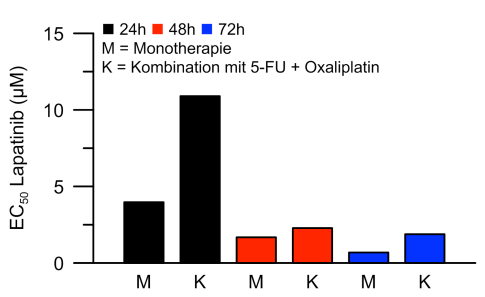

LS1034

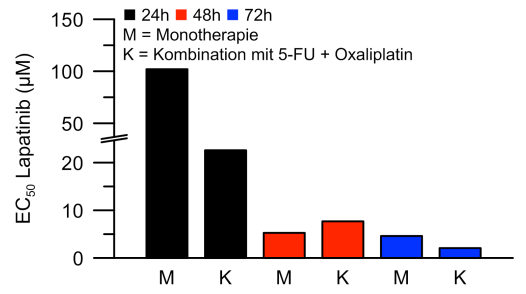

SW837

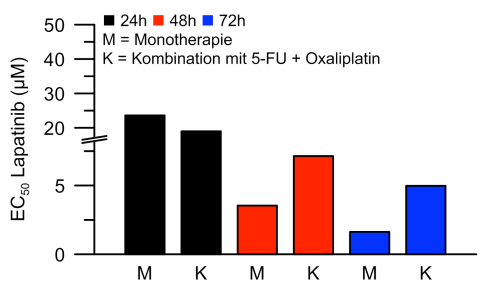

Abbildung 28: Vergleich der $\mathrm{EC}_{50}$ zwischen Mono- und Kombinationstherapie mit Lapatinib, 5-FU und Oxaliplatin

\subsubsection{Afatinib mit 5-FU und Oxaliplatin}

Für die Kombinationstherapie mit 5-FU, Oxaliplatin und Afatinib wurde wie auch bei Lapatinib die Konzentrationsreihe wieder um die höchste und niedrigste Konzentration reduziert, da sich auch hier kein Effekt bzw. eine vollständige Depletierung der Zellen ergab, und um die Werte 2,5 und 7,5 $\mu \mathrm{M}$ ergänzt (s. Abb. 15, S. 58).

Hier zeigte sich sowohl bezogen auf die Dosis (LS513: $p=2.4 \mathrm{e}-35$, LS1034: $p=5.2 \mathrm{e}-31$, SW837: $p=5 \mathrm{e}-24$ ) als auch auf die Dauer (LS513: $p=3.4 \mathrm{e}-11$, LS1034: $p=5.1 \mathrm{e}-09$, SW837: $p=1.3 e-05)$ der Therapie ein deutlicher und signifikanter Effekt in allen Zelllinien, welcher im Bereich der höchsten Dosierung sogar zu einem vollständigen Verlust der Zellviabilität führte (s. Abb. 29).

LS513

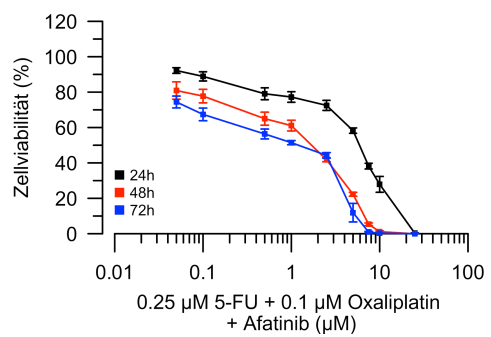

LS1034

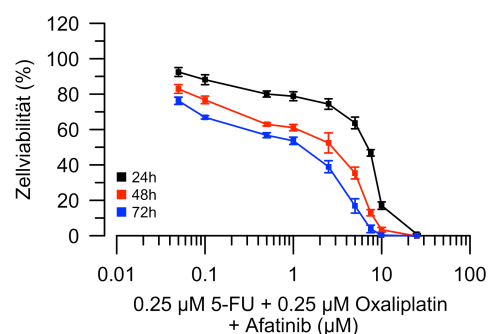

SW837

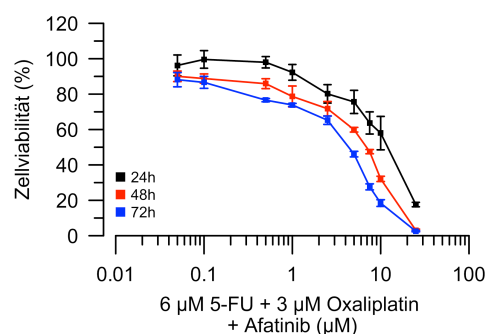

Abbildung 29: Zellviabilitätsmessung nach der Behandlung mit Afatinib, 5-FU und Oxaliplatin

Die Hinzunahme von 5-FU und Oxaliplatin zur Behandlung mit Afatinib zeigte in den Zelllinien LS513 und LS1034 einen signifikant stärkeren Effekt und eine niedrigere $\mathrm{EC}_{50}$ über alle Zeitpunkte (LS513: $p=7.9 \mathrm{e}-61$, LS1034: $p=2.2 \mathrm{e}-60$ ) (s. Abb. 30). Konkret bedeutet 
dies für die Zelllinie LS513 nach 24 Stunden eine $\mathrm{EC}_{50}$ von 6,2 $\mu \mathrm{M}$ in der Monotherapie verglichen mit $4,1 \mu \mathrm{M}$ in der Kombinationstherapie. Nach 48 Stunden betrug die $\mathrm{EC}_{50}$ $2 \mu \mathrm{M}$ in der Monotherapie und 0,9 $\mu \mathrm{M}$ in der Kombinationstherapie. Nach 72 Stunden lag die $\mathrm{EC}_{50}$ der Behandlung mit Afatinib bei 0,6 $\mu \mathrm{M}$ und der Behandlung mit Afatinib, 5-FU und Oxaliplatin bei 0,5 $\mu$ M (s. Tabelle 10, S. 99). Die Zelllinie LS1034 zeigte nach 24 Stunden eine $\mathrm{EC}_{50}$ von 7,4 $\mu \mathrm{M}$ nach Monotherapie im Vergleich zu 4,2 $\mu \mathrm{M}$ nach Kombinationstherapie. Nach 48 Stunden lag die $\mathrm{EC}_{50}$ bei 2,3 $\mu \mathrm{M}$ verglichen zu 1,1 $\mu \mathrm{M}$ in der Kombination mit 5-FU und Oxaliplatin. Auch nach 72 Stunden war im Vergleich zur Monotherapie mit einer $\mathrm{EC}_{50}$ von $1,6 \mu \mathrm{M}$ die Kombinationstherapie mit einer $\mathrm{EC}_{50}$ von $0,5 \mu \mathrm{M}$ effektiver (s. Tabelle 11, S. 99). In der Zelllinie SW837 war die Monotherapie zu allen Zeitpunkten wirkungsvoller als die Kombinationschemotherapie (SW837: $p=2.1 \mathrm{e}-50$ ) (s. Abb. 30). Die $\mathrm{EC}_{50}$ der Behandlung mit Afatinib lag nach 24 Stunden bei $6,3 \mu \mathrm{M}$ und in Kombination mit Chemotherapie bei $12,9 \mu \mathrm{M}$. Nach 48 Stunden lag die EC $_{50}$ durch Monotherapie bei 2,8 $\mu \mathrm{M}$, die $\mathrm{EC}_{50}$ durch Kombinationstherapie bei 4,4 $\mu \mathrm{M}$. Nach 72 Stunden war die $\mathrm{EC}_{50}$ der alleinigen Behandlung mit Afatinib 1,1 $\mu \mathrm{M}$ und der Kombinationstherapie 2,1 $\mu \mathrm{M}$ (s. Tabelle 12, S. 100).

LS513

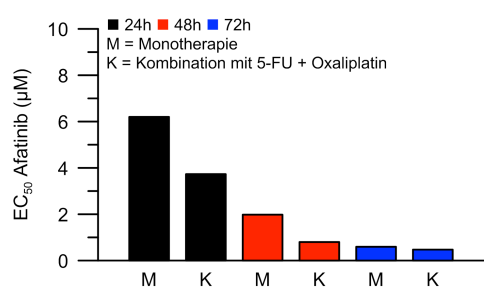

LS1034

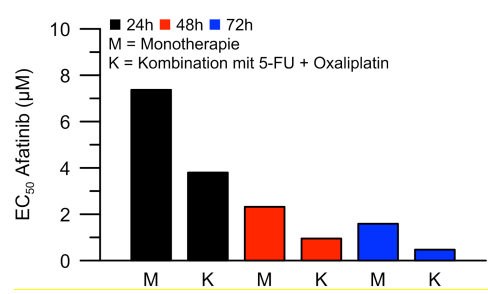

SW837

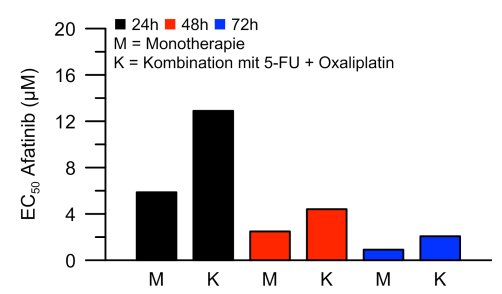

Abbildung 30: Vergleich der $\mathrm{EC}_{50}$ zwischen Mono- und Kombinationstherapie mit Afatinib, 5-FU und Oxaliplatin 


\subsubsection{Zusammenfassung der Ergebnisse}

Zusammenfassend konnte Folgendes gezeigt werden:

1. Ein klinisch relevanter Anteil kolorektaler Karzinomzelllinien (25\%) zeigt eine HER-2 Überexpression bzw. Genamplifikation.

2. Durch den Einsatz von Anti-HER-2-Substanzen, in Abhängigkeit von der getesteten Substanz, kann die Zellviabilität signifikant beeinflusst werden, wobei ein deutlich stärkerer Effekt durch das Antikörper-Wirkstoff-Konjugat T-DM1 und die kleinmolekularen Inhibitoren Lapatinib und Afatinib bewirkt wurde als durch die Antikörper Trastuzumab und Pertuzumab.

3. In den Zelllinien LS513 und LS1034 konnte, in Abhängigkeit von der Behandlungsdauer, durch Kombination mit den Chemotherapeutika 5-FU und Oxaliplatin die viabilitätshemmende Wirkung weiter gesteigert werden.

4. Diese Ergebnisse deuten darauf hin, dass eine medikamentöse Hemmung von HER-2 beim KRK sinnvoll erscheint. 


\section{Diskussion}

\subsection{Klinische Problematik}

Das KRK stellt eine der häufigsten Tumorentitäten und die zweithäufigste Krebsassoziierte Todesursache in der westlichen Welt dar (Bray et al. 2018; Siegel RL et al. 2018). Dies resultiert vor allem daraus, dass etwa die Hälfte aller Patienten synchrone oder metachrone Metastasen entwickeln, am häufigsten lokalisiert in der Leber und der Lunge (Graeter und Friedel 2016). Daher ist es notwendig, die Systemtherapie weiter zu optimieren und eine noch gezieltere, tumorspezifische Behandlung zu ermöglichen. Durch die Kombination der gängigen Chemotherapeutika mit Inhibitoren, welche gegen Proteine zellulärer Signalkaskaden im KRK gerichtet sind, konnten bereits Erfolge erzielt werden. Hierzu zählen beispielsweise Antikörper wie der VEGF-Inhibitor Bevacizumab (Ciombor und Goldberg 2015) sowie Cetuximab und Panitumumab, welche spezifisch am EGF-Rezeptor angreifen (Fakih 2015; Schmiegel et al. 2017). Jedoch ist die Effektivität einer solchen zielgerichteten Therapie häufig dadurch limitiert, dass primäre Resistenzen bestehen oder sich im Verlauf der Behandlung sekundäre Resistenzen entwickeln. Folglich besteht weiterhin die klinische Notwendigkeit, neue Zielstrukturen zu evaluieren und therapeutisch zu nutzen (Bergers und Hanahan 2008; Russo et al. 2016).

In dieser Arbeit wurde daher untersucht, ob HER-2 eine mögliche Zielstruktur für die Therapie des KRK darstellen könnte. Kolorektale Karzinomzelllinien, welche eine Überexpression bzw. moderate Genamplifikation von HER-2 zeigten, wurden mit Anti-HER-2Substanzen behandelt. Zum einen wurde betrachtet, welche Auswirkung eine HER-2Inhibition auf die nachgeschaltete Signalkaskade hat. Zum anderen wurden Viabilitätsassays durchgeführt, um zu überprüfen, ob eine Behandlung mit diesen Substanzen den Zellstoffwechsel inhibiert. Zuletzt wurden die Substanzen in Kombination mit einem Chemotherapieregime eingesetzt. Im Folgenden sollen die Ergebnisse dieser Experimente sowie deren potenzielle klinische Bedeutung diskutiert werden. 


\subsection{Interpretation der Ergebnisse}

\subsubsection{HER-2-Positivität der kolorektalen Karzinomzelllinien}

Initial wurden 12 kolorektale Karzinomzelllinien hinsichtlich ihres HER-2-Status untersucht. Letztendlich zeigten drei dieser Zelllinien (25\%) eine HER-2-Positivität. Dabei handelte es sich um die Zelllinien LS513, LS1034 und SW837 (s. Tabelle 8, S. 51). Zum Zeitpunkt dieser Experiment existierte jedoch kein einheitliches Scoring-System, um den HER-2-Status im KRK zu bestimmen (Fanotto et al. 2016). In der vorliegenden Arbeit erfolgte die Auswertung der immunzytochemischen Schnitte daher analog dem HER-2Scoring-System beim Magenkarzinom innerhalb der ToGA-Studie (s. Tabelle 9) (Bang et al. 2010). Dieses Scoring-System unterscheidet sich grundlegend vom Mammakarzinom. Beim Mammakarzinom wird vorausgesetzt, dass mindestens $10 \%$ der Karzinomzellen sowohl in Biopsien als auch in Resektaten eine Membranfärbung für HER-2 zeigen. Nur eine komplette zirkumferenzielle Membranfärbung wird mit einem Expressionsgrad von 2+ bzw. 3+ gewertet (Wolff et al. 2013). Da im Magenkarzinom die HER-2-Expression deutlich heterogener ist als beim Mammakarzinom, wird hier in Biopsaten das Vorhandensein von mindestens fünf kohäsiven Tumorzellen und nur im chirurgischen Resektat von mindestens $10 \%$ der Karzinomzellen mit Membranfärbung vorausgesetzt (Rüschoff et al. 2012). Eine zirkumferenzielle Membranfärbung ist für einen Expressionsgrad von 2+ bzw. 3+ nicht notwendig, da Zellen des Intestinums die Rezeptoren in der Regel nur basolateral und lateral ausbilden (Rüschoff et al. 2010). Das HER-2-Scoring kolorektaler Primärtumoren und kolorektaler Lebermetastasen wurde durch unsere Arbeitsgruppe bereits in früheren Arbeiten analog dem Magenkarzinom angewendet (Conradi et al. 2013; Styczen et al. 2015), da sich auch diese Tumorentität durch eine ausgeprägte Heterogenität auszeichnet (Fanotto et al. 2016). Im Verlauf wurde im Rahmen der HERACLES-Studie ein Scoring-System für das kolorektale Karzinom etabliert (s. 4.2.2) (Valtorta et al. 2015). Tabelle 9 vergleicht die Kriterien des HER-2-Scorings für das Mammakarzinom, Magenkarzinom und das kolorektale Karzinom im Rahmen der HERACLES-Studie. 


\begin{tabular}{|c|lll|}
\hline & Mammakarzinom & Magenkarzinom & KRK (HERACLES) \\
\hline Proteinexpression (IHC) & & & \\
\hline$\bullet \quad$ Ausmaß & Biopsie und Resektat & Biopsie $>5 \%$ Tumorzellen & Biopsie und Resektat \\
& $>10 \%$ & Resektat $>10 \%$ & $>10-50 \%$ \\
\hline$\bullet \quad$ Membranfärbung & zirkumferenziell & basolateral/lateral & $\begin{array}{l}\text { zirkumferenziell, } \\
\text { basolateral oder lateral }\end{array}$ \\
& & & FISH oder SISH (bei IHC 2+) \\
\hline Amplifikation (ISH) & FISH (bei IHC 2+) & FISH (bei IHC 2+) & Ratio $>2.0$ \\
\hline
\end{tabular}

Tabelle 9: Vergleich der HER-2-Scoring-Kriterien beim Mamma-, Magen- und kolorektalen Karzinom

In der vorliegenden Arbeit wurden die Kriterien wie beim Magenkarzinom angewendet und auf KRKZelllinien übertragen. Die Tabelle ist modifiziert nach Rüschoff et al. 2010 (S. 305, Table 2).

Da zum Zeitpunkt der durchgeführten Experimente keine Studie zur Beurteilung von Paraffinschnitten aus Zelllinien bezüglich des HER-2-Status im KRK vorlag, wurde - basierend auf unseren Vordaten (Paraffinschnitte von kolorektalen Primärtumoren und Metastasen) - das HER-2-Scoring auch auf die Beurteilung von Einzelzellen im Paraffinschnitt übertragen (Conradi et al. 2013; Styczen et al. 2015).

Die Zelllinie LS513, welche mit einer HER-2-Expression von 3+ beurteilt wurde, zeigte auch in der SISH eine, wenn auch moderate, Genamplifikation von HER-2 (s. Tabelle 8, S. 51). Von den fünf Zelllinien, welche einen HER-2-Expressionsgrad von 2+ aufwiesen, zeigten lediglich LS1034 und SW837 eine grenzwertig positive Amplifikation des HER-2-Gens (s. Tabelle 8, S. 51). Verglichen mit den Daten der o.g. Studien ist also davon auszugehen, dass eine kräftige Membranfärbung (3+) auch im Zellkulturmodell des KRK mit einer HER-2-Positivität gleichzusetzen ist und ein guter Indikator dafür ist, dass auch eine Genamplifikation von HER-2 vorliegt. Wie bei den anderen genannten Tumorentitäten bestätigt bei einem Expressionsstatus von 2+ erst die In-situ-Hybridisierung die HER-2Positivität (Rüschoff et al. 2012). Die Kriterien, welche innerhalb der kürzlich veröffentlichten HERACLES-Studie zur Beurteilung des HER-2-Status im KRK angewendet wurden (s. 4.2.2.), entsprechen eher dem Scoring im Mammakarzinom. Lediglich die nicht obligate zirkumferenzielle Membranfärbung entspricht in dieser Studie den Scoring-Kriterien beim Magenkarzinom (s. Tabelle 9) (Rüschoff et al. 2012). Dies ist ein möglicher Grund dafür, warum im Rahmen der HERACLES-Studie das als HER-2-positiv beurteilte Patientenkollek- 
tiv wesentlich kleiner ausfällt als in unserem Zellkulturmodell. Des Weiteren kann natürlich auch der Vergleich von In-vitro-Daten mit Ergebnissen aus dem klinischen Einsatz zu dieser Diskrepanz führen.

\subsubsection{HER-2-Positivität im kolorektalen Karzinom}

Basierend auf der Analyse primärer Rektumkarzinome und kolorektaler Lebermetastasen konnte unsere Arbeitsgruppe zeigen, dass ein relevanter Anteil HER-2 überexprimiert (Conradi et al. 2013). In einer ersten Arbeit wurden prätherapeutische Biopsien sowie chirurgische Resektate von 264 Patienten mit lokal fortgeschrittenem Rektumkarzinom mittels Immunhistochemie und SISH hinsichtlich des HER-2-Status untersucht. Eine HER-2Positivität konnte in 12,4\% der Biopsien und 26,7\% der Resektate aufgezeigt werden (Conradi et al. 2013). In einer weiteren Studie unserer Arbeitsgruppe wurden der HER-2und der HER-3-Status kolorektaler Lebermetastasen betrachtet. Es wurden 208 Tumore immunhistochemisch und auf eine HER-2-Amplifikation mittels SISH untersucht. Es zeigte sich eine HER-2-Positivität in 8,2\% und eine HER-3-Positivität in 75\% der Fälle (Styczen et al. 2015).

Für die Rekrutierung von Patienten mit metastasiertem KRK in die HERACLES-Studie wurde ein weiteres HER-2 Scoring-System vorgestellt: Immunhistochemisch gefärbte Proben, welche keine (0), eine schwache (1+), eine moderate (2+) Färbung in unter $50 \%$ oder eine kräftige (3+) Färbung in < $10 \%$ der Zellen für HER-2 zeigten, galten als HER-2-negativ und wurden nicht in die Studie aufgenommen (Valtorta et al. 2015). Zirkumferenziell, basolateral oder lateral moderat gefärbte Zellen mit einem Anteil über $50 \%$ sowie kräftig gefärbte Zellen zwischen $10 \%$ und $50 \%$ wurden durch eine In-situ-Hybridisierung weiter untersucht und nur im Fall einer Genamplifikation in die Studie einbezogen. Eine Membranfärbung von $3+$ in über $50 \%$ der Zellen galt obligatorisch als HER-2-Positivität, wurde aber ebenfalls durch ISH verifiziert und zeigte hier eine 100\%ige Konkordanz zwischen Expressionslevel und Genamplifikation für HER-2 (Valtorta et al. 2015). Ebenfalls wurde die Silber-in-situ-Hybridisierung mit der Fluoreszenz-in-situ-Hybridisierung verglichen, und beide Methoden wurden als gleichwertig beurteilt. Für das gleichzeitige Färben mehrerer Proben erschien die SISH in der Anwendung geeigneter, während die FISH für 
die Beurteilung einzelner Patientenproben als praktikabler gewertet wurde (Valtorta et al. 2015). Letztendlich wurden in einem Kollektiv von 914 Patienten mit metastasiertem KRK und KRAS-Wildtyp anhand dieses Scoring-Systems $5 \%$ der Tumore als HER-2 positiv gewertet (Sartore-Bianchi et al. 2016).

Die bisher fehlende Etablierung eines einheitlichen HER-2-Scorings für das KRK könnte ein Grund dafür sein, dass sich in der Literatur bezüglich einer Expression von HER-2 sehr unterschiedliche Resultate ergeben. Auch die Verwendung unterschiedlicher Antikörper, die Färbemethode und die Lokalisation von HER-2 sind uneinheitlich beurteilte Parameter. So divergieren Daten zur HER-2-Überexpression im KRK von $0 \%$ bis $84 \%$ (Blok et al. 2013).

\subsubsection{Klinischer Einsatz von Anti-HER-2-Substanzen}

Die bisher aufgeführten präklinischen und klinischen Daten zeigen, dass HER-2 in einem relevanten Anteil kolorektaler Karzinome exprimiert wird und damit einen möglichen Angriffspunkt für eine zielgerichtete Therapie darstellt. Daher wurden im nächsten Schritt die HER-2-positiven Zelllinien LS513, LS1034 und SW837 mit Anti-HER-2-Substanzen behandelt, welche bereits in anderen Tumorentitäten eingesetzt oder erprobt werden.

\subsubsection{Trastuzumab}

Trastuzumab gilt als Standardtherapeutikum in der Behandlung des metastasierten HER-2-positiven Mammakarzinoms, wird aber ebenso im neoadjuvanten und adjuvanten Setting eingesetzt (Arteaga et al. 2012). Auch in der Therapie des metastasierten Magenund/oder Kardiakarzinoms wird der monoklonale Antikörper aufgrund der positiven Ergebnisse der ToGA-Studie in der Erstlinientherapie eingesetzt. In dieser Studie wurden 3665 Patienten auf einen positiven HER-2-Status untersucht, welcher sich in $22 \%$ bestätigte (Bang et al. 2010). Es wurden schließlich 584 Patienten randomisiert. Im Kontrollarm wurden die Patienten mittels Standard-Chemotherapie (Capecitabine plus Cisplatin bzw. 5-FU plus Cisplatin) behandelt, während im Prüfarm die Standard-Chemotherapie zusammen mit Trastuzumab verabreicht wurde. Das mediane Gesamtüberleben war im Trastuzumab-Arm signifikant verlängert. Das beste Gesamtüberleben wurde bei Patienten 
mit einem hohen Expressionsstatus und hoher Genamplifikation von HER-2 verzeichnet (Bang et al. 2010).

In der vorliegenden Arbeit zeigte sich nach Behandlung der Zelllinien LS513 und LS1034 mit Trastuzumab nur bei hohen Dosen ein geringer Einfluss auf das pAkt-Level (s. Abb. $11 \mathrm{~A}, \mathrm{~S} .53)$, bei SW837 war dieser moderate Effekt bereits bei etwas niedrigeren Konzentrationen erkennbar (s. Abb. 11A, S. 53). Wie zu erwarten, bewirkte Trastuzumab daher auch in keiner dieser Zelllinien einen relevanten Effekt auf die Zellviabilität (s. Abb. 11B, S. 53). Warum Trastuzumab hier keine HER-2-Inhibierung vermittelt, lässt sich zu diesem Zeitpunkt nicht beantworten. Es gibt Hinweise darauf, dass das Ansprechen auf eine Trastuzumab-Therapie im Allgemeinen von der Ausprägung der HER-2-Expression abhängt (Scaltriti et al. 2015). Möglicherweise waren die Expressionslevel der drei KRKZelllinien nicht hoch genug. Ein weiterer zugrunde liegender Mechanismus könnte eine kompensatorische Hochregulierung des Membranrezeptors HER-3 sein. Dies konnte in einer immunhistochemischen Studie an Biopsien von 35 Patientinnen mit metastasiertem HER-2-positiven Mammakarzinom gezeigt werden (Cha et al. 2014). Eine Resistenz gegen die Therapie mit Trastuzumab war mit einer erhöhten Expression von pHER-3 assoziiert.

Innerhalb der HERACLES-Studie wurden ausgewählte Patienten mit HER-2 positivem metastasierten KRK und Resistenz gegen eine Anti-EGFR-Therapie bei KRAS Exon 2 Wildtyp erfolgreich mit einer Kombination aus Trastuzumab und Lapatinib behandelt (Siena et al. 2018) (s. 4.4).

\subsubsection{Pertuzumab}

Pertuzumab wird aktuell in Kombination mit Trastuzumab und Docetaxel als Erstlinientherapie des HER-2-positiven metastasierten Mammakarzinoms eingesetzt (Gerratana et al. 2017). Dies basiert auf den Ergebnissen der CLEOPATRA-Studie (NCT00567190). In dieser randomisierten, doppelblinden, Placebo-kontrollierten Studie mit 808 Patientinnen zeigte sich ein verlängertes progressionsfreies und Gesamtüberleben durch Hinzunahme von Pertuzumab im Vergleich zur Kontrollgruppe mit Trastuzumab und Docetaxel (Baselga et al. 2014; Swain et al. 2015b). Des Weiteren ist Pertuzumab in der neoadjuvanten The- 
rapie des Mammakarzinoms gemäß der NeoSphere-Studie (NCT00545688) zugelassen. In dieser Studie wurden 417 Patientinnen in vier neoadjuvante Arme randomisiert (Trastuzumab + Docetaxel, Pertuzumab + Trastuzumab + Docetaxel, Pertuzumab + Trastuzumab, Pertuzumab + Docetaxel). Es ergab sich eine signifikante Steigerung der kompletten Ansprechrate sowie des progressions- und krankheitsfreien Überlebens durch Pertuzumab in Kombination mit Trastuzumab und Docetaxel beim lokal begrenzten und lokal fortgeschrittenen Mammakarzinom im Vergleich zur neoadjuvanten Therapie ohne Pertuzumab (Gianni et al. 2012; Gianni et al. 2016). Aktuell wurde ebenfalls der adjuvante Einsatz von Pertuzumab in Kombination mit Trastuzumab und einer Standardchemotherapie beim frühen HER-2-positiven Mammakarzinom mit hohem Rezidivrisiko (positiver Lymphknotenstatus oder negativer Hormonrezeptorstatus) aufgrund der Ergebnisse der APHINITYStudie (NCT01358877) zugelassen (von Minckwitz et al. 2017).

Basierend auf den Ergebnissen der Phase-Ila JOSHUA-Studie (NCT01461057) zur Dosisfindung wurde im Rahmen der Phase-III JACOB-Studie (NCT01774786) die Effektivität einer Hinzunahme von Pertuzumab zur Erstlinientherapie mit Trastuzumab und einer Standardchemotherapie (Cisplatin + Capecitabine/5-FU) beim HER-2 positiven metastasierten Magen- oder Kardiakarzinom überprüft (Kang et al. 2014; Oh und Bang 2016; Tabernero et al. 2018). Es konnte bei den insgesamt 773 randomisierten Patienten bisher kein signifikanter Unterschied des Gesamtüberlebens zwischen Verum- und Placebogruppe gezeigt werden (Tabernero et al. 2018).

Die Ergebnisse der vorliegenden Arbeit zeigen eine effektivere Inhibition des nachgeschalteten Signalweges durch Pertuzumab im Vergleich zu Trastuzumab (s. Abb. 12A, S. 54). In präklinischen Studien konnte gezeigt werden, dass Pertuzumab die Rezeptordimerisierung von HER-2 effektiver verhindert als Trastuzumab (Franklin et al. 2004). Durch direkte Blockade im Bereich der Dimerisationsstelle verhindert Pertuzumab die Fusion von HER-2 mit den übrigen Mitgliedern der EGFR-Familie, insbesondere mit HER-3 (Adams et al. 2006). Es gibt Hinweise, dass Pertuzumab aufgrund dieses Wirkmechanismus selbst bei moderatem Expressionslevel von HER-2 aktiv ist, da eine ligandenabhängige Dimerisation verhindert wird (Agus et al. 2005). Interessanterweise zeigte Pertuzumab in den hier 
durchgeführten Experimenten dennoch keinen phänotypisch relevanten Effekt auf die Zellviabilität (s. Abb. 12B, S. 54). Der Grund hierfür ist unklar.

In der MyPathway-Studie (NCT02091141) wurden 37 therapierefraktäre Patienten mit einem HER-2-positiven metastasiertem KRK mit Trastuzumab und Pertuzumab behandelt. Hier zeigte sich eine partielle Ansprechrate in 38\% der Fälle (Hainsworth et al. 2018) (s. 4.4). In der vorliegenden Arbeit konnte jedoch auch durch Kombination beider Antikörper kein relevanter Einfluss auf die Zellviabilität erzielt werden (s. Abb. 16B, S. 59; Abb. 17B, S. 60; Abb. 18B, S. 61; Abb. 19B, S. 62).

\subsubsection{T-DM1}

T-DM1 wird als Antikörper-Wirkstoff-Konjugat seit 2013 in der Zweitlinientherapie des HER-2-positiven, nicht-resektablen lokal fortgeschrittenen oder metastasierten Mammakarzinoms eingesetzt, welches unter der Therapie mit Trastuzumab und Taxanen progredient ist (Martinez et al. 2016). Entsprechend den Resultaten der EMILIA-Studie zeigte die Therapie mit T-DM1 im Vergleich zur Therapie mit Lapatinib und Capecitabine ein verlängertes progressionsfreies und Gesamtüberleben bei geringerer Toxizität (Diéras et al. 2017; Verma et al. 2012). Im Rahmen der MARIANNE-Studie wurden Patientinnen mit einem HER-2 positiven irresektablen Mammakarzinom ohne Vorbehandlung randomisiert und entweder einer Therapie mit Trastuzumab und Docetaxel, T-DM-1 oder T-DM1 in Kombination mit Pertuzumab zugeführt. Es ergab sich kein signifikanter Unterschied der Subgruppen in Bezug auf das progressionsfreie Überleben, weshalb die Erstlinientherapie mit T-DM1 bei deutlich geringerem Nebenwirkungsprofil erwogen werden kann (Perez et al. 2017).

In der KATHERINE-Studie (NCT01772472) wurden 1486 Patientinnen mit frühem HER-2 positivem Mammakarzinom und intraoperativem Residualtumor nach neoadjuvanter Therapie mit Trastuzumab und Taxanen randomisiert und einer adjuvanten Behandlung entweder mit T-DM1 oder mit Trastuzumab unterzogen (von Minckwitz et al. 2019). Dabei konnte durch die Therapie mit T-DM1 das Risiko eines lokalen Wiederauftretens der Erkrankung um bis zu 50\% im Vergleich zur Therapie mit Trastuzumab gesenkt werden 
bei allerdings erhöhtem Nebenwirkungsprofil. Die Ergebnisse zur Auswirkung auf das Gesamtüberleben sind noch ausstehend (von Minckwitz et al. 2019). In der TH3RESA-Studie wurde gezeigt, dass sowohl das progressionsfreie als auch Gesamtüberleben von Patientinnen mit fortgeschrittenem Mammakarzinom und Progress unter bereits zweifacher Anti-HER-2-Therpaie mit Trastuzumab und Lapatinib durch die Behandlung mit T-DM1 im Vergleich zur Therapie nach Wahl des behandelnden Arztes (Chemotherapie, Anti-HER2Therapie, Hormontherapie als Mono- oder Kombinationstherapie) signifikant verbessert werden konnte. Dabei handelte es sich um ausgiebig vorbehandelte Patientinnen mit durchschnittlich vier vorangegangenen Therapieregimen (Krop et al. 2014; Krop et al. 2017).

Neoadjuvant wurde der Einsatz von T-DM1 in Kombination mit Pertuzumab im Vergleich zur Therapie mit Docetaxel, Carboplatin, Trastuzumab und Pertuzumab in der KRISTINEStudie (NCT02131064) beim HER-2-positiven resektablen Mammakarzinom untersucht (Hurvitz et al. 2018; Okines 2017). Dabei zeigten sich signifikant mehr Komplettremissionen durch die Chemotherapie in Kombination mit Trastuzumab und Pertuzumab (55,7\%) im Vergleich zur Therapie mit T-DM1 und Pertuzumab (44,4\%). Jedoch war das Nebenwirkungsprofil in der letzteren Gruppe deutlich geringer, weshalb dieses Regime eine Alternative bei Intoleranz gegenüber einer Therapie mit Taxanen darstellt (Hurvitz et al. 2018).

Präklinische Studien zeigten eine deutliche Wirkung von T-DM1 in Magenkarzinommodellen (Apicella et al. 2017). Barok et al. untersuchten die Effektivität von T-DM1 im Vergleich zu Trastuzumab in HER-2-amplifizierenden Magenkarzinomzelllinien und Xenografts im Mausmodell (Barok et al. 2011). Vier Magenkarzinomzelllinien (OE-19, MKN-7, N-87 und SNU-216) wiesen in der FISH-Analyse eine HER-2-Amplifikation auf. Mittels Bindung von Trastuzumab oder T-DM-1 konnte in der Durchflusszytometrie gezeigt werden, dass in den Zelllinien OE-19 und N-87 eine Protein-Überexpression von HER-2 vorlag, die Expression war in den beiden anderen Zelllinien schwächer ausgebildet. In Zellviabilitätsassays erbrachte die Behandlung mit Trastuzumab dosisabhängig einen Effekt in den Zelllinien OE-19, N-87 und SNU-216. Die Wirkung von T-DM1 war in gleicher Dosierung im Vergleich deutlich stärker bei den Zelllinien OE-19, N-87 und MKN-7, der Effekt auf 
SNU-216 war erst bei höchster Dosierung zu erkennen (Barok et al. 2011). Somit wurden von den Zelllinien OE-19 und N-87 Xenografts in immundefizienten (SCID-)Mäusen gebildet. Die Karzinomzellen wurden subcutan injiziert, die Tiere mit Trastuzumab, T-DM1 und Rituximab als Negativkontrolle behandelt und das Tumorvolumen kontrolliert. Bei den Xenograft-Mäusen der Karzinomzelllinie N-87 hatte die Behandlung mit Trastuzumab keinen Effekt. Nach 37 Tagen Behandlung mit T-DM1 hingegen war bei keinem Tier dieser Kohorte noch ein Tumor zu tasten. Histologisch zeigte sich hier eine Komplettremission in $50 \%$ der Fälle. Die Trastuzumab- und Rituximab-Kohorten wurden nach 29 Tagen auf eine Therapie mit T-DM1 umgestellt, und auch dadurch konnte im Verlauf eine deutliche Tumorreduktion erreicht werden. Die Xenografts der Zelllinie OE-19 zeigten ein deutlich verlangsamtes Tumorwachstum durch die Therapie mit Trastuzumab, jedoch einen exponentiellen Progress im Verlauf. Bereits nach 19 Tagen Behandlung mit T-DM1 konnten makroskopisch kein Tumor und nach Beenden des Experimentes nach 76 Tagen ebenfalls histologisch keine Residuen mehr nachgewiesen werden. Die Behandlung mit Trastuzumab wurde nach 49 Tagen bei $50 \%$ der Mäuse auf T-DM1 umgestellt, auch hier konnte wieder ein deutliches Schrumpfen der Tumore erreicht werden. Die Kontrollgruppe erhielt nach 22 Tagen zu $50 \%$ eine Behandlung mit Trastuzumab, was keinen Effekt bewirkte. Die übrigen $50 \%$ wurden mit T-DM1 behandelt und zeigten eine deutliche Reduktion des Tumorvolumens. Zusammenfassend hatte also die Behandlung mit T-DM1 in vitro und in vivo einen deutlichen Effekt bei HER-2-amplifizierten und -überexprimierten Magenkarzinomzelllinien und deren Tumorgrafts. Sogar nach Tumorprogress unter einer Trastuzumab-Behandlung konnte ein deutlicher Therapieeffekt durch T-DM1 in vivo erreicht werden (Barok et al. 2011).

Zu ähnlichen Ergebnissen kam es in einer weiteren präklinischen Studie. In einem Xenograft-Mausmodell (Magenkarzinomzelllinien) führte die Therapie mit T-DM1 bei einem positiven HER-2-Status (NCl-N87, SCH und 4-1ST) zu einer deutlichen Inhibition des Tumorwachstums, hingegen konnte kein signifikanter Effekt bei einem negativen HER-2Status (SNU-16 und MKN-28) erreicht werden (Yamashita-Kashima et al. 2013). Im Vergleich zu Vorexperimenten war der Effekt durch T-DM1 stärker als durch den Antikörper Trastuzumab (Yamashita-Kashima et al. 2013). Im Xenograft-Modell der Zelllinie NCI-N87 wurde weiterhin die Kombination aus T-DM1 und Pertuzumab untersucht. Hier konnte 
ein noch stärkerer Effekt auf die Reduktion des Tumorvolumens und immunhistochemisch eine fast vollständige Suppression von pHER3 erreicht werden. In vitro wurden Proliferationsassays mit der Zelllinie NCl-N87 durchgeführt. Die Kombination von T-DM1 und Pertuzumab bewirkte auch in Anwesenheit von EGF oder Heregulin- $\alpha$ als Wachstumsfaktoren eine deutliche Inhibition verglichen mit der Behandlung durch die Substanzen als Monotherapie. Auf Ebene des nachgeschalteten Signalweges kam es durch die Kombinationstherapie zu einer starken Suppression von pERK und pAKT (Yamashita-Kashima et al. 2013).

In der klinischen GATSBY-Studie wurde eine Zweitlinientherapie mit T-DM1 im Vergleich zur Therapie mit Taxanen (Docetaxel oder Paclitaxel) bei Patienten mit HER-2-positivem fortgeschrittenem Magen- oder Kardiakarzinom untersucht, welche einen Progress während der platin- und fluoropyrimidinbasierten neoadjuvanten oder adjuvanten Erstlinientherapie zeigten (Thuss-Patience et al. 2017). Bei der Randomisierung wurden Herkunft der Patienten, Vorbehandlung mit einer Anti-HER-2-Substanz (Trastuzumab, Lapatinib oder Pertuzumab) sowie der Resektionsstatus berücksichtigt. Es konnte im Gesamtkollektiv und in den Subgruppen keine Verbesserung im progressionsfreien und Gesamtüberleben durch die Therapie mit T-DM1 im Vergleich zur Therapie mit Taxanen bei bestehender Anti-Tumor-Aktivität erreicht werden. Das Nebenwirkungsprofil war dabei in beiden Fällen vergleichbar (Thuss-Patience et al. 2017). Mögliche Erklärungen für das negative Ergebnis waren die Heterogenität der HER-2-Positivität im Magenkarzinom verglichen mit dem Mammakarzinom, eine verminderte Wirksamkeit von Vincaalkaloiden im Magenkarzinom sowie eine Diskrepanz des HER-2-Status zwischen Primarius und Rezidiv/ Metastasen, da bei den meisten Patienten kein erneuter HER-2-Status erhoben wurde (ThussPatience et al. 2017).

In der vorliegenden Arbeit waren die Effekte einer Behandlung mit T-DM1 deutlich stärker ausgeprägt als bei Trastuzumab und Pertuzumab. Die Zelllinien LS1034 und SW837 wiesen bereits bei sehr niedrigen Konzentrationen von T-DM1 deutlich verminderte pAktLevel auf (s. Abb. 13A, S. 55). Dieser Einfluss konnte in LS513 nicht eindeutig nachgewiesen werden (s. Abb. 13A, S. 55). Jedoch bewirkte T-DM1 in allen Zelllinien eine deutliche dosis- und zeitabhängige Reduktion der Zellviabilität (s. Abb. 13B, S. 55). Durch Internali- 
sierung des Rezeptors zusammen mit dem Antikörper sowie dem Spindelgift Maytansin entsteht eine erhöhte Toxizität für die Zelle (Ballantyne und Dhillon 2013). Dies erklärt den deutlich stärkeren Einfluss von T-DM1 auf die Verminderung der Zellviabilität im Vergleich zum Antikörper Trastuzumab (s. Abb. 11B, S. 53 und 13B, S. 55). Auch der Effekt auf das pAkt Level ist deutlich stärker als durch Trastuzumab (s. Abb. 11A, S. 53 und 13A, S. 55).

Klinisch wird der Einsatz von T-DM1 aktuell im Rahmen der HERACLES B- und HERACLESRESCUE-Studie bei Patienten mit HER-2-positivem KRK und Wildtyp im KRAS Exon 2 untersucht (Greally et al. 2018) (s. 4.4).

\subsubsection{Lapatinib}

Lapatinib wird beim Trastuzumab-resistenten HER-2-positiven oder metastasierten Mammakarzinom eingesetzt (Geyer et al. 2006; Zardavas et al. 2015). Insbesondere im Fall von Metastasen des zentralen Nervensystems ist der kleinmolekulare Inhibitor dem Antikörper überlegen, da er die Blut-Hirn-Schranke überwinden kann (Ahn ER et al. 2012; Bendell et al. 2003). In der EGF104900-Studie zeigte sich für Trastuzumab plus Lapatinib ein verbessertes progressionsfreies und Gesamtüberleben in der Behandlung HER-2positiver, intensiv vorbehandelter metastasierter Mammakarzinome im Vergleich zur Monotherapie mit Lapatinib (Blackwell et al. 2012).

In einer präklinischen Studie ergaben sich antiproliferative Effekte durch die Behandlung von Magen- und Ösophaguskarzinomzelllinien mit Lapatinib mit oder ohne Trastuzumab (Wainberg et al. 2010). Es wurden aus 14 Zelllinien zwei mit einer HER-2-Amplifikation mittels FISH identifiziert ( $\mathrm{NCl}-\mathrm{N} 87$ und OE19). Bereits bei geringen Konzentrationen von Lapatinib zeigte sich in diesen beiden Zelllinien ein deutlicher antiproliferativer Effekt. Auch im Bereich der nachgeschalteten Signalwege konnte eine Reduktion von pAkt erreicht werden. Dieser Effekt konnte durch die Kombination mit Trastuzumab gesteigert werden. Mit der Zelllinie NCl-N87 wurden zusätzlich Tumorxenografts in CD-1 athymen Nacktmäusen generiert und es konnte gezeigt werden, dass durch die Monotherapie mit Trastuzumab oder Lapatinib eine Tumorregression, durch die Kombination beider Wirk- 
stoffe sogar nahezu eine Komplettremission erreicht werden konnte (Wainberg et al. 2010). Klinisch konnte die Hinzunahme von Lapatinib zu Capecitabine und Oxaliplatin in der Erstlinientherapie des nicht resektablen HER-2-positiven Adenokarzinoms des Magens, der Kardia oder des Ösophagus im Rahmen der TRIO-013/LOGiC-Studie hingegen keinen signifikanten Effekt auf das Gesamtüberleben der Patienten im Vergleich zur Kontrollgruppe zeigen (Hecht et al. 2016). Auch in der TyTAN-Studie resultierte durch die Hinzunahme von Lapatinib als Zweitlinientherapie beim fortgeschrittenen Magenkarzinoms zwar zunächst eine erhöhte Antitumor-Aktivität, jedoch wirkte sich diese Therapie im Vergleich zur Standardchemotherapie mit Paclitaxel nicht auf das Gesamtüberleben aus. Insgesamt war die Effektivität bei Patienten mit einem IHC-Scoring von 3+ besser (Satoh et al. 2014).

Im HER-2-positiven KRK mit KRAS Exon 2 Wildtyp konnte im Rahmen der HERACLES-Studie präklinisch und klinisch ein deutlicher Effekt durch eine Kombinationstherapie mit Lapatinib gezeigt werden (Bertotti et al. 2011; Siena et al. 2018) (s. 4.4).

In der vorliegenden Arbeit resultierte aus der Behandlung mit Lapatinib bereits bei sehr niedrigen Dosen eine starke Inhibierung von pAkt (s. Abb. 14A, S. 56). Übereinstimmend damit wurde auch die Zellviabilität signifikant gemindert (s. Abb. 14B, S. 56). Eine naheliegende Erklärung ist, dass auch andere Rezeptoren der EGFR-Familie durch Lapatinib inhibiert werden (Zanardi et al. 2015).

Lapatinib stellt somit als kleinmolekularer Inhibitor eine vielversprechende Substanz dar, insbesondere in Kombination mit dem Antikörper Trastuzumab (Leto et al. 2015) (s. 4.3). Im Vergleich zu Trastuzumab ist Lapatinib jedoch mit einer erhöhten Toxizität assoziiert, welche sich unter anderem in starken gastrointestinalen Beschwerden, Neutropenie, Transaminasenanstieg sowie Hautausschlag zeigt (Ahn ER et al. 2012).

\subsubsection{Afatinib}

Afatinib repräsentiert einen irreversiblen Tyrosinkinaseinhibitor. Therapeutisch wird dieser Inhibitor bereits in der Erstlinientherapie des EGFR-mutierten nicht-kleinzelligen Lun- 
genkarzinoms (NSCLC) eingesetzt (Dungo und Keating 2013). In mehreren klinischen Studien (LUX-Lung-Studien) zeigte sich eine Überlegenheit von Afatinib bezogen auf das progressionsfreie Überleben und die relative Ansprechrate der Substanz im Vergleich zur Chemotherapie und anderen Tyrosinkinaseinhibitoren mit reversiblem Bindungsmuster, welche in der Therapie des NSCLC ohne EGFR-Mutation gute Ergebnisse erzielten (D'Arcangelo und Hirsch 2014). In klinischen Studien zum HER-2-positiven metastasierten, unter der Therapie mit Trastuzumab progressiven Mammakarzinom gab es kontroverse Ergebnisse hinsichtlich eines therapeutischen Vorteils durch Hinzunahme von Afatinib (Cortes et al. 2015; Lin et al. 2012). In der LUX-Breast-1-Studie konnte keine Verbesserung des progressionsfreien Überlebens verglichen mit der Trastuzumab-basierten Therapie erreicht werden (Harbeck et al. 2016). Zudem wurden im Afatinib-Arm mehr unerwünschte Arzneimittelwirkungen beobachtet.

In einer präklinischen Studie wurden die Effekte einer Behandlung mit Trastuzumab und Afatinib an drei Magenkarzinomzelllinien (MKN1, MKN7 und NCl-N87) getestet (Keller et al. 2018). Mittels Immunhistochemie wurde anhand der in Paraffin eingebetteten Zelllinien die HER-2-Expression getestet. Dabei hatten die Zelllinien MKN7 und NCI-N87 ein hohes Expressionslevel, die Zelllinie MKN1 war diesbezüglich negativ. Es wurden nach Behandlung mit Trastuzumab oder Afatinib Proteom-Analysen durchgeführt. Dabei zeigten sich in der Zelllinie NCI-N87 eine deutliche Reduktion von pHER-2 und pEGFR nach Behandlung mit Trastuzumab sowie eine deutliche Reduktion von pEGFR und pHER-3 nach Behandlung mit Afatinib. Erst durch die Kombination von Trastuzumab und Afatinib konnten gleichzeitig pEGFR, pHER-2 und pHER-3 stark reduziert werden. Dieser Effekt konnte in der Zelllinie MKN7 nur abgeschwächt und in der Zelllinie MKN1 nicht nachgewiesen werden. Eine mögliche Erklärung dafür ist, dass bereits variierende Level der aktivierten Rezeptoren ohne Behandlung bestanden. In Proliferationsassays zeigte die Behandlung mit Trastuzumab in keiner Zelllinie einen Effekt, die Behandlung mit Afatinib (als Mono- oder Kombinationstherapie mit Trastuzumab) jedoch bewirkte eine deutliche Verminderung der metabolischen Aktivität, besonders in der Zelllinie NCl-N87 (Keller et al. 2018). 
Aktuell werden Patienten mit einem HER-2-postitiven, Trastuzumab-resistenten Magenoder Kardiakarzinom rekrutiert, um eine Therapie mit Afatinib und Paclitaxel als Zweitlinientherapie zu evaluieren (NCT01522768). In einer anderen Phase-II-Studie wird aktuell Afatinib in Kombination mit Cisplatin und 5-FU als Erstlinientherapie des HER-2 positiven inoperablen Magen- oder Kardiakarzinoms untersucht (NCT01743365).

In einer präklinischen Studie wurden Zelllinien verschiedener Tumorentitäten mittels Western Blot auf eine HER-2 Überexpression getestet. Für weitere Experimente wurden die HER-2-exprimierende kolorektale Karzinomzellinie HCT-15 und die HER-2exprimierende Magenkarzinomzelllinie AGS sowie die nicht-HER-2-exprimierende Magenkarzinomzelllinie MKN45 ausgewählt. Die HER-2-exprimierenden Karzinomzelllinien waren signifikant sensibler auf eine Behandlung mit Afatinib bezogen auf die Proliferationshemmung im Viabilitätsassay und zeigten eine signifikant höhere Apoptoserate mittels Durchflusszytometrie (Guan et al. 2014). Mit den Zelllinien HCT-15 und MKN45 wurden Tumorxenografts im Mausmodell gebildet. Durch die Therapie mit Afatinib konnte das Tumorwachstum gehemmt und die Tumorgröße im Xenograft der Zelllinie HCT-15 deutlich reduziert werden, ohne dass ein Effekt im Xenograft der HER-2-negativen Zelllinie MKN45 gezeigt werden konnte (Guan et al. 2014).

In einer weiteren präklinischen Studie zur Effektivität einer Anti-HER-2-Therapie im KRK und Magenkarzinom konnte gezeigt werden, dass allein eine Kombination des Antikörpers Trastuzumab mit Lapatinib oder die Monotherapie mit Afatinib eine dauerhafte Inaktivierung der Rezeptoren HER-2, HER-3 und EGFR bewirken und somit den nachgeschalteten Signalweg über PI3K/Akt hemmen (Leto et al. 2015) (s. 4.3, 4.4).

Die Ergebnisse der vorliegenden Arbeit zeigen - ähnlich wie bei Lapatinib - einen deutlichen Einfluss einer Behandlung mit Afatinib bezogen auf die Reduktion von pAkt (s. Abb. 15A, S. 58) und die deutliche Verminderung der Zellviabilität (s. Abb. 15B, S. 58) in allen drei kolorektalen Karzinomzelllinien. Ebenso wie Lapatinib inhibiert auch Afatinib neben HER-2 andere Rezeptoren der EGFR-Familie und bewirkt möglicherweise dadurch eine potentere Inhibierung der nachgeschalteten Signalkaskade (Li et al. 2008; Spector et al. 2005), was sich auch in den Ergebnissen der vorliegenden Arbeit widerspiegelt. 


\subsubsection{Vergleich der Monotherapie und der Kombination mit 5-FU und Oxaliplatin}

Die Systemtherapie des KRK beinhaltet standardmäßig die Wirkstoffe 5-FU und Oxaliplatin (Schmiegel et al. 2017). Daher wurde in der vorliegenden Arbeit auch der Effekt einer Kombination der Anti-HER-2-Substanzen mit 5-FU und Oxaliplatin untersucht. Hier zeigte sich nur teilweise ein stärkerer Effekt auf die Zellviabilität im Vergleich zur Monotherapie (s. 3.2.4). Die Ursache dafür kann zum jetzigen Zeitpunkt nicht ausreichend erklärt werden. Die Zelllinie SW837 zeigte jedoch nahezu durchgängig ein vermindertes Ansprechen der Therapie durch Hinzunahme der o.g. Chemotherapeutika im Vergleich zur AntiHER-2-Monotherapie. Es bleibt unklar, ob dieses Ergebnis im Zusammenhang mit den wesentlich höheren Konzentrationen von 5-FU und Oxaliplatin steht, welche für SW837 benötigt wurden (s. 3.2.4.1). Möglicherweise besteht hier eine relative Resistenz gegenüber 5-FU und Oxaliplatin.

Die Antikörper Trastuzumab und Pertuzumab bewirkten auch in der Kombination mit den Chemotherapeutika keine maßgebliche Reduktion der Zellviabilität, lediglich in den Zelllinien LS513 und LS1034 war eine Parallelverschiebung der Dosis-Wirkungs-Kurven mit zunehmender Behandlungszeit zu beobachten (s. Abb. 23, S. 66 und Abb. 24, S. 67). Die Behandlung mit T-DM1 zeigte in Kombination mit 5-FU und Oxaliplatin in allen Zelllinien einen deutlichen Effekt, welcher sich bei den Zelllinien LS513 und LS1034 jedoch erst bei höheren Dosen zeigte (s. Abb. 26, S. 69). Lapatinib und Afatinib hatten auch in Kombination mit 5-FU und Oxaliplatin den deutlichsten Einfluss auf die Zellviabilität. Mit Ausnahme der Zelllinie SW837 wurde die Behandlung mit den verwendeten Substanzen durch eine Hinzunahme von 5-FU und Oxaliplatin auf Ebene der Zellviabilität zu den meisten Messzeitpunkten effektiver (s. Abb. 28, S. 71 und Abb. 30, S. 72).

\subsection{Mögliche Rolle von HER-3 in der Resistenz gegenüber Anti-HER-2- Substanzen}

Unklar bleibt zum jetzigen Zeitpunkt, warum die Antikörper Trastuzumab und Pertuzumab keine Wirkung auf die Zellviabilität zeigten, weder als Monotherapie noch in Kombina- 
tion miteinander. Eine mögliche Ursache dafür könnte sein, dass HER-3 kompensatorisch vermehrt exprimiert wird und somit eine Reaktivierung des Signalweges induziert wird (Cha et al. 2014).

HER-3 scheint eine Schlüsselrolle in der Resistenz gegenüber einer Anti-HER-2-Therapie einzunehmen. Dies ist nicht zuletzt darin begründet, dass auch durch HER-3 eine potente Aktivierung des Signalweges über PI3K/Akt bewirkt wird (Hsieh und Moasser 2007). Als Mitglied der Rezeptortyrosinkinasen-Familie kann HER-3 Heterodimere mit anderen Rezeptoren bilden, ist jedoch bei nahezu fehlender intrinsischer Tyrosinkinaseaktivität auf die Transphosphorylierung durch den Bindungspartner angewiesen (Berger et al. 2004). In einer präklinischen in vivo und in vitro Studie für HER-2 überexprimierende gastrointestinale Zelllinien konnte gezeigt werden, dass eine Behandlung mit Trastuzumab eine verminderte HER-3-Phosphorylierung bewirkte (Leto et al. 2015) (s. 4.4). Diese war zwar lang anhaltend, zeigte jedoch nur einen mäßigen Einfluss auf den nachgeschalteten Signalweg. Die alleinige Behandlung mit Lapatinib hingegen führte neben der verminderten Phosphorylierung aller Rezeptoren der EGFR-Familie auch zu einer deutlichen Repression der intrazellulären Signalkaskaden, bewirkte jedoch eine Rephosphorylierung von HER-3 und EGFR. Erst die Kombination aus Trastuzumab und Lapatinib oder die Behandlung mit Afatinib konnte sowohl eine nachhaltige Dephosphorylierung als auch eine verminderte Aktivierung des nachgeschalteten Signalweges bewirken. Durch eine RNAi-vermittelte Inhibierung von HER-3 konnte die Sensibilität auf die Therapie mit Lapatinib weiter gesteigert werden. Auch im Tiermodell bestätigte sich der Effekt im Sinne eines Tumorregresses unter der Behandlung mit der Kombination aus Trastuzumab und Lapatinib oder der alleinigen Behandlung mit Afatinib (Leto et al. 2015). Scartozzi et al. identifizierten HER-3 als einen prädiktiven Marker für das klinische Outcome von KRK-Patienten mit KRAS-Wildtyp unter Cetuximab-Therapie (Scartozzi et al. 2012). Zusammenfassend ist es also denkbar, dass eine duale Hemmung von HER-2 und HER-3 einen synergistischen Effekt in der Therapie HER-2-positiver Tumore bewirken und zur Überwindung von Resistenzmechanismen in der Anti-HER-2-Therapie führen könnte. 


\subsection{Einsatz von Anti-HER-2-Substanzen im kolorektalen Karzinom}

Es wurden bereits präklinische und klinische Daten zur Therapie des HER-2 positiven metastasierten KRK veröffentlicht. Bertotti et al. erstellten Xenograft-Mausmodelle aus kolorektalen Lebermetastasen von 85 Patienten, welche bis zur zweiten Generation passagiert wurden. Es entstanden je zwei Kohorten von 12 Mäusen eines Tumorursprungs (Bertotti et al. 2011). Schließlich wurden die Experimente an Populationen von 47 der primären Tumoren durchgeführt. Zunächst wurden diese mit Cetuximab Placebo-kontrolliert behandelt. In einem nächsten Schritt wurden diejenigen Populationen mit KRAS-Wildtyp selektioniert und erneut mit Cetuximab behandelt. Etwa $23 \%$ waren resistent gegen die Therapie mit Cetuximab. In dieser Subgruppe von 11 Populationen zeigten vier Fälle (M051, M077, M091 und M147) einen positiven HER-2-Status (HercepTest und FISH). Unter der Vorstellung, dass ein positiver HER-2-Status sowohl einen Indikator für eine Resistenz gegen eine EGFR-Inhibition als auch einen potenziellen Angriffspunkt für eine zielgerichtete Therapie darstellen könnte, wurden exemplarisch M077 und M091 weiteren Experimenten zugeführt. Diese Xenograft-Populationen wurden nun randomisiert und mit Pertuzumab, Pertuzumab plus Cetuximab, Lapatinib, Lapatinib plus Cetuximab oder Pertuzumab plus Lapatinib Placebo-kontrolliert behandelt. Eine Resistenz gegen die Therapie mit Pertuzumab oder Pertuzumab plus Cetuximab zeigte sich bei M077. Hingegen konnte durch eine Behandlung mit Lapatinib ein Wachstum des Tumors eingeschränkt werden. Die Kombination von Lapatinib und Pertuzumab zeigte sowohl eine deutliche Reduktion des Tumorvolumens von bis zu $93 \%$ über 6 Wochen als auch eine signifikante Reduktion der Aktivierung von Proteinen des nachgeschalteten Signalweges. Auch die Kombination von Lapatinib und Cetuximab bewirkte eine signifikante Tumorreduktion, jedoch nicht im gleichen Ausmaß. Die Ergebnisse bei der Xenograftlinie M091 waren ähnlich, wobei die Monotherapie mit Lapatinib keinen wesentlichen Effekt zeigte, hingegen die Kombination aus Pertuzumab und Cetuximab das Tumorwachstum deutlicher verzögerte. Zusammenfassend stellte vor allem die Kombination von Lapatinib mit Pertuzumab eine wirksame Therapie in dieser selektionierten Population dar (Bertotti et al. 2011).

In einer anderen präklinischen Studie zur Effektivität einer Anti-HER-2-Therapie im KRK und Magenkarzinom konnte gezeigt werden, dass allein eine Kombination des Antikör- 
pers Trastuzumab mit Lapatinib oder die Monotherapie mit Afatinib eine dauerhafte Inaktivierung der Rezeptoren HER-2, HER-3 und EGFR bewirken und somit den nachgeschalteten Signalweg über PI3K/Akt hemmen (Leto et al. 2015).

Es wurden zum einen in vitro Experimente mit der HER-2 amplifizierten MagenkarzinomZelllinie NCl-N87 und einer kolorektalen Karzinomzelllinie NCl-H508, welche mittels lentiviraler Transduktion eine HER-2-Überexpression zeigte, durchgeführt. Dabei wurden die Zelllinien mit Trastuzumab, Lapatinib, einer Kombination von Trastuzumab und Lapatinib und schließlich auch mit Afatinib behandelt. Es wurden Proliferationsassays dosis- und zeitabhängig sowie Western Blots durchgeführt. In der Zelllinie NCI-N508-HER2 konnte auf Proteinebene nach Behandlung mit Trastuzumab dosisabhängig kein Effekt auf die Phosphorylierung von HER-2 und EGFR, sehr wohl aber von HER-3 gezeigt werden. Lapatinib bewirkte dosisabhängig eine deutliche Reduzierung der Phospho-Proteinlevel aller Rezeptoren genau wie die Kombination von Lapatinib und Trastuzumab. Mit steigender Behandlungsdauer zeigte sich durch Trastuzumab ein moderater Effekt auch auf HER-2 und EGFR. Die Behandlung mit Lapatinib bewirkte mit der Zeit eine Rephosphorylierung insbesondere von HER-3 neben einem generell erhöhten HER-3-Proteinlevel. Nur durch die Kombination beider Inhibitoren wurde eine dauerhafte Reduktion von pHER-2, pHER-3 und pEGFR bewirkt. Die Proteine der nachgeschalteten Signalwege wurden entsprechend durch Lapatinib und die Kombination von Lapatinib und Trastuzumab gehemmt, insbesondere im Bereich des Signalweges über PI3K und Akt. Erhöhte Proteinlevel von HER-3 wurden auch während der Behandlung mit Afatinib gezeigt, jedoch ergab sich durch diesen irreversiblen Inhibitor keine Erhöhung der pHER-3-Level mit der Zeit (Leto et al. 2015).

Zum anderen wurden In-vivo-Experimente im Mausmodell mit dem HER-2-amplifizierten Tumorgraft eines metastasierten KRK (M051) und einem Xenograft aus der o.g. Magenkarzinom-Zelllinie (NCl-N87) durchgeführt. Es konnte bei M051 nach der Behandlung mit den genannten Inhibitoren gezeigt werden, dass eine Therapie mit Trastuzumab allein keinen Effekt auf das Tumorvolumen im Vergleich zum Placebo zeigte. Während der Therapie mit Lapatinib zeigte sich nach einer stabilen Latenzzeit des Tumorwachstums ein Tumorprogress. Die Kombination bewirkte eine dauerhafte Regression des Tumors über 
den Untersuchungszeitraum von 40 Tagen. Im Xenograft-Modell der MagenkarzinomZelllinie konnte dadurch sogar ein Schrumpfen des Tumors bewirkt werden. Hier war der Effekt von Trastuzumab allein jedoch auch deutlicher, was am ehesten der deutlich höheren Amplifikation von HER-2 im Vergleich zu M051 zuzuschreiben war. Die Behandlung mit Afatinib bewirkte einen ähnlichen Effekt wie die Behandlung mit der Kombination aus Lapatinib und Trastuzumab (Leto et al. 2015). Die vermehrte Transphosphorylierung von HER-3 bewirkte in HER-2-amplifizierten Zellen eine verstärkte Aktivierung des Signalweges über PI3K/Akt und kann somit als Resistenzmechanismus verstanden werden (s. 4.3) (Leto et al. 2015).

Eine weitere präklinische Studie bestätigte ebenfalls den Zusammenhang einer Resistenz gegen Cetuximab durch HER-2-Mutationen im KRK mit KRAS-Wildtyp. Zunächst wurden vier aktivierende HER-2-Mutationen mittels retroviraler Vektoren in immortalisierte murine Kolonepithelzellen transfiziert (Kavuri et al. 2015). Auf Proteinebene zeigte sich dadurch eine deutliche Aktivierung des HER-2-nachgeschalteten Signalweges, und auch das Zellwachstum konnte im Kolonie-Bildungs-Assay gesteigert werden (Kavuri et al. 2015). Die Transfektion der HER-2-Mutationen in Cetuximab-sensible, KRAS-Wildtyp tragende kolorektale Karzinomzellinien DIFI und $\mathrm{NCI}-\mathrm{H} 508$ resultierte in einer deutlichen Resistenz gegen die Anti-EGFR-Therapie. Sowohl die Zelllinien als auch Xenografts der Tumorzelllinien im Mausmodell zeigten ein deutlich vermindertes Wachstum durch die Behandlung mit den irreversiblen Tyrosinkinaseinhibitoren Afatinib und Neratinib und auch durch die Kombinationstherapie von Neratinib und Trastuzumab. Hingegen waren im Vergleich die KRAS-mutierten kolorektalen Karzinomzellinien SW480 und HCT116 resistent gegenüber Neratinib (Kavuri et al. 2015). Schließlich wurden aus 48 von Patienten abgeleiteten Tumorxenografts mit Cetuximab-Resistenz und KRAS-Wildtyp vier mit HER-2Mutationen identifiziert und davon zwei für weitere Experimente in vivo ausgewählt. Diese wurden zunächst mit Trastuzumab, Neratinib oder Lapatinib therapiert. Diese Therapie bewirkte zunächst ein verzögertes Tumorwachstum, im Verlauf zeigte sich jedoch ein Progress. Die Kombinationstherapie aus Trastuzumab und Neratinib resultierte in einer dauerhaften Tumorregression über den Untersuchungszeitraum. Dieser Effekt konnte in einem Tumorxenograft mit KRAS-Mutation nicht aufgezeigt werden (Kavuri et al. 2015). 
Ebenfalls wurden erste Ergebnisse der HERACLES-Studie (NCT03225937) veröffentlicht (Sartore-Bianchi et al. 2016; Siena et al. 2018). In dieser Phase-Il Studie wurden in der Kohorte A 33 Patienten mit HER-2-positivem metastasiertem KRK und KRAS-Wildtyp im Exon 2 mit einer primären Resistenz gegen die Standardtherapie inklusive Cetuximab oder Panitumumab mit einer Kombination aus Trastuzumab und Lapatinib therapiert. Nach einem zuvor etablierten Scoring-System (s. 4.2.1) wurde das Patientenkollektiv aus vier verschiedenen Zentren hinsichtlich des HER-2 Status untersucht. Circa 5\% der Patienten, welche einen KRAS-Wildtyp im Exon 2 aufwiesen, zeigten eine HER-2-Positivität. In der Studie zeigte sich bei ca. $30 \%$ der Patienten eine objektive Ansprechrate auf das 0.g. Therapieregime, bei zwei Patienten sogar eine Komplettremission (Siena et al. 2018). Bei $44 \%$ der Patienten konnte im Zeitraum der Nachsorge ein stabiler Krankheitsverlauf konstatiert werden. Das mediane progressionsfreie Überleben lag bei 5,2 Monaten (SartoreBianchi et al. 2016). Die Therapie mit Trastuzumab und Lapatinib wurde gut vertragen bei geringer Toxizität. Durch die HERACLES-Studie wurde die Relevanz einer zielgerichteten Therapie gegen HER-2 im KRK klar gezeigt. Zwar profitierte nur eine kleine Kohorte von der Therapie, dabei handelte es sich jedoch um ausgiebig vorbehandelte Patienten, im Durchschnitt nach fünf vorausgehenden Therapieregimen, im Krankheitsprogress, also um Patienten, für die es praktisch keine weiteren Therapieoptionen gab.

Basierend auf präklinischen Daten wird in der HERACLES B Phase-II-Studie aktuell eine weitere Kohorte von Patienten mit HER-2 positivem KRK und KRAS-Wildtyp im Exon 2 mit Pertuzumab und T-DM1 behandelt (Trusolino et al.). Vorläufige Ergebnisse zeigen ein gutes und zum Teil dauerhaftes Ansprechen, die endgültigen Ergebnisse sind zu diesem Zeitpunkt noch ausstehend (Greally et al. 2018). Eine Monotherapie mit T-DM1 wird in der laufenden HERACLES RESCUE-Studie (NCT03418558) als Teil des HERACLES-Projektes an einer Kohorte untersucht, welche unter der Therapie mit Lapatinib und Trastuzumab einen Krankheitsprogress entwickelten (Greally et al. 2018). Bereits im Xenograft-Modell dieser Patienten konnte gezeigt werden, dass eine deutlich erhöhte HER-2-Expression bestand und durch die Therapie mit T-DM1 eine signifikante Tumorregression im Vergleich zur Therapie mit Pertuzumab erreicht werden konnte (Kanat et al. 2018). 
In der laufenden multizentrischen nicht-randomisierten Phase-Ila MyPathway-Studie wurden bisher 230 Patienten mit fortgeschrittenen, therapierefraktären metastasierten soliden Tumoren und molekularen Veränderungen von HER-2, EGFR, BRAF sowie dem Hedgehog-Signalweg mit zielgerichteten Substanzen therapiert (Hainsworth et al. 2018). Darunter war die Gruppe mit einer Überexpression und/oder Amplifikation von HER-2 im metastasierten KRK mit 37 Patienten am größten. Diese Patienten waren im Durchschnitt mit bereits vier vorausgehenden Therapieregimen vorbehandelt und wurden nun mit einer Kombination aus Trastuzumab und Pertuzumab therapiert. Die objektive Ansprechrate dieser Kohorte lag bei $38 \%$, wobei keine Komplettremission erreicht wurde. Vier Patienten hatten unter dieser Therapie einen stabilen Krankheitszustand über mindestens 120 Tage (Hainsworth et al. 2018).

Eine weitere klinische Phase-II-Studie, die MOUNTAINEER-Studie (NCT03043313), rekrutiert aktuell Patienten mit HER-2 positivem, metastasierten KRK und RAS-Wildtyp, welche bereits eine Chemotherapie mit 5-FU, Oxaliplatin, Irinotecan und einem monoklonalen Antikörper gegen VEGF erhalten haben. Es wird die Therapie mit einer Kombination aus Trastuzumab und Tucatinib, einem oral verfügbaren kleinmolekularen Inhibitor der Tyrosinkinasedomäne von HER-2, untersucht (Greally et al. 2018).

In einer Phase-II Studie der Southwestern Oncology Group (S1613, NCT03365882) werden aktuell Patienten mit HER-2 positivem metastasiertem oder irresektablem KRK und RASsowie BRAF-Wildtyp rekrutiert. Nach Progress unter der systemischen Standardchemotherapie ohne Anti-EGFR- oder Anti-HER-2-Therapie werden diese Patienten randomisiert, um eine Therapie mit einer Kombination aus Trastuzumab und Pertuzumab oder Cetuximab und Irinotecan zu erhalten (Greally et al. 2018)

Die Ergebnisse dieser präklinischen und klinischen Studien zeigen, dass die zielgerichtete Behandlung gegen HER-2 im kolorektalen Karzinom eine maßgebliche klinische Relevanz hat, da sowohl mögliche Resistenzen in der Standardtherapie identifiziert als auch neue Therapieoption bei deutlich vorbehandelten Patienten evaluiert werden können. Es bedarf weiterer großer klinischer Studien zur Validierung dieser Ergebnisse und schließlich auch die Evaluation einer primären Diagnostik. 


\subsection{Zusammenfassung und Ausblick}

Zusammengefasst weist ein relevanter Anteil (25\%) der untersuchten kolorektalen Karzinomzelllinien einen positiven HER-2-Status auf. Entsprechende klinische Ergebnisse konnten ebenfalls anhand von Vordaten unserer Arbeitsgruppe gezeigt werden. Von 264 Patienten mit lokal fortgeschrittenem Rektumkarzinom ließ sich bei 12,4\% der prätherapeutischen Biopsien bzw. 26,7\% der chirurgischen Resektate nach neoadjuvanter RCT ein positiver HER-2-Status erheben (Conradi et al. 2013). In der HERACLES-Studie betrug der Anteil HER-2-positiver KRK mit KRAS-Wildtyp $5 \%$ des Gesamtkollektivs (Sartore-Bianchi et al. 2016). Unterschiede in der Häufigkeit der HER-2-Positivität in den verschiedenen Studien liegen unter anderem darin begründet, dass noch kein einheitliches Scoring für diese Tumorentität existiert. Es wäre daher vorteilhaft, die Scoring-Systeme beim kolorektalen Karzinom zu vergleichen und zu standardisieren.

In der vorliegenden Arbeit konnte gezeigt werden, dass die Inhibition von HER-2 in KRKZelllinien eine effektive Reduktion der Zellviabilität bewirkte, wobei deren Ausprägung abhängig war vom Wirkmechanismus der verschiedenen Substanzen. Dabei scheint der Einsatz irreversibler Inhibitoren oder die Kombination einer HER-2-Inhibition mit anderen EGFR-Inhibitoren am wirksamsten zu sein. Auch trotz der vermeintlich kleinen Gruppe an potenziell profitierenden Patienten erscheint eine zielgerichtete Therapie des HER-2positiven KRK sinnvoll zu sein. Dies liegt auch darin begründet, dass das KRK eine der häufigsten Tumorentitäten darstellt. Selbst ein geringer Prozentsatz an Patienten mit einer HER-2-Positivität entspricht daher einer großen Fallzahl für eine zielgerichtete Therapie. Es bleibt zu prüfen, zu welchem Zeitpunkt eine Anti-HER-2 Therapie sinnvoll erscheint beispielsweise in einem neoadjuvanten oder adjuvanten Setting oder lediglich in der metastasierten Situation. 


\section{Zusammenfassung}

Das kolorektale Karzinom (KRK) stellt die zweithäufigste Krebs-assoziierte Todesursache in der westlichen Welt dar. Trotz Implementierung multimodaler Therapiestrategien und der Entwicklung spezifischer Inhibitoren wird das Gesamtüberleben weiterhin durch das Auftreten von Fernmetastasen limitiert, welche in ca. 50\% der Fälle entstehen. Die einzige kurative Therapiestrategie stellt hier die chirurgische Resektion dar. Allerdings ist eine kurative Resektion technisch nicht immer möglich, und nach erfolgreicher Resektion ist häufig ein erneutes Auftreten der Erkrankung zu verzeichnen. Daher ist es notwendig, neue und effektive therapeutische Zielstrukturen zu evaluieren. In dieser Arbeit wurde untersucht, ob eine gegen HER-2 gerichtete Therapie beim KRK sinnvoll ist.

Initial wurden 12 kolorektale Karzinomzelllinien mittels Immunzytochemie und Silber-insitu-Hybridisierung untersucht. Es konnte gezeigt werden, dass ein relevanter Anteil (25\%) eine HER-2 Überexpression bzw. Genamplifikation aufweist. Diese drei Zelllinien LS513, LS1034 und SW837 - wurden nachfolgend mit fünf gegen HER-2 gerichteten Substanzen behandelt. Hieraus resultierte zumeist eine Inhibierung des nachgeschalteten Signalweges und der Zellviabilität, wobei der Effekt abhängig vom Wirkmechanismus der eingesetzten Anti-HER-2 Substanzen war. Die HER-2-spezifischen Antikörper Trastuzumab und Pertuzumab zeigten sowohl in der Monotherapie als auch in Kombination miteinander nur einen geringen Einfluss auf die Viabilität der Tumorzellen. Demgegenüber war ein starker Effekt durch das Antikörper-Wirkstoff-Konjugat T-DM1 (spezifische Bindung an HER-2 und Freisetzung des als Mikrotubuli-Inhibitor wirksamen Maytansin-Derivates DM1 nach Internalisierung) sowie die kleinmolekularen Inhibitoren Lapatinib (reversible Hemmung der Tyrosinkinasedomäne von HER-2 und EGFR) und Afatinib (irreversible Hemmung der Tyrosinkinasedomäne von HER-2, EGFR und HER-4) zu verzeichnen. Durch Kombination mit den Chemotherapeutika 5-FU und Oxaliplatin konnte in Abhängigkeit von Zelllinie und Behandlungsdauer die viabilitätshemmende Wirkung selektiv weiter gesteigert werden.

Zusammenfassend weisen diese Daten darauf hin, dass eine alleinige Inhibierung von HER-2 nicht ausreichend wirksam beim KRK ist. Hingegen erscheint die Kombination einer 
HER-2-Inhibition mit simultaner Hemmung anderer EGF-Rezeptoren sehr wirksam zu sein.

Dies sollte daher in kontrollierten Studien getestet werden, wobei die verschiedenen HER-2-Scoring-Systeme, die derzeit beim KRK zum Einsatz kommen, vorher vereinheitlicht werden sollten. 


\section{Anhang}

Substanz Zeitpunkt (h) $\mathrm{EC}_{50}$-Monotherapie $\mathrm{EC}_{50}$-Kombinationstherapie

\begin{tabular}{c|ccc|}
\hline \multirow{4}{*}{ T-DM1 } & 24 & $(2280 \mu \mathrm{g} / \mathrm{ml})^{*}$ & $(906 \mu \mathrm{g} / \mathrm{ml})^{*}$ \\
& 48 & $72,4 \mu \mathrm{g} / \mathrm{ml}$ & $27,7 \mu \mathrm{g} / \mathrm{ml}$ \\
& 72 & $25,8 \mu \mathrm{g} / \mathrm{ml}$ & $11,7 \mu \mathrm{g} / \mathrm{ml}$ \\
\hline \multirow{3}{*}{ Lapatinib } & 24 & $4 \mu \mathrm{M}$ & $10,2 \mu \mathrm{M}$ \\
& 48 & $1,7 \mu \mathrm{M}$ & $2,5 \mu \mathrm{M}$ \\
& 72 & $0,7 \mu \mathrm{M}$ & $2,1 \mu \mathrm{M}$ \\
\hline \multirow{3}{*}{ Afatinib } & 24 & $6,2 \mu \mathrm{M}$ & $4,1 \mu \mathrm{M}$ \\
& 48 & $2 \mu \mathrm{M}$ & $0,9 \mu \mathrm{M}$ \\
& 72 & $0,6 \mu \mathrm{M}$ & $0,5 \mu \mathrm{M}$
\end{tabular}

Tabelle 10: $\overline{E C}_{50}$-Werte der Mono-/ Kombinationstherapie der Zelllinie LS513

Substanz Zeitpunkt (h) $\quad \mathrm{EC}_{50}$-Monotherapie $\mathrm{EC}_{50}$-Kombinationstherapie

\begin{tabular}{c|ccc|}
\hline \multirow{4}{*}{ T-DM1 } & 24 & $(1040 \mu \mathrm{g} / \mathrm{ml})^{*}$ & $(1280 \mu \mathrm{g} / \mathrm{ml})^{*}$ \\
& 48 & $159 \mu \mathrm{g} / \mathrm{ml}$ & $142 \mu \mathrm{g} / \mathrm{ml}$ \\
& 72 & $61,7 \mu \mathrm{g} / \mathrm{ml}$ & $23,3 \mu \mathrm{g} / \mathrm{ml}$ \\
\hline \multirow{3}{*}{ Lapatinib } & 24 & $102 \mu \mathrm{M}$ & $22,6 \mu \mathrm{M}$ \\
& 48 & $5,3 \mu \mathrm{M}$ & $7,4 \mu \mathrm{M}$ \\
& 72 & $4,6 \mu \mathrm{M}$ & $2,1 \mu \mathrm{M}$ \\
\hline \multirow{3}{*}{ Afatinib } & 24 & $7,4 \mu \mathrm{M}$ & $4,2 \mu \mathrm{M}$ \\
& 48 & $2,3 \mu \mathrm{M}$ & $1,1 \mu \mathrm{M}$ \\
& 72 & $1,6 \mu \mathrm{M}$ & $0,5 \mu \mathrm{M}$
\end{tabular}

Tabelle 11: $\overline{\mathrm{EC}_{50} \text {-Werte der Mono-/ Kombinationstherapie der Zelllinie LS1034 }}$ 
Substanz Zeitpunkt (h) $\mathrm{EC}_{50}$-Monotherapie $\mathrm{EC}_{50}$-Kombinationstherapie

\begin{tabular}{c|ccc|}
\hline \multirow{4}{*}{ T-DM1 } & 24 & $(345 \mu \mathrm{g} / \mathrm{ml})^{*}$ & $(3550 \mu \mathrm{g} / \mathrm{ml})^{*}$ \\
& 48 & $92,2 \mu \mathrm{g} / \mathrm{ml}$ & $(556 \mu \mathrm{g} / \mathrm{ml})^{*}$ \\
& 72 & $19,8 \mu \mathrm{g} / \mathrm{ml}$ & $18,2 \mu \mathrm{g} / \mathrm{ml}$ \\
\hline \multirow{3}{*}{ Lapatinib } & 24 & $23,6 \mu \mathrm{M}$ & $14,8 \mu \mathrm{M}$ \\
& 48 & $3,5 \mu \mathrm{M}$ & $6,3 \mu \mathrm{M}$ \\
& 72 & $1,6 \mu \mathrm{M}$ & $4,3 \mu \mathrm{M}$ \\
\hline \multirow{3}{*}{ Afatinib } & 24 & $6,3 \mu \mathrm{M}$ & $12,9 \mu \mathrm{M}$ \\
& 48 & $2,8 \mu \mathrm{M}$ & $4,4 \mu \mathrm{M}$ \\
& 72 & $1,1 \mu \mathrm{M}$ & $2,1 \mu \mathrm{M}$
\end{tabular}

Tabelle 12: $\overline{\mathrm{EC}_{50} \text {-Werte der Mono-/ Kombinationstherapie der Zelllinie SW837 }}$ 


\section{Literaturverzeichnis}

Adam R, De Gramont A, Figueras J, Guthrie A, Kokudo N, Kunstlinger F, Loyer E, Poston G, Rougier P, Rubbia-Brandt L et al. (2012): The oncosurgery approach to managing liver metastases from colorectal cancer: a multidisciplinary international consensus. Oncologist $17,1225-1239$

Adams CW, Allison DE, Flagella K, Presta L, Clarke J, Dybdal N, McKeever K, Sliwkowski MX (2006): Humanization of a recombinant monoclonal antibody to produce a therapeutic HER dimerization inhibitor, pertuzumab. Cancer Immunol Immunother 55, 717-727

Agus DB, Gordon MS, Taylor C, Natale RB, Karlan B, Mendelson DS, Press MF, Allison DE, Sliwkowski MX, Lieberman G et al. (2005): Phase I clinical study of pertuzumab, a novel HER dimerization inhibitor, in patients with advanced cancer. J Clin Oncol 23, 2534-2543

Ahn DH, Wu C, Wei L, Williams TM, Wuthrick E, Abdel-Misih S, Harzman A, Husain S, Schmidt C, Goldberg RM et al. (2017): The Efficacy of Adjuvant Chemotherapy in Patients With Stage II/III Resected Rectal Cancer Treated With Neoadjuvant Chemoradiation Therapy. Am J Clin Oncol 40, 531-534

Ahn ER, Wang E, Gluck S (2012): Is the Improved Efficacy of Trastuzumab and Lapatinib Combination Worth the Added Toxicity? A Discussion of Current Evidence, Recommendations, and Ethical Issues Regarding Dual HER2-Targeted Therapy. Breast Cancer (Auckl) 6, 191-207

Apicella M, Corso S, Giordano S (2017): Targeted therapies for gastric cancer: failures and hopes from clinical trials. Oncotarget $\underline{8}$, 57654-57669

Arteaga CL, Sliwkowski MX, Osborne CK, Perez EA, Puglisi F, Gianni L (2012): Treatment of HER2-positive breast cancer: current status and future perspectives. Nat Rev Clin Oncol $\underline{9}$, $16-32$ 
Baker SJ, Preisinger AC, Jessup JM, Paraskeva C, Markowitz S, Willson JK, Hamilton S, Vogelstein B (1990): p53 gene mutations occur in combination with 17p allelic deletions as late events in colorectal tumorigenesis. Cancer Res 50, 7717-7722

Ballantyne A, Dhillon S (2013): Trastuzumab emtansine: first global approval. Drugs $\underline{73}$, 755-765

Bang YJ, Van Cutsem E, Feyereislova A, Chung HC, Shen L, Sawaki A, Lordick F, Ohtsu A, Omuro Y, Satoh T et al. (2010): Trastuzumab in combination with chemotherapy versus chemotherapy alone for treatment of HER2-positive advanced gastric or gastrooesophageal junction cancer (ToGA): a phase 3, open-label, randomised controlled trial. Lancet 376, 687-697

Barillari P, Ramacciato G, De Angelis R, Gozzo P, Indinnimeo M, Valabrega S, Aurello P, Fegiz G (1990): Effect of preoperative colonoscopy on the incidence of synchronous and metachronous neoplasms. Acta Chir Scand 156, 163-166

Barok M, Tanner M, Koninki K, Isola J (2011): Trastuzumab-DM1 is highly effective in preclinical models of HER2-positive gastric cancer. Cancer Lett 306, 171-179

Baselga J, Swain SM (2009): Novel anticancer targets: revisiting ERBB2 and discovering ERBB3. Nat Rev Cancer 9 , 463-475

Baselga J, Cortes J, Im SA, Clark E, Ross G, Kiermaier A, Swain SM (2014): Biomarker analyses in CLEOPATRA: a phase III, placebo-controlled study of pertuzumab in human epidermal growth factor receptor 2-positive, first-line metastatic breast cancer. J Clin Oncol 32, 3753-3761

Baselga J, Cortes J, Kim SB, Im SA, Hegg R, Im YH, Roman L, Pedrini JL, Pienkowski T, Knott A et al. (2012): Pertuzumab plus trastuzumab plus docetaxel for metastatic breast cancer. N Engl J Med 366, 109-119 
Bendell JC, Domchek SM, Burstein HJ, Harris L, Younger J, Kuter I, Bunnell C, Rue M, Gelman R, Winer E (2003): Central nervous system metastases in women who receive trastuzumab-based therapy for metastatic breast carcinoma. Cancer 97, 2972-2977

Berger MB, Mendrola JM, Lemmon MA (2004): ErbB3/HER3 does not homodimerize upon neuregulin binding at the cell surface. FEBS Lett 569, 332-336

Bergers G, Hanahan D (2008): Modes of resistance to anti-angiogenic therapy. Nat Rev Cancer $\underline{8}, 592-603$

Bertotti A, Migliardi G, Galimi F, Sassi F, Torti D, Isella C, Cora D, Di Nicolantonio F, Buscarino M, Petti C et al. (2011): A molecularly annotated platform of patient-derived xenografts ("xenopatients") identifies HER2 as an effective therapeutic target in cetuximab-resistant colorectal cancer. Cancer Discov 1, 508-523

Bisgaard ML, Fenger K, Bulow S, Niebuhr E, Mohr J (1994): Familial adenomatous polyposis (FAP): frequency, penetrance, and mutation rate. Hum Mutat $\underline{3}, 121-125$

Blackwell KL, Burstein HJ, Storniolo AM, Rugo HS, Sledge G, Aktan G, Ellis C, Florance A, Vukelja S, Bischoff J et al. (2012): Overall survival benefit with lapatinib in combination with trastuzumab for patients with human epidermal growth factor receptor 2-positive metastatic breast cancer: final results from the EGF104900 Study. J Clin Oncol 30, 25852592

Blok EJ, Kuppen PJ, van Leeuwen JE, Sier CF (2013): Cytoplasmic Overexpression of HER2: a Key Factor in Colorectal Cancer. Clin Med Insights Oncol 7, 41-51

Bonjer HJ, Deijen CL, Haglind E, Group CIS (2015): A Randomized Trial of Laparoscopic versus Open Surgery for Rectal Cancer. N Engl J Med 373, 194

Bosetti C, Levi F, Rosato V, Bertuccio P, Lucchini F, Negri E, La Vecchia C (2011): Recent trends in colorectal cancer mortality in Europe. Int J Cancer 129, 180-191 
Bray F, Ferlay J, Soerjomataram I, Siegel RL, Torre LA, Jemal A (2018): Global cancer statistics 2018: GLOBOCAN estimates of incidence and mortality worldwide for 36 cancers in 185 countries. CA Cancer J Clin 68, 394-424

Camps J, Nguyen QT, Padilla-Nash HM, Knutsen T, McNeil NE, Wangsa D, Hummon AB, Grade M, Ried T, Difilippantonio MJ (2009): Integrative genomics reveals mechanisms of copy number alterations responsible for transcriptional deregulation in colorectal cancer. Genes Chromosomes Cancer 48, 1002-1017

Camps J, Pitt JJ, Emons G, Hummon AB, Case CM, Grade M, Jones TL, Nguyen QT, Ghadimi BM, Beissbarth T et al. (2013): Genetic amplification of the NOTCH modulator LNX2 upregulates the WNT/beta-catenin pathway in colorectal cancer. Cancer Res 73, 20032013

Cha Y, Han SW, Seol H, Oh DY, Im SA, Bang YJ, Park IA, Han W, Noh DY, Kim TY (2014): Immunohistochemical features associated with sensitivity to lapatinib-plus-capecitabine and resistance to trastuzumab in HER2-positive breast cancer. Anticancer Res $\underline{34}, 4275-$ 4280

Chan AT, Giovannucci EL (2010): Primary prevention of colorectal cancer. Gastroenterology 138, 2029-2043

Cho HS, Mason K, Ramyar KX, Stanley AM, Gabelli SB, Denney DW, Jr., Leahy DJ (2003): Structure of the extracellular region of HER2 alone and in complex with the Herceptin Fab. Nature $\underline{421}, 756-760$

Ciombor KK, Goldberg RM (2015): Update on Anti-Angiogenesis Therapy in Colorectal Cancer. Curr Colorectal Cancer Rep 11, 378-387

Clevers H (2006): Wnt/beta-catenin signaling in development and disease. Cell 127, 469480 
Conradi LC, Styczen H, Sprenger T, Wolff HA, Rodel C, Nietert M, Homayounfar K, Gaedcke J, Kitz J, Talaulicar R et al. (2013): Frequency of HER-2 positivity in rectal cancer and prognosis. Am J Surg Pathol 37, 522-531

Cortes J, Dieras V, Ro J, Barriere J, Bachelot T, Hurvitz S, Le Rhun E, Espie M, Kim SB, Schneeweiss A et al. (2015): Afatinib alone or afatinib plus vinorelbine versus investigator's choice of treatment for HER2-positive breast cancer with progressive brain metastases after trastuzumab, lapatinib, or both (LUX-Breast 3): a randomised, openlabel, multicentre, phase 2 trial. Lancet Oncol 16, 1700-1710

Cunningham JM, Christensen ER, Tester DJ, Kim CY, Roche PC, Burgart L, Thibodeau SN (1998): Hypermethylation of the hMLH1 promoter in colon cancer with microsatellite instability. Cancer Res $\underline{58}$, 3455-3460

D'Arcangelo M, Hirsch FR (2014): Clinical and comparative utility of afatinib in non-small cell lung cancer. Biologics $\underline{8}, 183-192$

Day DW, Morson BC (1978): The adenoma-carcinoma sequence. Major Probl Pathol $\underline{10}$, 58-71

Diéras V, Miles D, Verma S, Pegram M, Welslau M, Baselga J, Krop IE, Blackwell K, Hoersch S, Xu J et al. (2017): Trastuzumab emtansine versus capecitabine plus lapatinib in patients with previously treated HER2-positive advanced breast cancer (EMILIA): a descriptive analysis of final overall survival results from a randomised, open-label, phase 3 trial. Lancet Oncol 18, 732-742

Dietel M, Ellis IO, Hofler H, Kreipe H, Moch H, Dankof A, Kolble K, Kristiansen G (2007): Comparison of automated silver enhanced in situ hybridisation (SISH) and fluorescence ISH (FISH) for the validation of HER2 gene status in breast carcinoma according to the guidelines of the American Society of Clinical Oncology and the College of American Pathologists. Virchows Arch 451, 19-25 
Duffy MJ, Lamerz R, Haglund C, Nicolini A, Kalousova M, Holubec L, Sturgeon C (2014): Tumor markers in colorectal cancer, gastric cancer and gastrointestinal stromal cancers: European group on tumor markers 2014 guidelines update. Int J Cancer 134, 2513-2522

Dungo RT, Keating GM (2013): Afatinib: first global approval. Drugs 73, 1503-1515

el-Deiry WS, Harper JW, O'Connor PM, Velculescu VE, Canman CE, Jackman J, Pietenpol JA, Burrell M, Hill DE, Wang $Y$ et al. (1994): WAF1/CIP1 is induced in p53-mediated G1 arrest and apoptosis. Cancer Res 54, 1169-1174

Emons G, Ghadimi M, Grade M (2015): Allgemeine Grundlagen der Tumorbiologie in der Viszeralchirurgie. Zentralbl Chir 140, 74-82

Erickson HK, Park PU, Widdison WC, Kovtun YV, Garrett LM, Hoffman K, Lutz RJ, Goldmacher VS, Blattler WA (2006): Antibody-maytansinoid conjugates are activated in targeted cancer cells by lysosomal degradation and linker-dependent intracellular processing. Cancer Res 66, 4426-4433

Fakih MG (2015): Metastatic colorectal cancer: current state and future directions. J Clin Oncol 33, 1809-1824

Fanotto V, Ongaro E, Rihawi K, Avallone A, Silvestris N, Fornaro L, Vasile E, Antonuzzo L, Leone F, Rosati G et al. (2016): HER-2 inhibition in gastric and colorectal cancers: tangible achievements, novel acquisitions and future perspectives. Oncotarget $\underline{7}, 69060-69074$

Fearon ER (2011): Molecular genetics of colorectal cancer. Annu Rev Pathol $\underline{6}$, 479-507

Fearon ER, Vogelstein B (1990): A genetic model for colorectal tumorigenesis. Cell 61, 759-767 
Ferguson KM, Berger MB, Mendrola JM, Cho HS, Leahy DJ, Lemmon MA (2003): EGF activates its receptor by removing interactions that autoinhibit ectodomain dimerization. Mol Cell 11, 507-517

Folprecht G, Gruenberger T, Bechstein W, Raab HR, Weitz J, Lordick F, Hartmann JT, Stoehlmacher-Williams J, Lang H, Trarbach T et al. (2014): Survival of patients with initially unresectable colorectal liver metastases treated with FOLFOX/cetuximab or FOLFIRI/cetuximab in a multidisciplinary concept (CELIM study). Ann Oncol 25, 1018-1025

Franklin MC, Carey KD, Vajdos FF, Leahy DJ, de Vos AM, Sliwkowski MX (2004): Insights into ErbB signaling from the structure of the ErbB2-pertuzumab complex. Cancer Cell $\underline{5}$, 317-328

Fuchs R, Guggenberger D, Neumann U, Trautwein C (Hrsg.): Gastrointestinale Tumore. 17. Auflage; Nora-Verlag, Stolberg 2018

Gaedcke J, Liersch T, Hess C, Becker H, Rodel C, Ghadimi BM (2011): Rektumkarzinom: Aktueller Stand der multimodalen Therapie - wann und wie? Zentralbl Chir 136, 334-342

Gaedcke J, Grade M, Jung K, Schirmer M, Jo P, Obermeyer C, Wolff HA, Herrmann MK, Beissbarth T, Becker $\mathrm{H}$ et al. (2010): KRAS and BRAF mutations in patients with rectal cancer treated with preoperative chemoradiotherapy. Radiother Oncol 94, 76-81

Gala M, Chung DC (2011): Hereditary colon cancer syndromes. Semin Oncol 38, 490-499

Garrett TP, McKern NM, Lou M, Elleman TC, Adams TE, Lovrecz GO, Kofler M, Jorissen RN, Nice EC, Burgess AW et al. (2003): The crystal structure of a truncated ErbB2 ectodomain reveals an active conformation, poised to interact with other ErbB receptors. Mol Cell $\underline{11}$, 495-505 
Gerratana L, Bonotto M, Bozza C, Ongaro E, Fanotto V, Pelizzari G, Puglisi F (2017): Pertuzumab and breast cancer: another piece in the anti-HER2 puzzle. Expert Opin Biol Ther 17, 365-374

Geyer CE, Forster J, Lindquist D, Chan S, Romieu CG, Pienkowski T, Jagiello-Gruszfeld A, Crown J, Chan A, Kaufman B et al. (2006): Lapatinib plus capecitabine for HER2-positive advanced breast cancer. N Engl J Med 355, 2733-2743

Gianni L, Pienkowski T, Im YH, Roman L, Tseng LM, Liu MC, Lluch A, Staroslawska E, de la Haba-Rodriguez J, Im SA et al. (2012): Efficacy and safety of neoadjuvant pertuzumab and trastuzumab in women with locally advanced, inflammatory, or early HER2-positive breast cancer (NeoSphere): a randomised multicentre, open-label, phase 2 trial. Lancet Oncol $\underline{13}, 25-32$

Gianni L, Pienkowski T, Im YH, Tseng LM, Liu MC, Lluch A, Staroslawska E, de la HabaRodriguez J, Im SA, Pedrini JL et al. (2016): 5-year analysis of neoadjuvant pertuzumab and trastuzumab in patients with locally advanced, inflammatory, or early-stage HER2positive breast cancer (NeoSphere): a multicentre, open-label, phase 2 randomised trial. Lancet Oncol $\underline{17}, 791-800$

Gill S, Loprinzi CL, Sargent DJ, Thome SD, Alberts SR, Haller DG, Benedetti J, Francini G, Shepherd LE, Francois Seitz J et al. (2004): Pooled analysis of fluorouracil-based adjuvant therapy for stage II and III colon cancer: who benefits and by how much? J Clin Oncol 22, 1797-1806

Gonzalez M, Gervaz P (2015): Risk factors for survival after lung metastasectomy in colorectal cancer patients: systematic review and meta-analysis. Future Oncol 11, 31-33

Grade M, Difilippantonio MJ, Camps J (2015): Patterns of Chromosomal Aberrations in Solid Tumors. Recent Results Cancer Res 200, 115-142 
Grade M, Becker H, Liersch T, Ried T, Ghadimi BM (2006): Molecular cytogenetics: genomic imbalances in colorectal cancer and their clinical impact. Cell Oncol 28, 71-84

Grade M, Hummon AB, Camps J, Emons G, Spitzner M, Gaedcke J, Hoermann P, Ebner R, Becker H, Difilippantonio MJ et al. (2011): A genomic strategy for the functional validation of colorectal cancer genes identifies potential therapeutic targets. Int J Cancer 128, 10691079

Graeter TP, Friedel G (2016): Pulmonale Metastasenchirurgie des kolorektalen Karzinoms. Zentralbl Chir 141, 341-354

Graus-Porta D, Beerli RR, Daly JM, Hynes NE (1997): ErbB-2, the preferred heterodimerization partner of all ErbB receptors, is a mediator of lateral signaling. EMBO J $16,1647-1655$

Gravalos C, Jimeno A (2008): HER2 in gastric cancer: a new prognostic factor and a novel therapeutic target. Ann Oncol 19, 1523-1529

Greally M, Kelly CM, Cercek A (2018): HER2: An emerging target in colorectal cancer. Curr Probl Cancer $42,560-571$

Groden J, Thliveris A, Samowitz W, Carlson M, Gelbert L, Albertsen H, Joslyn G, Stevens J, Spirio L, Robertson M et al. (1991): Identification and characterization of the familial adenomatous polyposis coli gene. Cell $\underline{66}, 589-600$

Guan SS, Chang J, Cheng CC, Luo TY, Ho AS, Wang CC, Wu CT, Liu SH (2014): Afatinib and its encapsulated polymeric micelles inhibits HER2-overexpressed colorectal tumor cell growth in vitro and in vivo. Oncotarget $\underline{5}, 4868-4880$

Guy PM, Platko JV, Cantley LC, Cerione RA, Carraway KL, 3rd (1994): Insect cell-expressed p180erbB3 possesses an impaired tyrosine kinase activity. Proc Natl Acad Sci U S A 91 , $8132-8136$ 
Hainsworth JD, Meric-Bernstam F, Swanton C, Hurwitz H, Spigel DR, Sweeney C, Burris H, Bose R, Yoo B, Stein A et al. (2018): Targeted Therapy for Advanced Solid Tumors on the Basis of Molecular Profiles: Results From MyPathway, an Open-Label, Phase Ila Multiple Basket Study. J Clin Oncol 36, 536-542

Half E, Broaddus R, Danenberg KD, Danenberg PV, Ayers GD, Sinicrope FA (2004): HER-2 receptor expression, localization, and activation in colorectal cancer cell lines and human tumors. Int J Cancer 108, 540-548

Harbeck N, Huang CS, Hurvitz S, Yeh DC, Shao Z, Im SA, Jung KH, Shen K, Ro J, Jassem J et al. (2016): Afatinib plus vinorelbine versus trastuzumab plus vinorelbine in patients with HER2-overexpressing metastatic breast cancer who had progressed on one previous trastuzumab treatment (LUX-Breast 1): an open-label, randomised, phase 3 trial. Lancet Oncol 17, 357-366

Hecht JR, Bang YJ, Qin SK, Chung HC, Xu JM, Park JO, Jeziorski K, Shparyk Y, Hoff PM, Sobrero A et al. (2016): Lapatinib in Combination With Capecitabine Plus Oxaliplatin in Human Epidermal Growth Factor Receptor 2-Positive Advanced or Metastatic Gastric, Esophageal, or Gastroesophageal Adenocarcinoma: TRIO-013/LOGiC--A Randomized Phase III Trial. J Clin Oncol 34, 443-451

Hirashima N, Takahashi W, Yoshii S, Yamane T, Ooi A (2001): Protein overexpression and gene amplification of C-erb B-2 in pulmonary carcinomas: a comparative immunohistochemical and fluorescence in situ hybridization study. Mod Pathol 14, 556562

Hsieh AC, Moasser MM (2007): Targeting HER proteins in cancer therapy and the role of the non-target HER3. Br J Cancer 97, 453-457

Hudis CA (2007): Trastuzumab--mechanism of action and use in clinical practice. N Engl J Med 357, 39-51 
Hurvitz SA, Martin M, Symmans WF, Jung KH, Huang CS, Thompson AM, Harbeck N, Valero V, Stroyakovskiy D, Wildiers H et al. (2018): Neoadjuvant trastuzumab, pertuzumab, and chemotherapy versus trastuzumab emtansine plus pertuzumab in patients with HER2-positive breast cancer (KRISTINE): a randomised, open-label, multicentre, phase 3 trial. Lancet Oncol 19, 115-126

Huxley RR, Ansary-Moghaddam A, Clifton P, Czernichow S, Parr CL, Woodward M (2009): The impact of dietary and lifestyle risk factors on risk of colorectal cancer: a quantitative overview of the epidemiological evidence. Int J Cancer $\underline{125}, 171-180$

Jayne D, Pigazzi A, Marshall H, Croft J, Corrigan N, Copeland J, Quirke P, West N, Rautio T, Thomassen N et al. (2017): Effect of Robotic-Assisted vs Conventional Laparoscopic Surgery on Risk of Conversion to Open Laparotomy Among Patients Undergoing Resection for Rectal Cancer: The ROLARR Randomized Clinical Trial. JAMA 318, 1569-1580

Jorgensen JT, Hersom M (2012): HER2 as a Prognostic Marker in Gastric Cancer - A Systematic Analysis of Data from the Literature. J Cancer 3 , 137-144

Kanas GP, Taylor A, Primrose JN, Langeberg WJ, Kelsh MA, Mowat FS, Alexander DD, Choti MA, Poston G (2012): Survival after liver resection in metastatic colorectal cancer: review and meta-analysis of prognostic factors. Clin Epidemiol 4 , 283-301

Kanat O, Ertas H, Caner B (2018): Dual HER2 inhibition strategies in the management of treatment-refractory metastatic colorectal cancer: History and status. World J Clin Cases 6, $418-425$

Kang YK, Rha SY, Tassone P, Barriuso J, Yu R, Szado T, Garg A, Bang YJ (2014): A phase Ila dose-finding and safety study of first-line pertuzumab in combination with trastuzumab, capecitabine and cisplatin in patients with HER2-positive advanced gastric cancer. $\mathrm{Br} \mathrm{J}$ Cancer 111, 660-666 
Kavuri SM, Jain N, Galimi F, Cottino F, Leto SM, Migliardi G, Searleman AC, Shen W, Monsey J, Trusolino L et al. (2015): HER2 activating mutations are targets for colorectal cancer treatment. Cancer Discov $\underline{5}, 832-841$

Keller S, Zwingenberger G, Ebert K, Hasenauer J, Wasmuth J, Maier D, Haffner I, Schierle K, Weirich G, Luber B (2018): Effects of trastuzumab and afatinib on kinase activity in gastric cancer cell lines. Mol Oncol 12, 441-462

Kerber RA, Neklason DW, Samowitz WS, Burt RW (2005): Frequency of familial colon cancer and hereditary nonpolyposis colorectal cancer (Lynch syndrome) in a large population database. Fam Cancer 4 , 239-244

Krop IE, Kim SB, Gonzalez-Martin A, LoRusso PM, Ferrero JM, Smitt M, Yu R, Leung AC, Wildiers H (2014): Trastuzumab emtansine versus treatment of physician's choice for pretreated HER2-positive advanced breast cancer (TH3RESA): a randomised, open-label, phase 3 trial. Lancet Oncol 15, 689-699

Krop IE, Kim SB, Martin AG, LoRusso PM, Ferrero JM, Badovinac-Crnjevic T, Hoersch S, Smitt M, Wildiers H (2017): Trastuzumab emtansine versus treatment of physician's choice in patients with previously treated HER2-positive metastatic breast cancer (TH3RESA): final overall survival results from a randomised open-label phase 3 trial. Lancet Oncol 18, 743-754

Lane DP (1992): Cancer. p53, guardian of the genome. Nature 358, 15-16

Lengauer C, Kinzler KW, Vogelstein B (1998): Genetic instabilities in human cancers. Nature 396, 643-649

Leto SM, Sassi F, Catalano I, Torri V, Migliardi G, Zanella ER, Throsby M, Bertotti A, Trusolino L (2015): Sustained Inhibition of HER3 and EGFR Is Necessary to Induce Regression of HER2-Amplified Gastrointestinal Carcinomas. Clin Cancer Res 21, 5519-5531 
Li D, Ambrogio L, Shimamura T, Kubo S, Takahashi M, Chirieac LR, Padera RF, Shapiro GI, Baum A, Himmelsbach F et al. (2008): BIBW2992, an irreversible EGFR/HER2 inhibitor highly effective in preclinical lung cancer models. Oncogene $27,4702-4711$

Liersch T, Langer C, Ghadimi BM, Becker H (2005): Aktuelle Behandlungsstrategien beim Rektumkarzinom. Chirurg 76, 309-332; quiz 333-304

Lin NU, Winer EP, Wheatley D, Carey LA, Houston S, Mendelson D, Munster P, Frakes L, Kelly S, Garcia AA et al. (2012): A phase II study of afatinib (BIBW 2992), an irreversible ErbB family blocker, in patients with HER2-positive metastatic breast cancer progressing after trastuzumab. Breast Cancer Res Treat 133, 1057-1065

Loree JM, Cheung WY (2016): Optimizing adjuvant therapy and survivorship care of stage III colon cancer. Future Oncol 12, 2021-2035

LoRusso PM, Weiss D, Guardino E, Girish S, Sliwkowski MX (2011): Trastuzumab emtansine: a unique antibody-drug conjugate in development for human epidermal growth factor receptor 2-positive cancer. Clin Cancer Res 17, 6437-6447

Lu Y, Zi X, Zhao Y, Mascarenhas D, Pollak M (2001): Insulin-like growth factor-I receptor signaling and resistance to trastuzumab (Herceptin). J Natl Cancer Inst 93, 1852-1857

Luglio G, Nelson H (2010): Laparoscopy for colon cancer: state of the art. Surg Oncol Clin N Am 19, 777-791

Markowitz SD, Bertagnolli MM (2009): Molecular origins of cancer: Molecular basis of colorectal cancer. N Engl J Med 361, 2449-2460

Martinez MT, Perez-Fidalgo JA, Martin-Martorell P, Cejalvo JM, Pons V, Bermejo B, Martin M, Albanell J, Lluch A (2016): Treatment of HER2 positive advanced breast cancer with TDM1: A review of the literature. Crit Rev Oncol Hematol 97, 96-106 
Mazelin L, Bernet A, Bonod-Bidaud C, Pays L, Arnaud S, Gespach C, Bredesen DE, Scoazec JY, Mehlen P (2004): Netrin-1 controls colorectal tumorigenesis by regulating apoptosis. Nature $431,80-84$

Mehlen P, Rabizadeh S, Snipas SJ, Assa-Munt N, Salvesen GS, Bredesen DE (1998): The DCC gene product induces apoptosis by a mechanism requiring receptor proteolysis. Nature 395, 801-804

Menard S, Casalini P, Campiglio M, Pupa SM, Tagliabue E (2004): Role of HER2/neu in tumor progression and therapy. Cell Mol Life Sci 61, 2965-2978

Moasser MM (2007): The oncogene HER2: its signaling and transforming functions and its role in human cancer pathogenesis. Oncogene $26,6469-6487$

Molina MA, Codony-Servat J, Albanell J, Rojo F, Arribas J, Baselga J (2001): Trastuzumab (herceptin), a humanized anti-Her2 receptor monoclonal antibody, inhibits basal and activated Her2 ectodomain cleavage in breast cancer cells. Cancer Res 61 , 4744-4749

Morson B (1974): President's address. The polyp-cancer sequence in the large bowel. Proc R Soc Med 67, 451-457

Muller PA, Vousden KH (2014): Mutant p53 in cancer: new functions and therapeutic opportunities. Cancer Cell 25, 304-317

Navarro M, Nicolas A, Ferrandez A, Lanas A (2017): Colorectal cancer population screening programs worldwide in 2016: An update. World J Gastroenterol 23, 3632-3642

Oh DY, Bang YJ (2016): Pertuzumab in gastrointestinal cancer. Expert Opin Biol Ther 16, 243-253

Okines AF (2017): T-DM1 in the Neo-Adjuvant Treatment of HER2-Positive Breast Cancer: Impact of the KRISTINE (TRIO-021) Trial. Rev Recent Clin Trials 12, 216-222 
Okines AF, Cunningham D (2012): Trastuzumab: a novel standard option for patients with HER-2-positive advanced gastric or gastro-oesophageal junction cancer. Therap Adv Gastroenterol 5, 301-318

Pegram MD, Lipton A, Hayes DF, Weber BL, Baselga JM, Tripathy D, Baly D, Baughman SA, Twaddell T, Glaspy JA et al. (1998): Phase II study of receptor-enhanced chemosensitivity using recombinant humanized anti-p185HER2/neu monoclonal antibody plus cisplatin in patients with HER2/neu-overexpressing metastatic breast cancer refractory to chemotherapy treatment. J Clin Oncol 16, 2659-2671

Peltomaki P (2003): Role of DNA mismatch repair defects in the pathogenesis of human cancer. J Clin Oncol 21, 1174-1179

Perez EA, Barrios C, Eiermann W, Toi M, Im YH, Conte P, Martin M, Pienkowski T, Pivot X, Burris H, 3rd et al. (2017): Trastuzumab Emtansine With or Without Pertuzumab Versus Trastuzumab Plus Taxane for Human Epidermal Growth Factor Receptor 2-Positive, Advanced Breast Cancer: Primary Results From the Phase III MARIANNE Study. J Clin Oncol $35,141-148$

Pinkas-Kramarski R, Soussan L, Waterman H, Levkowitz G, Alroy I, Klapper L, Lavi S, Seger R, Ratzkin BJ, Sela M et al. (1996): Diversification of Neu differentiation factor and epidermal growth factor signaling by combinatorial receptor interactions. EMBO J $\underline{15}$, 2452-2467

Polyak K, Xia Y, Zweier JL, Kinzler KW, Vogelstein B (1997): A model for p53-induced apoptosis. Nature 389, 300-305

Quasar Collaborative Group, Gray R, Barnwell J, McConkey C, Hills RK, Williams NS, Kerr DJ (2007): Adjuvant chemotherapy versus observation in patients with colorectal cancer: a randomised study. Lancet $\underline{370,2020-2029}$ 
Reichelt U, Duesedau P, Tsourlakis M, Quaas A, Link BC, Schurr PG, Kaifi JT, Gros SJ, Yekebas EF, Marx A et al. (2007): Frequent homogeneous HER-2 amplification in primary and metastatic adenocarcinoma of the esophagus. Mod Pathol 20, 120-129

Remillard S, Rebhun LI, Howie GA, Kupchan SM (1975): Antimitotic activity of the potent tumor inhibitor maytansine. Science $\underline{189}, 1002-1005$

Ried T (2004): Cytogenetics--in color and digitized. N Engl J Med 350, 1597-1600

Rödel C, Liersch T, Becker H, Fietkau R, Hohenberger W, Hothorn T, Graeven U, Arnold D, Lang-Welzenbach M, Raab HR et al. (2012): Preoperative chemoradiotherapy and postoperative chemotherapy with fluorouracil and oxaliplatin versus fluorouracil alone in locally advanced rectal cancer: initial results of the German CAO/ARO/AIO-04 randomised phase 3 trial. Lancet Oncol 13, 679-687

Rödel C, Graeven U, Fietkau R, Hohenberger W, Hothorn T, Arnold D, Hofheinz RD, Ghadimi M, Wolff HA, Lang-Welzenbach M et al. (2015): Oxaliplatin added to fluorouracilbased preoperative chemoradiotherapy and postoperative chemotherapy of locally advanced rectal cancer (the German CAO/ARO/AIO-04 study): final results of the multicentre, open-label, randomised, phase 3 trial. Lancet Oncol 16, 979-989

Romond EH, Perez EA, Bryant J, Suman VJ, Geyer CE, Jr., Davidson NE, Tan-Chiu E, Martino S, Paik S, Kaufman PA et al. (2005): Trastuzumab plus adjuvant chemotherapy for operable HER2-positive breast cancer. N Engl J Med 353, 1673-1684

Roskoski R, Jr. (2014): The ErbB/HER family of protein-tyrosine kinases and cancer. Pharmacol Res 79, 34-74

Rüschoff J, Hanna W, Bilous M, Hofmann M, Osamura RY, Penault-Llorca F, van de Vijver M, Viale G (2012): HER2 testing in gastric cancer: a practical approach. Mod Pathol $\underline{25}$, $637-650$ 
Rüschoff J, Dietel M, Baretton G, Arbogast S, Walch A, Monges G, Chenard MP, PenaultLlorca F, Nagelmeier I, Schlake W et al. (2010): HER2 diagnostics in gastric cancerguideline validation and development of standardized immunohistochemical testing. Virchows Arch 457, 299-307

Russo M, Siravegna G, Blaszkowsky LS, Corti G, Crisafulli G, Ahronian LG, Mussolin B, Kwak EL, Buscarino M, Lazzari L et al. (2016): Tumor Heterogeneity and Lesion-Specific Response to Targeted Therapy in Colorectal Cancer. Cancer Discov $\underline{6}$, 147-153

Saito M, Yamaguchi A, Goi T, Tsuchiyama T, Nakagawara G, Urano T, Shiku H, Furukawa K (1999): Expression of DCC protein in colorectal tumors and its relationship to tumor progression and metastasis. Oncology 56, 134-141

Sartore-Bianchi A, Trusolino L, Martino C, Bencardino K, Lonardi S, Bergamo F, Zagonel V, Leone F, Depetris I, Martinelli E et al. (2016): Dual-targeted therapy with trastuzumab and lapatinib in treatment-refractory, KRAS codon 12/13 wild-type, HER2-positive metastatic colorectal cancer (HERACLES): a proof-of-concept, multicentre, open-label, phase 2 trial. Lancet Oncol 17, 738-746

Satoh T, Xu RH, Chung HC, Sun GP, Doi T, Xu JM, Tsuji A, Omuro Y, Li J, Wang JW et al. (2014): Lapatinib plus paclitaxel versus paclitaxel alone in the second-line treatment of HER2-amplified advanced gastric cancer in Asian populations: TYTAN--a randomized, phase III study. J Clin Oncol 32, 2039-2049

Sauer R, Liersch T, Merkel S, Fietkau R, Hohenberger W, Hess C, Becker H, Raab HR, Villanueva MT, Witzigmann $H$ et al. (2012): Preoperative versus postoperative chemoradiotherapy for locally advanced rectal cancer: results of the German CAO/ARO/AIO-94 randomized phase III trial after a median follow-up of 11 years. J Clin Oncol 30, 1926-1933 
Sauer R, Becker H, Hohenberger W, Rodel C, Wittekind C, Fietkau R, Martus P, Tschmelitsch J, Hager E, Hess CF et al. (2004): Preoperative versus postoperative chemoradiotherapy for rectal cancer. N Engl J Med 351, 1731-1740

Scaltriti M, Nuciforo P, Bradbury I, Sperinde J, Agbor-Tarh D, Campbell C, Chenna A, Winslow J, Serra V, Parra JL et al. (2015): High HER2 expression correlates with response to the combination of lapatinib and trastuzumab. Clin Cancer Res 21, 569-576

Scartozzi M, Giampieri R, Maccaroni E, Mandolesi A, Giustini L, Silva R, Zaniboni A, Biscotti T, Biagetti S, Galizia E et al. (2012): Analysis of HER-3, insulin growth factor-1, nuclear factor-kB and epidermal growth factor receptor gene copy number in the prediction of clinical outcome for K-RAS wild-type colorectal cancer patients receiving irinotecancetuximab. Ann Oncol 23, 1706-1712

Schechter AL, Stern DF, Vaidyanathan L, Decker SJ, Drebin JA, Greene MI, Weinberg RA (1984): The neu oncogene: an erb-B-related gene encoding a 185,000-Mr tumour antigen. Nature $312,513-516$

Schmiegel W, Buchberger B, Follmann M, Graeven U, Heinemann V, Langer T, Nothacker M, Porschen R, Rodel C, Rosch T et al. (2017): S3 Guidelines for Colorectal Carcinoma. Z Gastroenterol 55, 1344-1498

Siegel R, DeSantis C, Virgo K, Stein K, Mariotto A, Smith T, Cooper D, Gansler T, Lerro C, Fedewa S et al. (2012): Cancer treatment and survivorship statistics, 2012. CA Cancer J Clin 62, 220-241

Siegel RL, Miller KD, Jemal A (2018): Cancer statistics, 2018. CA Cancer J Clin 68, 7-30

Siegel RL, Miller KD, Fedewa SA, Ahnen DJ, Meester RGS, Barzi A, Jemal A (2017): Colorectal cancer statistics, 2017. CA Cancer J Clin 67, 177-193 
Siegenthaler W, Blum H (Hrsg.): Klinische Pathophysiologie. 9. Auflage; Georg Thieme Verlag, Stuttgart 2006

Siena S, Sartore-Bianchi A, Marsoni S, Hurwitz HI, McCall SJ, Penault-Llorca F, Srock S, Bardelli A, Trusolino L (2018): Targeting the human epidermal growth factor receptor 2 (HER2) oncogene in colorectal cancer. Ann Oncol 29, 1108-1119

Slamon DJ, Clark GM, Wong SG, Levin WJ, Ullrich A, McGuire WL (1987): Human breast cancer: correlation of relapse and survival with amplification of the HER-2/neu oncogene. Science 235, 177-182

Slamon DJ, Leyland-Jones B, Shak S, Fuchs H, Paton V, Bajamonde A, Fleming T, Eiermann W, Wolter J, Pegram M et al. (2001): Use of chemotherapy plus a monoclonal antibody against HER2 for metastatic breast cancer that overexpresses HER2. N Engl J Med 344, 783-792

Solca F, Dahl G, Zoephel A, Bader G, Sanderson M, Klein C, Kraemer O, Himmelsbach F, Haaksma E, Adolf GR (2012): Target binding properties and cellular activity of afatinib (BIBW 2992), an irreversible ErbB family blocker. J Pharmacol Exp Ther 343, 342-350

Soltoff SP, Carraway KL, 3rd, Prigent SA, Gullick WG, Cantley LC (1994): ErbB3 is involved in activation of phosphatidylinositol 3-kinase by epidermal growth factor. Mol Cell Biol 14, 3550-3558

Spector NL, Xia W, Burris H, 3rd, Hurwitz H, Dees EC, Dowlati A, O'Neil B, Overmoyer B, Marcom PK, Blackwell KL et al. (2005): Study of the biologic effects of lapatinib, a reversible inhibitor of ErbB1 and ErbB2 tyrosine kinases, on tumor growth and survival pathways in patients with advanced malignancies. J Clin Oncol 23, 2502-2512

Spitzner M, Emons G, Kramer F, Gaedcke J, Rave-Frank M, Scharf JG, Burfeind P, Becker H, Beissbarth T, Ghadimi BM et al. (2010): A gene expression signature for chemoradiosensitivity of colorectal cancer cells. Int J Radiat Oncol Biol Phys $\underline{78}, 1184-1192$ 
Strand M, Prolla TA, Liskay RM, Petes TD (1993): Destabilization of tracts of simple repetitive DNA in yeast by mutations affecting DNA mismatch repair. Nature $365,274-276$

Styczen H, Nagelmeier I, Beissbarth T, Nietert M, Homayounfar K, Sprenger T, Boczek U, Stanek K, Kitz J, Wolff HA et al. (2015): HER-2 and HER-3 expression in liver metastases of patients with colorectal cancer. Oncotarget $\underline{6}$, 15065-15076

Swain SM, Clark E, Baselga J (2015a): Treatment of HER2-positive metastatic breast cancer. N Engl J Med 372, 1964-1965

Swain SM, Baselga J, Kim SB, Ro J, Semiglazov V, Campone M, Ciruelos E, Ferrero JM, Schneeweiss A, Heeson S et al. (2015b): Pertuzumab, trastuzumab, and docetaxel in HER2-positive metastatic breast cancer. N Engl J Med 372, 724-734

Tabernero J, Hoff PM, Shen L, Ohtsu A, Shah MA, Cheng K, Song C, Wu H, Eng-Wong J, Kim K et al. (2018): Pertuzumab plus trastuzumab and chemotherapy for HER2-positive metastatic gastric or gastro-oesophageal junction cancer (JACOB): final analysis of a double-blind, randomised, placebo-controlled phase 3 study. Lancet Oncol 19, 1372-1384

Takegawa N, Yonesaka K, Sakai K, Ueda H, Watanabe S, Nonagase Y, Okuno T, Takeda M, Maenishi O, Tsurutani J et al. (2016): HER2 genomic amplification in circulating tumor DNA from patients with cetuximab-resistant colorectal cancer. Oncotarget $\underline{7}, 3453-3460$

The Cancer Genome Atlas Network (2012): Comprehensive molecular characterization of human colon and rectal cancer. Nature $\underline{487}, 330-337$

Thuss-Patience PC, Shah MA, Ohtsu A, Van Cutsem E, Ajani JA, Castro H, Mansoor W, Chung HC, Bodoky G, Shitara K et al. (2017): Trastuzumab emtansine versus taxane use for previously treated HER2-positive locally advanced or metastatic gastric or gastrooesophageal junction adenocarcinoma (GATSBY): an international randomised, openlabel, adaptive, phase 2/3 study. Lancet Oncol 18, 640-653 
Trusolino L, Bertotti A, Lonardi S, Sartore-Bianchi A, Martino C, Cottino F, Vurchio V, Valtorta E, Lauricella C, Regge D et al.: Abstract CT082: Pertuzumab and trastuzumabemtansine in HER2-positive colorectal cancer: the HERACLES B trial. Proceedings of the 107th Annual Meeting of the American Association for Cancer Research; 16.-20. Apr. 2016; New Orleans, LA. Cancer Res 76 Suppl14, СТ082

Valabrega G, Montemurro F, Aglietta M (2007): Trastuzumab: mechanism of action, resistance and future perspectives in HER2-overexpressing breast cancer. Ann Oncol 18, 977-984

Valtorta E, Martino C, Sartore-Bianchi A, Penaullt-Llorca F, Viale G, Risio M, Rugge M, Grigioni W, Bencardino K, Lonardi S et al. (2015): Assessment of a HER2 scoring system for colorectal cancer: results from a validation study. Mod Pathol 28, 1481-1491

Van Cutsem E, Cervantes A, Adam R, Sobrero A, Van Krieken JH, Aderka D, Aranda Aguilar E, Bardelli A, Benson A, Bodoky G et al. (2016): ESMO consensus guidelines for the management of patients with metastatic colorectal cancer. Ann Oncol 27, 1386-1422

van der Pas MH, Haglind E, Cuesta MA, Furst A, Lacy AM, Hop WC, Bonjer HJ, Group COcLoORIS (2013): Laparoscopic versus open surgery for rectal cancer (COLOR II): shortterm outcomes of a randomised, phase 3 trial. Lancet Oncol 14, 210-218

Verma S, Miles D, Gianni L, Krop IE, Welslau M, Baselga J, Pegram M, Oh DY, Dieras V, Guardino E et al. (2012): Trastuzumab emtansine for HER2-positive advanced breast cancer. N Engl J Med 367, 1783-1791

Vogel CL, Cobleigh MA, Tripathy D, Gutheil JC, Harris LN, Fehrenbacher L, Slamon DJ, Murphy M, Novotny WF, Burchmore M et al. (2002): Efficacy and safety of trastuzumab as a single agent in first-line treatment of HER2-overexpressing metastatic breast cancer. J Clin Oncol 20, 719-726 
Vogelstein B, Fearon ER, Hamilton SR, Kern SE, Preisinger AC, Leppert M, Nakamura Y, White R, Smits AM, Bos JL (1988): Genetic alterations during colorectal-tumor development. N Engl J Med 319, 525-532

von Minckwitz G, Procter M, de Azambuja E, Zardavas D, Benyunes M, Viale G, Suter T, Arahmani A, Rouchet N, Clark E et al. (2017): Adjuvant Pertuzumab and Trastuzumab in Early HER2-Positive Breast Cancer. N Engl J Med 377, 122-131

von Minckwitz G, Huang CS, Mano MS, Loibl S, Mamounas EP, Untch M, Wolmark N, Rastogi P, Schneeweiss A, Redondo A et al. (2019): Trastuzumab Emtansine for Residual Invasive HER2-Positive Breast Cancer. N Engl J Med 380, 617-628

Wainberg ZA, Anghel A, Desai AJ, Ayala R, Luo T, Safran B, Fejzo MS, Hecht JR, Slamon DJ, Finn RS (2010): Lapatinib, a dual EGFR and HER2 kinase inhibitor, selectively inhibits HER2-amplified human gastric cancer cells and is synergistic with trastuzumab in vitro and in vivo. Clin Cancer Res 16, 1509-1519

Weber JL, Wong C (1993): Mutation of human short tandem repeats. Hum Mol Genet 2, $1123-1128$

Wittekind C (Hrsg.): TNM Klassifikation maligner Tumoren. 8. Auflage; Wiley-VCH, Weinheim 2017

Wolff AC, Hammond ME, Hicks DG, Dowsett M, McShane LM, Allison KH, Allred DC, Bartlett JM, Bilous M, Fitzgibbons P et al. (2013): Recommendations for human epidermal growth factor receptor 2 testing in breast cancer: American Society of Clinical Oncology/College of American Pathologists clinical practice guideline update. J Clin Oncol $31,3997-4013$ 
Wood ER, Truesdale AT, McDonald OB, Yuan D, Hassell A, Dickerson SH, Ellis B, Pennisi C, Horne E, Lackey K et al. (2004): A unique structure for epidermal growth factor receptor bound to GW572016 (Lapatinib): relationships among protein conformation, inhibitor offrate, and receptor activity in tumor cells. Cancer Res 64, 6652-6659

Xia W, Mullin RJ, Keith BR, Liu LH, Ma H, Rusnak DW, Owens G, Alligood KJ, Spector NL (2002): Anti-tumor activity of GW572016: a dual tyrosine kinase inhibitor blocks EGF activation of EGFR/erbB2 and downstream Erk1/2 and AKT pathways. Oncogene 21, 6255-6263

Yamashita-Kashima Y, Shu S, Harada N, Fujimoto-Ouchi K (2013): Enhanced antitumor activity of trastuzumab emtansine (T-DM1) in combination with pertuzumab in a HER2positive gastric cancer model. Oncol Rep 30, 1087-1093

Yarden Y, Sliwkowski MX (2001): Untangling the ErbB signalling network. Nat Rev Mol Cell Biol 2, 127-137

Zanardi E, Bregni G, de Braud F, Di Cosimo S (2015): Better Together: Targeted Combination Therapies in Breast Cancer. Semin Oncol 42, 887-895

Zardavas D, Fouad TM, Piccart M (2015): Optimal adjuvant treatment for patients with HER2-positive breast cancer in 2015. Breast 24 Suppl 2, S143-148

ZfKD, GEKID: Krebs in Deutschland für 2013/2014. Robert Koch-Institut, Berlin 2017

Zhang H, Berezov A, Wang Q, Zhang G, Drebin J, Murali R, Greene MI (2007): ErbB receptors: from oncogenes to targeted cancer therapies. J Clin Invest 117, 2051-2058 


\section{Konferenzbeiträge}

Jakubzik AL, Conradi LC, Spitzner M, Scheel A, Ghadimi BM, Beissbarth T, Grade M: Targeting HER-2/HER-3 in colorectal cancer. Vortrag im Rahmen der 19. Chirurgischen Forschungstage, Würzburg, 08.-10.10.2015

Jakubzik AL, Conradi LC, Spitzner M, Scheel A, Bohnenberger H, Gaedcke J, Ghadimi BM, Beissbarth T, Koenig A, Grade M: HER-2 and HER-3 as promising therapeutic candidates in colorectal cancer. Vortrag im Rahmen des International Workshop: Translating Colorectal Cancer Research, Porto, 09.-10.02.2017 


\section{Danksagung}

Mein besonderer Dank gilt Frau PD Dr. med. Dr. rer. nat. Lena-Christin Conradi und PD Dr. med. Marian Grade für die Entwicklung des spannenden Themas, welches Gegenstand meiner Doktorarbeit werden durfte. Durch die exzellente Betreuung, die Motivation und die konstruktiven Diskussionen sowie die Bereitschaft, jederzeit für mich ansprechbar zu sein, konnte die Fertigstellung dieser Arbeit überhaupt erfolgen.

Bedanken möchte ich mich bei Prof. Dr. med. Michael Ghadimi für die Gelegenheit, in seiner Klinik für Allgemein-, Viszeral- und Kinderchirurgie und unter seiner Leitung in der Klinischen Forschergruppe 179 zu promovieren.

Bei Frau Dr. rer. nat. Melanie Spitzner möchte ich mich herzlich für die Einarbeitung und konsequente Betreuung in den experimentellen Teil sowie die Hilfestellung bei der Erarbeitung zahlreicher Abbildungen bedanken.

Frau Jessica Eggert und Frau Stefanie Müller waren jederzeit bereit, mir in der Zellkultur sowie bei jeglichen Experimenten mit Rat und Tat zur Seite zu stehen, dafür möchte ich mich ganz herzlich bedanken.

Bei Frau Birgit Jünemann möchte ich mich bedanken für die wiederholten Anfertigungen und Färbungen der immunzytochemischen Schnitte.

Ich danke Herrn Prof. Dr. rer. nat. Tim Beißbarth für die Erhebung der statistischen Analysen und somit zum Beitrag der Ergebnisse der vorliegenden Arbeit.

Außerdem danke ich den weiteren Doktoranten der Arbeitsgruppe, Frau Dr. med. Ute Bozcek, Frau Dr. med. Henriette Quack, Herrn Dr. med. Felix Rühlmann, Frau Kathrin Stanek und Herrn Dr. med. Marcus Storch für die buchstäbliche und mentale Unterstützung, dieses Projekt fertigzustellen. 